\title{
Upgrade to MODFLOW-GUI: Addition of MODPATH, ZONEBDGT, and additional MODFLOW packages to the U.S. Geological Survey MODFLOW-96 Graphical-User Interface
}

\section{U.S. GEOLOGICAL SURVEY \\ Open-File Report 99-184}
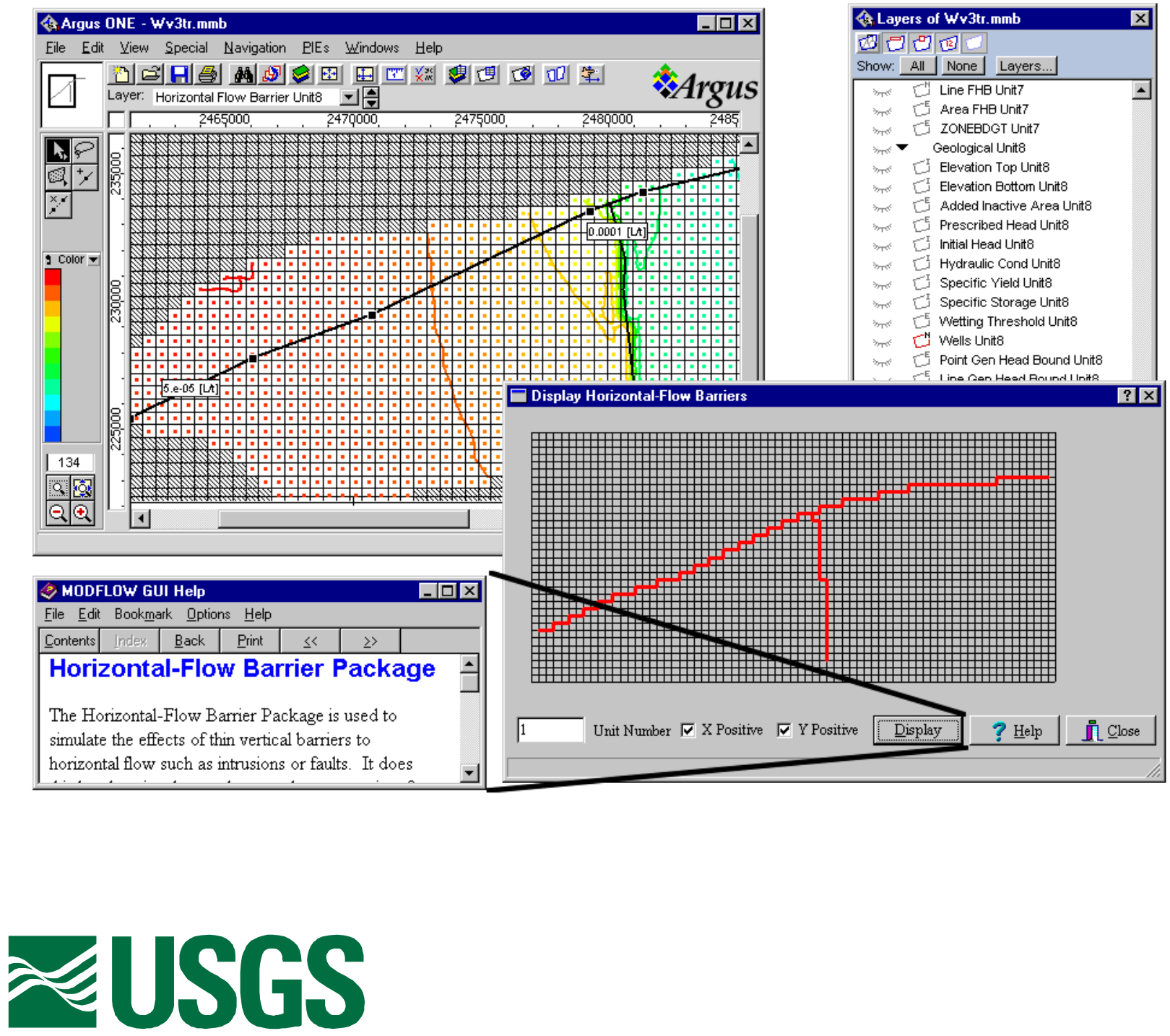

science for a changing world 
Cover: The cover shows the application of the MODFLOW-GUI to an area in Warren Valley, California (Tracy Nishikawa, written commun., 1999). In the study, faults are simulated using horizontal flow barriers, as shown in the window in the upper left corner. The precise locations of the horizontal flow barriers in the model are shown in the window in the lower right corner. The beginning of the help window for the Horizontal-Flow Barrier package is shown in the lower left corner. 


\section{Upgrade to MODFLOW-GUI: Addition of MODPATH, ZONEBDGT, and additional MODFLOW packages to the U.S. Geological Survey MODFLOW-96 Graphical-User Interface}

By Richard B. Winston

U.S. GEOLOGICAL SURVEY

Open-File Report 99-184 


\section{U.S. DEPARTMENT OF THE INTERIOR}

BRUCE BABBITT, Secretary

U.S. GEOLOGICAL SURVEY

Charles G. Groat, Director

Although the computer program described in this report has been tested and used by the U.S. Geological Survey (USGS), no warranty, expressed or implied, is made by the USGS as to the accuracy of the functioning of the program and related material. The code may be updated and revised periodically.

Any use of trade, product, or firm names in this publication is for descriptive purposes only and does not imply endorsement by the U.S. Government.

For additional information write to:

Office of Ground Water

U.S. Geological Survey

411 National Center

Reston, VA 20192
Copies of this report can be purchased from:

U.S. Geological Survey

Branch of Information Services

Box 25286

Denver, Colorado 80225-0286 


\section{Contents}

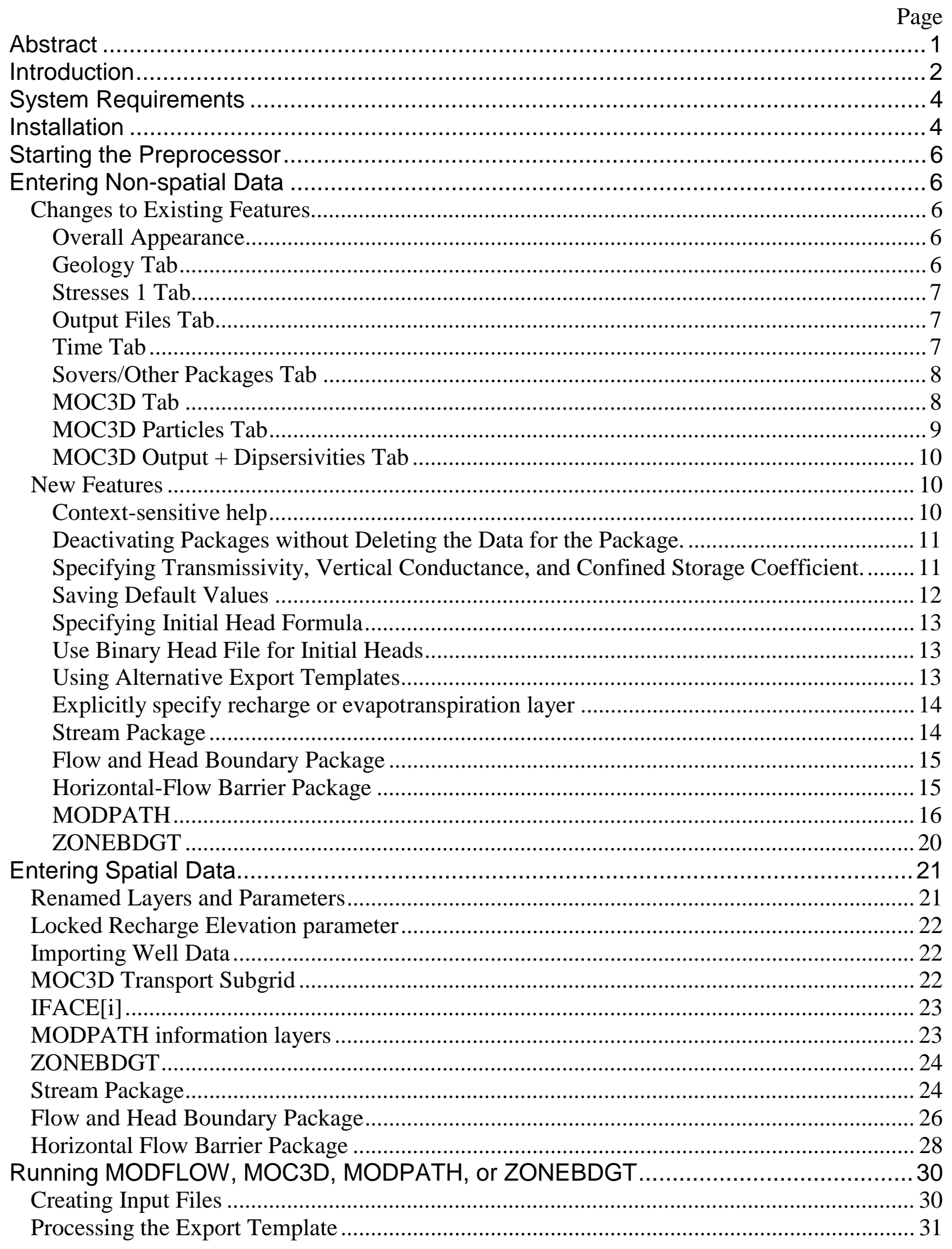


Running MODFLOW, MOC3D, MODPATH, or ZONEBDGT-Continued

Using the MODFLOW PIE with Calibration Programs..................................................... 32

Running independent templates with the MODFLOW PIE …........................................ 33

Converting contours on information layers to data points on data layers ................................ 33

Preparing Calibration Statistics ....................................................................................... 33

Files Created for MODFLOW-96, MODPATH, and ZONEBDGT Simulations ...............34

Files Created by Executing MODFLOW-96, MODPATH, and ZONEBDGT .................. 36

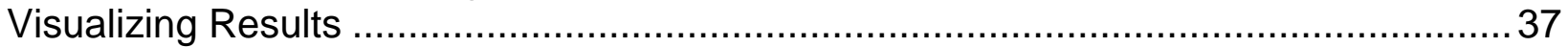

Visualizing results from MODFLOW or MOC3D .................................................... 37

Visualizing Results from MODPATH ...................................................................... 40

Visualizing Results from ZONEBDGT...................................................................... 40

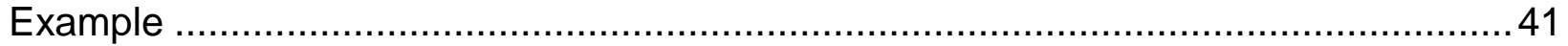

Problem Description ............................................................................................. 41

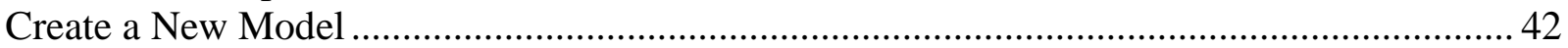

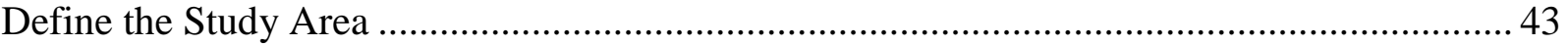

Defining Specified-Head Boundaries .......................................................................... 44

Choosing the Stream Package ................................................................................. 44

Changing the Number of Geologic Units ................................................................ 44

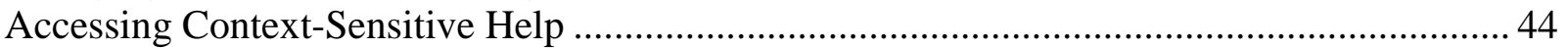

Finish Changing the Number of Geologic Units .......................................................... 45

Defining a Stream Boundary .................................................................................... 45

Define No-Flow Boundaries................................................................................. 46

Other Packages and Options ............................................................................. 47

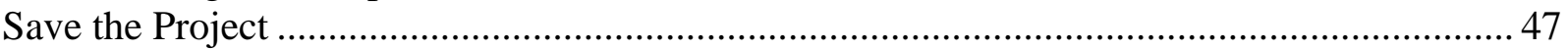

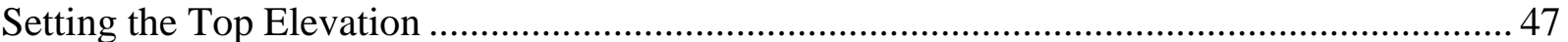

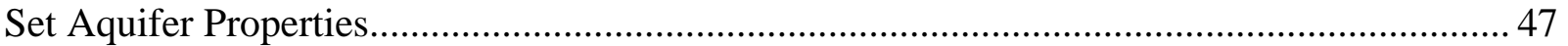

Create Pumping Wells ............................................................................................... 48

Create Specified-Flow Boundary ......................................................................... 48

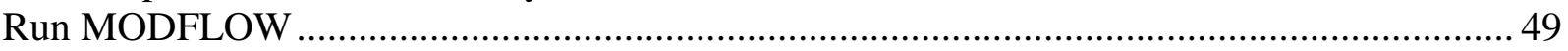

Plot Heads Generated by MODFLOW ....................................................................... 49

Define MODPATH Particle Starting Points................................................................. 50

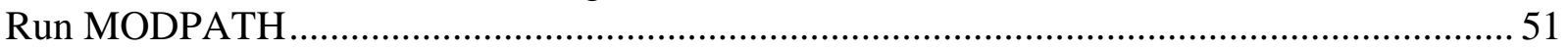

Plot MODPATH Results .................................................................................. 51

Define Horizontal-Flow Barrier and Rerun MODFLOW ……....................................... 52

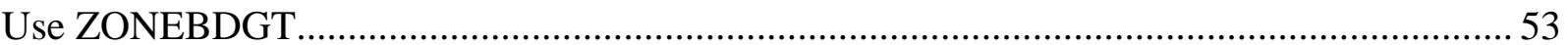

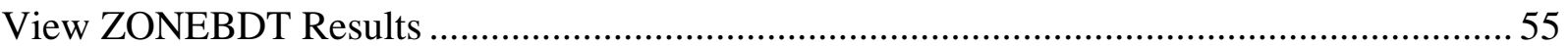

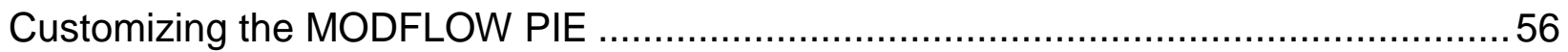

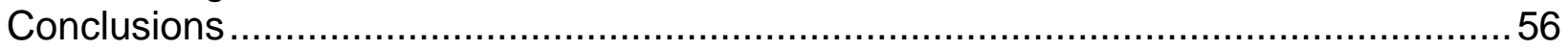

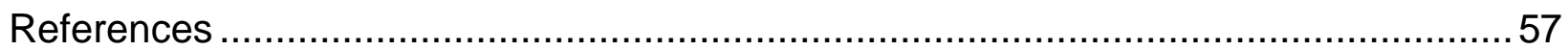

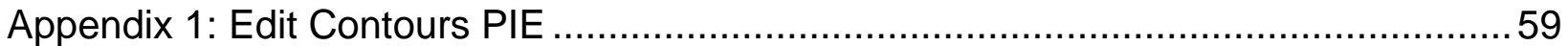

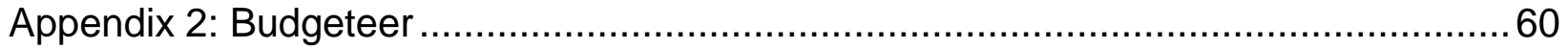

Appendix 3: RotateCells ......................................................................... 60

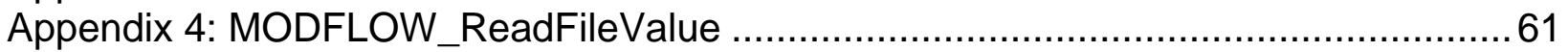

Appendix 5: GetMyDirectory, SelectChar.exe, and WaitForMe.exe ......................62

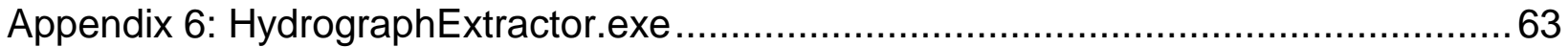

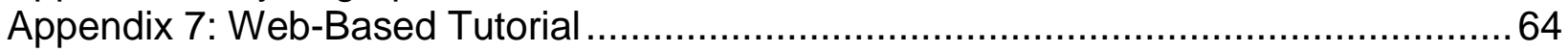




\section{Figures}

Figure 1. Revised Appearance of the Geology Tab. .......................................................... 7

Figure 2. Revised Appearance of the Time Tab.............................................................. 8

Figure 3. Revised Appearance of the MOC3D Tab (formerly Transport Subgrid Tab).............. 9

Figure 4. Revised Appearance of the MOC3D Particles Tab (formerly Particles Tab)............. 10

Figure 5. Example of context-sensitive help............................................................. 11

Figure 6. Geology tabs with columns used to choose whether to specify Transmissivity

(Specify T), Vertical Conductivity (Specify Vcont), and Confined Storage Coefficient

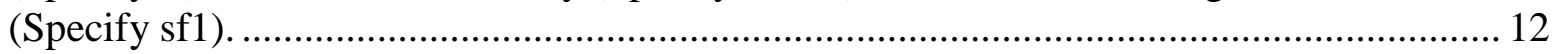

Figure 7. Stresses 2 tab used for selecting the Stream Package and Flow and Head Boundary

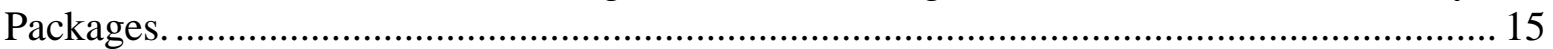

Figure 8. Solvers/Other Packages Tab. ............................................................................... 16

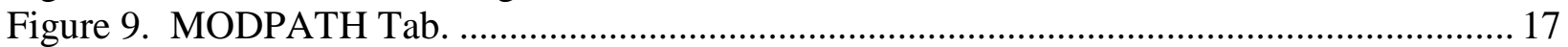

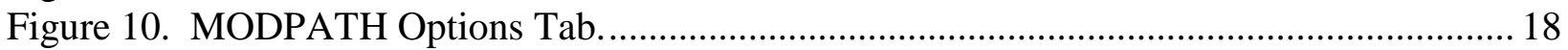

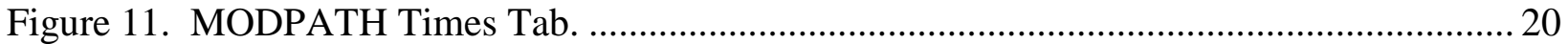

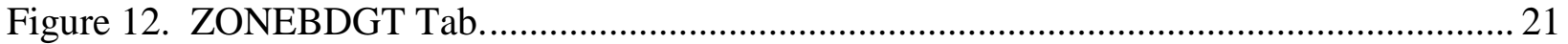

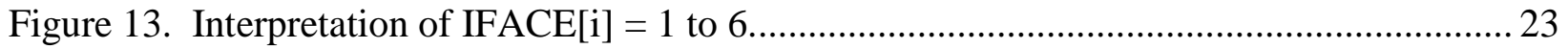

Figure 14. Illustration of the linkage among stream segments. ...................................... 25

Figure 15. Two models that differ only in the orientation of the area surrounded by a

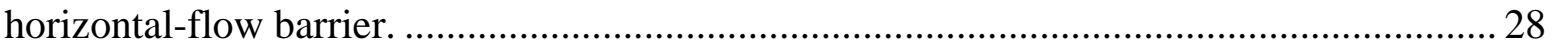

Figure 16. Close up of a section of the horizontal-flow barrier in model 2......................... 29

Figure 17. Method to calculate the reduction of HYDCHR when horizontal-flow barriers are

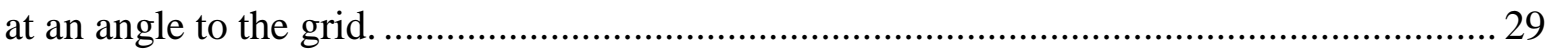

Figure 18. Revised Run MODFLOW/MOC3D Dialog box. In this example, MOC3D is not installed at the location specified in the MOC3D Path edit-box so the background of the

status bar, would appear red..................................................................................... 31

Figure 19. PIE-Generated Progress Bar with error messages. ....................................... 32

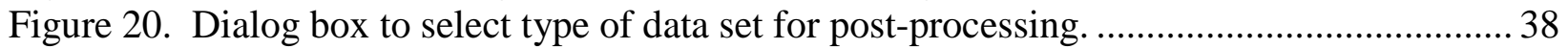

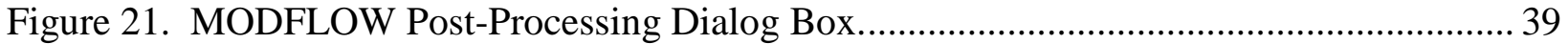

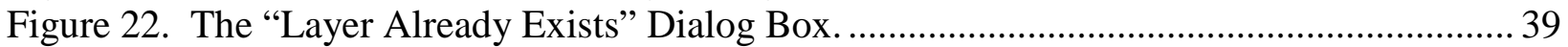

Figure 23. Plot MODPATH Results Dialog box after reading a set of pathlines. ................... 40

Figure 24. Base map for a two-dimensional sample problem.....................................42

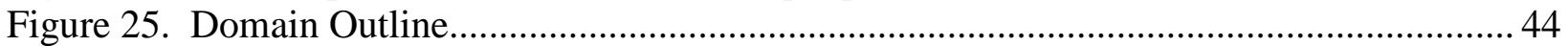

Figure 26. The label of the stream segment indicates the stream flows from right to left......... 45

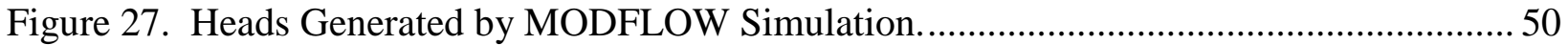

Figure 28. Contours on "MODPATH Particles Unit1" layer.......................................... 51

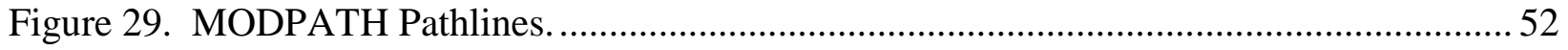

Figure 30. Slurry wall connecting the two, internal, bedrock outcrops. ................................53

Figure 31. Pathlines and head contours in the vicinity of the horizontal-flow barrier...............53

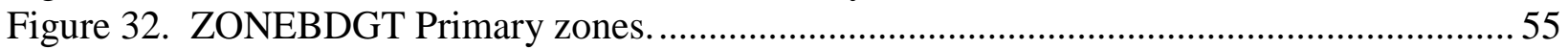

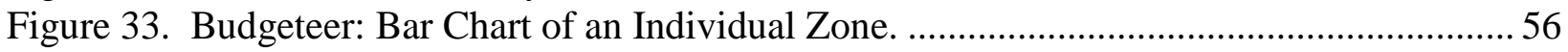




\section{Tables}

Page

Table 1. System Requirements.................................................................................... 4

Table 2. New Files Created for MODFLOW Simulations. ........................................... 35

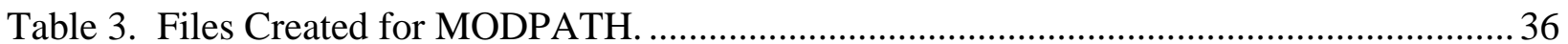

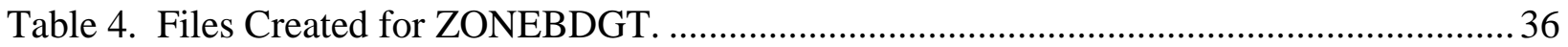

Table 5. Files Created by MODFLOW........................................................................... 37

Table 6. Files Created by MODPATH and ZONEBDGT. ................................................. 37

Table 7. Parameter values for two-dimensional sample problem........................................... 41 


\title{
Upgrade to MODFLOW-GUI: Addition of MODPATH, ZONEBDGT, and additional MODFLOW packages to the U.S. Geological Survey MODFLOW-96 Graphical-User Interface
}

\author{
Richard B. Winston
}

\begin{abstract}
This report describes enhancements to a Graphical-User Interface (GUI) for MODFLOW-96, the U.S. Geological Survey (USGS) modular, three-dimensional, finitedifference ground-water flow model, and MOC3D, the USGS three-dimensional, method-ofcharacteristics solute-transport model. The GUI is a plug-in extension (PIE) for the commercial program Argus ONE ${ }^{\mathrm{TM}}$. The GUI has been modified to support MODPATH (a particle tracking post-processing package for MODFLOW), ZONEBDGT (a computer program for calculating subregional water budgets), and the Stream, Horizontal-Flow Barrier, and Flow and Head Boundary packages in MODFLOW. Context-sensitive help has been added to make the GUI easier to use and to understand. In large part, the help consists of quotations from the relevant sections of this report and its predecessors. The revised interface includes automatic creation of geospatial information layers required for the added programs and packages, and menus and dialog boxes for input of parameters for simulation control. The GUI creates formatted ASCII files that can be read by MODFLOW-96, MOC3D, MODPATH, and ZONEBDGT. All four programs can be executed within the Argus ONE ${ }^{\mathrm{TM}}$ application (Argus Interware, Inc., 1997). Spatial results of MODFLOW-96, MOC3D, and MODPATH can be visualized within Argus $\mathrm{ONE}^{\mathrm{TM}}$. Results from ZONEBDGT can be visualized in an independent program that can also be used to view budget data from MODFLOW, MOC3D, and SUTRA. Another independent program extracts hydrographs of head or drawdown at individual cells from formatted MODFLOW head and drawdown files. A web-based tutorial on the use of MODFLOW with Argus ONE has also been updated. The internal structure of the GUI has been modified to make it possible for advanced users to easily customize the GUI. Two additional, independent PIE's were developed to allow users to edit the positions of nodes and to facilitate exporting the grid geometry to external programs.
\end{abstract}




\section{Introduction}

The purpose of this report is to describe enhancements to the USGS MODFLOW Graphical-User Interface (GUI) Version 2 (Hornberger and Konikow, 1998; Shapiro and others, 1997). Major changes introduced in this revision of the GUI include addition of contextsensitive help and incorporation of interfaces for the following programs or packages:

- MODPATH (Pollock, 1994),

- ZONEBDGT (Harbaugh, 1990),

- Stream Package (Prudic, 1989),

- Horizontal-Flow Barrier Package (Hsieh and Freckleton, 1993), and

- Flow and Head Boundary Package (Leake and Lilly, 1997).

In addition, a variety of less significant changes have been made to the GUI. These include the following.

- It is now possible to specify transmissivity, vertical conductance, and the confined storage parameter directly rather than having them calculated from other parameters.

- It is now possible to specify that a unit be convertible between confined and unconfined conditions but with a constant transmissivity ( $\mathrm{LAYCON}=2$ ).

- It is now possible to deactivate a package without deleting the layers and parameters for that package.

- The Modify buttons previously used to make changes to text in tables have been eliminated. Changes are now made directly in the table.

- An option has been added to allow users to choose among several expressions for defining the initial head and IBOUND parameters on the MODFLOW FD Grid layer.

- An option has been added to allow the user to use alternative export templates for the River, Drain, or General-Head Boundary packages. The alternative templates allow for more flexible specification of the river parameters but do not permit more than a single boundary of a given type in a cell.

- An About tab has been added to the Edit Project Info dialog box. The About tab includes the USGS identifier, bibliographic citations of the documentation of the GUI, the version of the GUI, a hypertext link to the URL where the GUI may be downloaded, and a link to email address for technical support.

- The edit-box for the WSEED parameter on the SIP tab is disabled unless the WSEED parameter is used by MODFLOW.

- The title of the PCG tab has been changed to PCG2 to reflect the version of PCG currently used by the USGS.

- On the PCG2 tab, the parameter IPCGCD has been replaced by DAMP because IPCGCD has been replaced by DAMP in the PCG2 package.

- The GUI no longer imposes any restriction on the number of geologic units or stress periods. However, if the number of MODFLOW layers exceeds 200, the limit in the standard release of MODFLOW-96, a warning message will be displayed.

- The dialog boxes provided by the GUI can now be resized.

- A variety of non-spatial data are now entered in different locations than previously to make data entry more intuitive.

- If any layers or parameters that should be present are missing, they will be added when clicking on the OK button in the Edit Project Info dialog box. A layer or parameter may be 
absent because it was not used in a previous version of the GUI or because a user has mistakenly deleted it manually. By restoring missing layers or parameters, a model is returned to a useable state despite user-errors.

- The method for specifying the extent of the transport subgrid for MOC3D has been changed. Previously, users would enter the first and last row and column numbers of the transport subgrid. Now users define the subgrid boundary on an information layer. The change makes it possible to modify the grid without need to re-enter values of ISROW1, ISROW2, ISCOL1, and ISCOL2. To update old models, the user may need to open and then close the Edit Project Info dialog-box so that the MOC3D Transport Subgrid layer can be created. The user will be prompted to open it, if required, when reading a data set prepared with an older version of the GUI.

- A method of importing well information has been added that makes it simpler to import well data from spreadsheets than previously.

- It is now possible to specify the location of an executable file without needing to modify the export template.

- During the export process, a dialog-box appears. It displays the progress of the export process and the estimated time remaining for the export process to finish. It also displays error and warning messages.

- The speed of the export process has been increased especially for models with multiple stress periods.

- More extensive error checking is done during the export process.

- In post-processing charts, inactive cells are skipped. Because the inactive cells may vary among MODFLOW layers, it is no longer possible to make post-processing charts of different MODFLOW layers using the same data layer. Thus, the Post-processing PIE must be called separately for each MODFLOW layer for which a post-processing plot will be made.

- The language in which the GUI is written has been changed from $\mathrm{C}++$ to Object Pascal.

- The internal structure of the GUI has been altered to make it possible for advanced users to customize the GUI. If the customization is done properly, it will be possible to incorporate future changes to the USGS version of the GUI into a customized version of the GUI with relatively little effort.

In addition to changes in the GUI a number of independent programs were created to facilitate various tasks that do not require integration with Argus ONE (Argus Interware, Inc., 1997). One program, Budgeteer (Appendix 2), extracts, water budget data from files created by MODFLOW (McDonald and Harbaugh, 1988; Harbaugh and McDonald, 1996), MOC3D (Konikow and others, 1996), ZONEBDGT (Harbaugh, 1990), or SUTRA (Voss, 1984) and plots it. The data can be saved in a form suitable for import into commercial spreadsheet programs. Another program, Hydrograph Extractor (Appendix 6), reads head or drawdown for individual cells from the formatted head or drawdown files produced by MODFLOW. It also plots the data and allows it to be saved in a form suitable for import into commercial spreadsheet programs.

A web-based tutorial on the use of MODFLOW with Argus ONE is available for downloading together with version 3 of the MODFLOW GUI (Appendix 7). The tutorial was originally prepared by Argus Interware for use with version 1 of the MODFLOW GUI.

I appreciate the suggestions for improvements made by USGS colleagues A.M. Shapiro, L.F. Konikow, G.Z. Hornberger, Earl Greene, and numerous users of previous versions of the MODFLOW-GUI. I wish to thank S. Dolev and J. Margolin of Argus Interware for their 
technical assistance. I would also like to thank all those who provided "bug-reports" or other advice while the revised GUI was under development.

I would like to thank Argus Interware for granting permission to update their MODFLOW tutorial.

\section{System Requirements}

The revised MODFLOW-GUI has been tested on personal computers with Windows 95 and Windows NT 4.0. It has not been tested extensively on Windows 98. The user must have the Windows version of Argus Open Numerical Environments (Argus ONE ${ }^{\mathrm{TM}}$ ). Argus ONE ${ }^{\mathrm{TM}}$ largely determines hardware requirements. At the time this was written, the requirements for Argus $\mathrm{ONE}^{\mathrm{TM}}$ were the following:

CPU Pentium, Pentium Pro recommended

Mouse Required

RAM $\quad 32 \mathrm{MB}$ or more recommended

DISK $7 \mathrm{MB}$

Display VGA/SVGA Display, 65,000 colors

In addition, the MODFLOW-GUI requires a display with a resolution of at least $632 \times 590$.

\section{Installation}

Table 1. System Requirements.

\begin{tabular}{|c|c|}
\hline Files required for installation & Location to install \\
\hline MFGUI_30.dll & $<$ Argus directory $>\backslash$ ArgusPIE\MODFLOW \\
\hline MODFLOW.cnt & $<$ Argus directory $>\backslash$ ArgusPIE\MODFLOW \\
\hline MODFLOW.hlp & $<$ Argus directory $>\backslash$ ArgusPIELMODFLOW \\
\hline $\begin{array}{l}* \text {.met (see readme.txt file for } \\
\text { details) }\end{array}$ & $<$ Argus directory $>\backslash$ ArgusPIE\MODFLOW \\
\hline MODFLOW JoinFiles.dll & $<$ Argus directory $>\backslash$ ArgusPIE $\backslash$ JoinFiles \\
\hline MODFLOW_BlockList.dll & $<$ Argus directory $>\backslash$ ArgusPIE $\backslash$ BlockList \\
\hline MODFLOW_ReadFileValue.dll & $<$ Argus directory $>\backslash$ ArgusPIE $\backslash$ ReadFileValue \\
\hline MODFLOW_List.dll & $<$ Argus directory $>\backslash$ ArgusPIElList \\
\hline GetMyDirectory.dll & $<$ Argus directory $>\backslash$ ArgusPIE $\backslash$ GetMyDirectory \\
\hline SelectChar.exe & $<$ Argus directory $>\backslash$ ArgusPIE $\backslash$ GetMyDirectory \\
\hline WaitForMe.exe & $<$ Argus directory $>\backslash$ ArgusPIE $\backslash$ GetMyDirectory \\
\hline MODFLOW_ProgressBarPIE.dll & $<$ Argus directory $>\backslash$ ArgusPIE $\backslash$ ProgressBarPIE \\
\hline Ctl3d32.dll (Windows NT 3.51) & $<$ Windows directory $>$ SSystem 32 \\
\hline
\end{tabular}

Except for ctl3d32.dll, all the files used by the PIE should be placed in the ArgusPIE directory or in subdirectories under the ArgusPIE directory. Unless otherwise noted, it is generally a good idea to place each PIE in its own subdirectories under the ArgusPIE directory. The export templates used by the PIE (*.met), and the help system files (modflow.hlp and modflow.cnt) should be placed in the same directory as the MODFLOW PIE (MFGUI_30.dll). $\mathrm{Ctl3d} 32 . \mathrm{dll}$ is only required for Windows NT 3.51. If required, it should be placed in the System 32 directory under the main directory for the operating system (normally WinNT). 
Many, but not all, users will already have Ctl3d32.dll on their computer and in such cases they generally should not replace the existing version with the one distributed with the PIE. Export templates that are meant to be modified and executed manually by the user may be placed in any convenient location. These include contour2data.met and statistics.met. All the files comprising the PIE are available from the U.S. Geological Survey, but they require an executable version of Argus ONE ${ }^{\mathrm{TM}}$ (version 4.20i or higher) to operate. Although not required to operate the MODFLOW PIE, the EditContours, RotateCells, MODFLOW_ReadFileValue, and GetMyDirectory PIE's and the Budgeteer, SelectChar, WaitForMe, Extract Hydrograph programs and MODFLOW tutorial (see Appendices 1-7) were designed for use with models in the MODFLOW PIE and are thus distributed with the MODFLOW PIE. The may also be useful for other purposes.

Previous versions of the GUI (Shapiro and others, 1997; Hornberger and Konikow, 1998) used a number of array PIE's that are not used by the current version of the PIE (Chk_BlockArray.dll, Chk_LayArray.dll). If those files are present, they may be deleted without affecting the new version of the MODFLOW-GUI. Previous versions of the MODFLOW-GUI and post-processing PIE's (mfgui_20.dll, mfpost20.dll, mcpost10.dll) should be deleted from the Argus PIE directory because they will interfere with the new version of the PIE. The functions performed by all three of these older PIE's have been incorporated into the new GUI.

Executable versions of MOC3D (Version 1.2 or later), MODFLOW-96, MODPATH, and ZONEBDGT must be installed to run these models from the Argus ONE ${ }^{\mathrm{TM}}$ environment. The MODFLOW-96 code and the MOC3D code are integrated into one code (MOC3D). MODFLOW-96 (without MOC3D) is executed when using the GUI to simulate ground-water flow only, without transport; MOC3D is executed when simulating ground-water flow with transport. Although it does not matter what compiler was used to create the executable versions of the models, it is important that they all be compiled with compatible compilers. This is because ZONEBDGT and MODPATH read binary files created by MOC3D and MODFLOW96. The format of the binary files is compiler-dependent. The versions of these programs on the USGS software web site are all compatible with one another.

The MODFLOW-GUI consists of a dynamic-link library (MFGUI_30.DLL) that provides the core functionality. It provides the Edit Project Info, Run MODFLOW, and a variety of other dialog boxes. It is responsible for creating and destroying MODFLOW-related layers and parameters in the Argus ONE ${ }^{\mathrm{TM}}$ project and for accessing its context-sensitive help. It processes the model-related export templates and prepares them for execution by Argus ONE ${ }^{\mathrm{TM}}$. It also provides a number of hidden PIE functions that are called when the export templates are executed. The model-related export templates are the files MODFLOW.met, ZoneBud.met, and MODPATH.met. These files contain the instructions for creating the input files for MODFLOW, MOC3D, ZONEBDGT, and MODPATH. When they are executed, the export templates use PIE functions provided by the following dll's: List.dll, BlockList.dll, ProgressBar.dll, and JoinFiles.dll. Of these, only ProgressBar.dll will be visible to the user. It displays a progress bar during the execution of export templates and provides an estimate of the time required until execution of the export template is complete. It also displays error and warning messages. Modflow.hlp and Modflow.cnt provide the online help for the PIE. Finally, ctl3d32.dll, a dynamic-link library from Microsoft Corporation ${ }^{\mathrm{TM}}$, provides the three-dimensional appearance of the certain portions of the dialog boxes when the PIE is operated on computers using the Windows NT 3.51 operating system. 


\section{Starting the Preprocessor}

The user can start a new model or open an existing model in the same way as in previous versions of the MODFLOW-GUI. To start a new model, start Argus ONE ${ }^{\mathrm{TM}}$ and select PIEs|New MODFLOW Project. To open an existing model, start Argus ONETM and select File|Open... and then select the file to open. In some cases, if the user opens a model created by the previous version of the MODFLOW/MOC3D PIE, the PIE will need to update the data for specifying the transport subgrid. If this is the case, a message will notify the user that he will need to open the Edit Project Info dialog box and close it again. The data will be automatically updated when the user clicks OK after opening the Edit Project Info dialog box. Other layers, such as group layers for each geological unit may also be created at the same time. (The group layers provide a convenient mechanism for organizing Argus ONE ${ }^{\mathrm{TM}}$ layers but are not required for the model to operate.)

\section{Entering Non-spatial Data}

Non-spatial data are entered in the Edit Project Info dialog box. The user can display it by selecting PIEs|Edit Project Info... Most of the non-spatial data are the same as in previous versions of the MODFLOW-GUI (Shapiro and others, 1997; Hornberger and Konikow, 1998). Only those portions of the Edit Project Info dialog box that have changed or are new will be described here. Complete explanations of all items in the Edit Project Info dialog box are included in the online help.

\section{Changes to Existing Features}

\section{Overall Appearance}

The tabs in the Edit Project Info dialog box now appear on multiple rows and all tabs currently in use are always visible. In the previous versions, the tabs were on a single row and the user would sometimes need to scroll to the right or left to select another tab.

The Misc. Controls tab has been removed. The data that were formerly entered in this tab are now entered on the Wetting, Geology, or Output Files tabs.

The SIP, SOR, PCG, and PCG tabs have been removed. The data formerly displayed on those tabs is now displayed in the new Solvers/Other Packages tab.

\section{Geology Tab}

On the Geology tab (figure 1), the edit-boxes and modify button from version 2 have been removed. The user should now enter data directly in the table. For Simulated, Interblock Transmissivity, Aquifer Type, Specify T, Specify Vcont and Specify sp1 select a cell and then click in it or press the Enter key on the keyboard to display a list of choices. For the other columns, just select the cell and type the data. A new button, Add can be used to add a new geologic unit to the end of the list of geologic units. The GUI now supports LAYCON $=2$ in the Block-Centered-Flow package (convertible layers with constant transmissivity). You can resize the columns on this or other tables. To ensure that the title of a column is always legible regardless of the size of a column, the title of the column over which the mouse is positioned will be displayed in the status bar at the bottom of the dialog box.

On the Geology Tab, IAPART is now automatically set to the correct value and disabled if the Interblock Transmissivity is set to Arithmetic \& Logarithmic in any geological unit. IAPART was formerly on the Misc. Controls tab. 


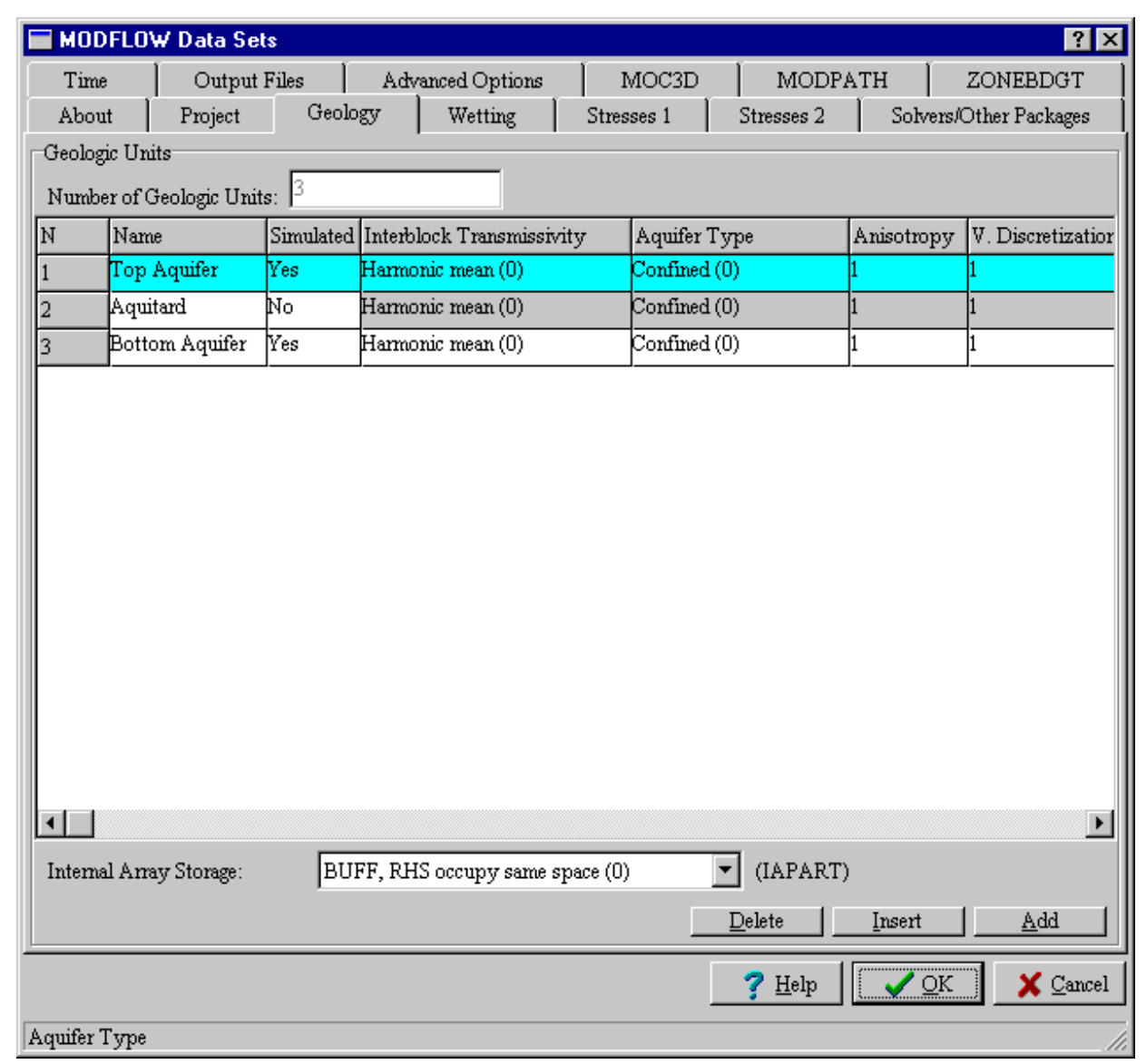

Figure 1. Revised Appearance of the Geology Tab.

\section{Stresses 1 Tab}

The Stresses/Solvers tab has been replaced by three new tabs Stresses 1, Stresses 2, and Solvers/Other Packages. The choice of solvers has been moved to the Solvers/Other Packages tab. The check box for selecting MOC3D and the radio buttons for selecting the MOC3D solver have been moved to the MOC3D tab.

\section{Output Files Tab}

On the Output Files Tab, CHTOCH is automatically set to the proper value if the MOC3D checkbox on the MOC3D tab is checked. The control is also disabled if the MOC3D checkbox is checked so that it can not be changed to an incorrect value. CHTOCH was formerly set with a combo-box. It is now set with a check-box. The root name is now limited to eight characters and will be converted to lower case. The latter facilitates using the MODFLOW input files on computers with UNIX operating systems. The eight-character limitation is imposed because the current version of MODFLOW-96 for the DOS operating system distributed by the USGS does not support long file names. Combo boxes have been added to allow the user to specify the format in which to print heads and drawdowns.

\section{Time Tab}

On the Time tab (figure 2), the edit-boxes and Modify button have been removed. The user now enters data directly into the table. A new Add button can be used to add a new stress 
period to the end of the list of stress periods. The user now can change the number of stress periods by entering a number in the Number of stress periods edit-box. The change takes effect as soon as the user clicks outside the edit-box. A new field has been added to the table. It displays the length of the first time step in the stress period. This number can not be edited directly. Instead it is calculated based on the length of the stress period, the number of time steps and the time step multiplier. It is displayed as a convenience to the user but is not exported to the MODFLOW input files.

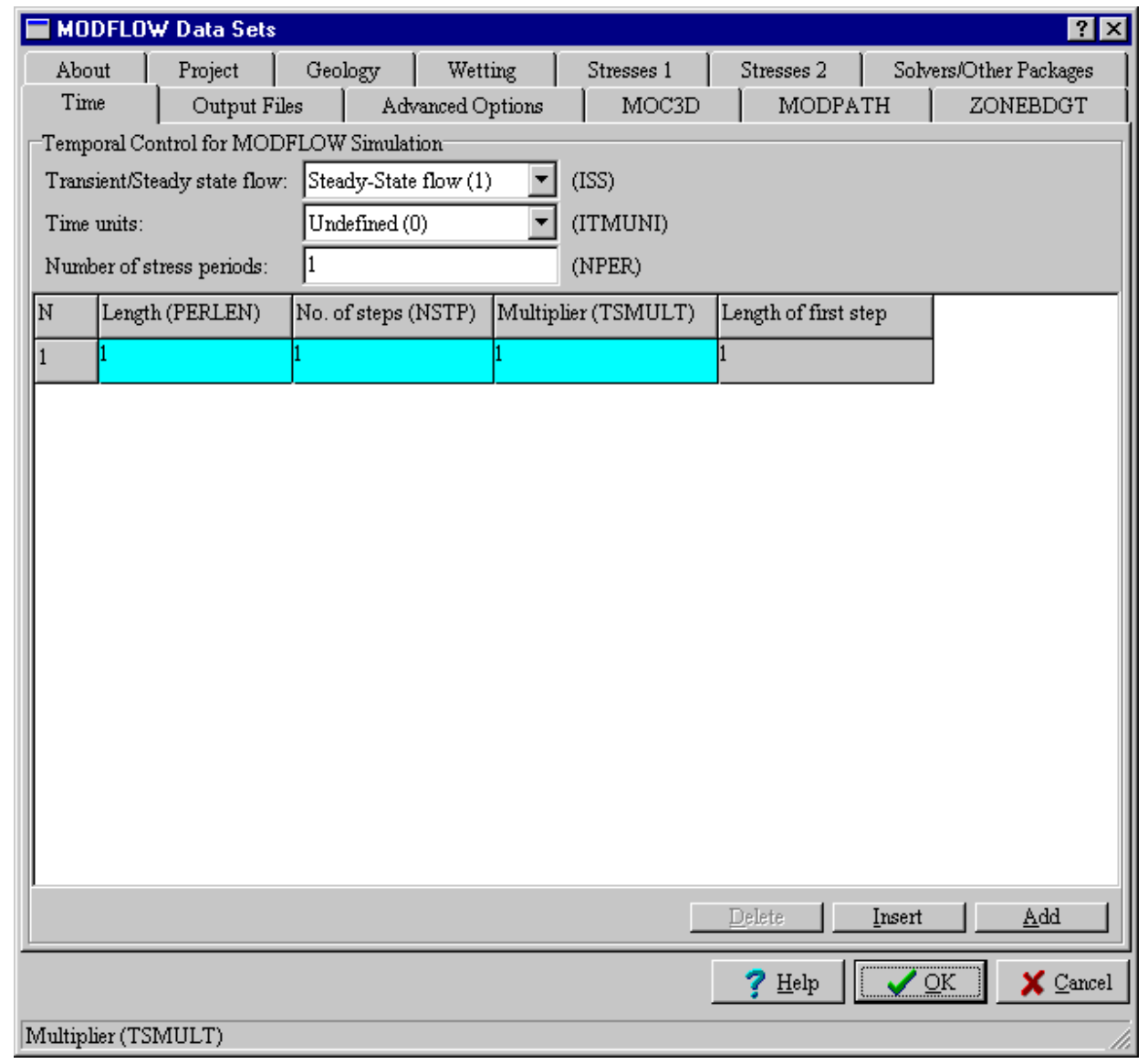

Figure 2. Revised Appearance of the Time Tab.

\section{Sovers/Other Packages Tab}

On the new Sovers/Other Packages tab, the IPCGCD parameter of the PCG2 package has been replaced by DAMP. DAMP replaces IPCGCD in the most recent version of the PCG2 solver. In setting data for the SIP solver, it is now only possible to specify WSEED if IPCALC is set to 0. This is because MODFLOW will only use WSEED if IPCALC is set to 0.

\section{MOC3D Tab}

The Transport Subgrid tab has been renamed the MOC3D tab (figure 3). On the MOC3D tab, the user no longer specifies the rows and columns in the transport subgrid. This is now done on the information layer named MOC3D Transport Subgrid. In addition the Help button next to INCRCH has been eliminated. The help for INCRCH has been incorporated into the new context-sensitive help for the PIE. The check box for selecting MOC3D and the radio 
buttons for selecting the MOC3D solver have been moved from the Stresses/Solvers tab to the MOC3D tab.

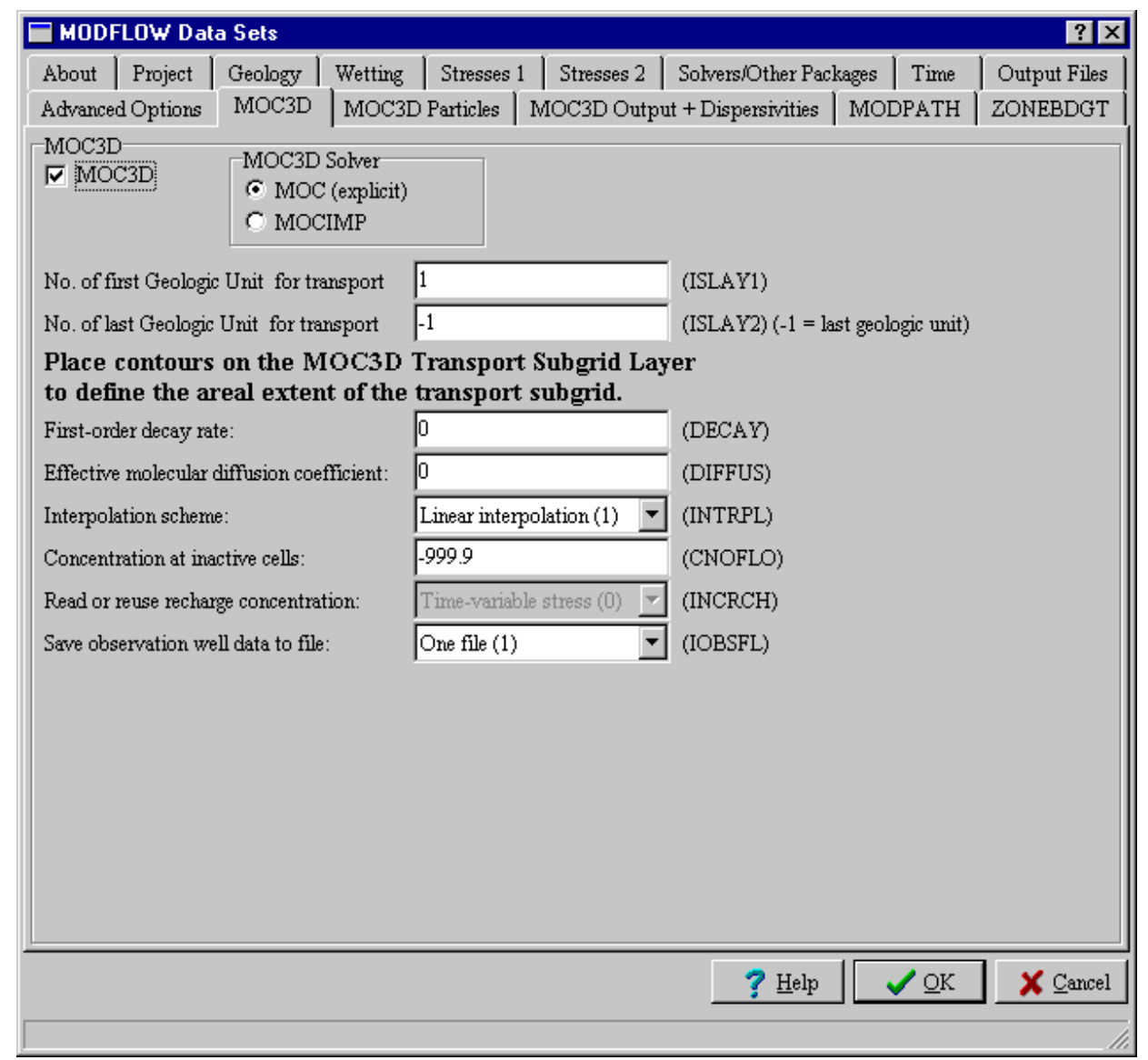

Figure 3. Revised Appearance of the MOC3D Tab (formerly Transport Subgrid Tab).

\section{MOC3D Particles Tab}

The Particles tab has been renamed the MOC3D Particles tab (figure 4). On it, the three help buttons have been eliminated. The help that they formerly provided has been incorporated into the new context-sensitive help for the PIE. The edit fields and Modify button have also been eliminated. Instead, enter values directly into the table. 


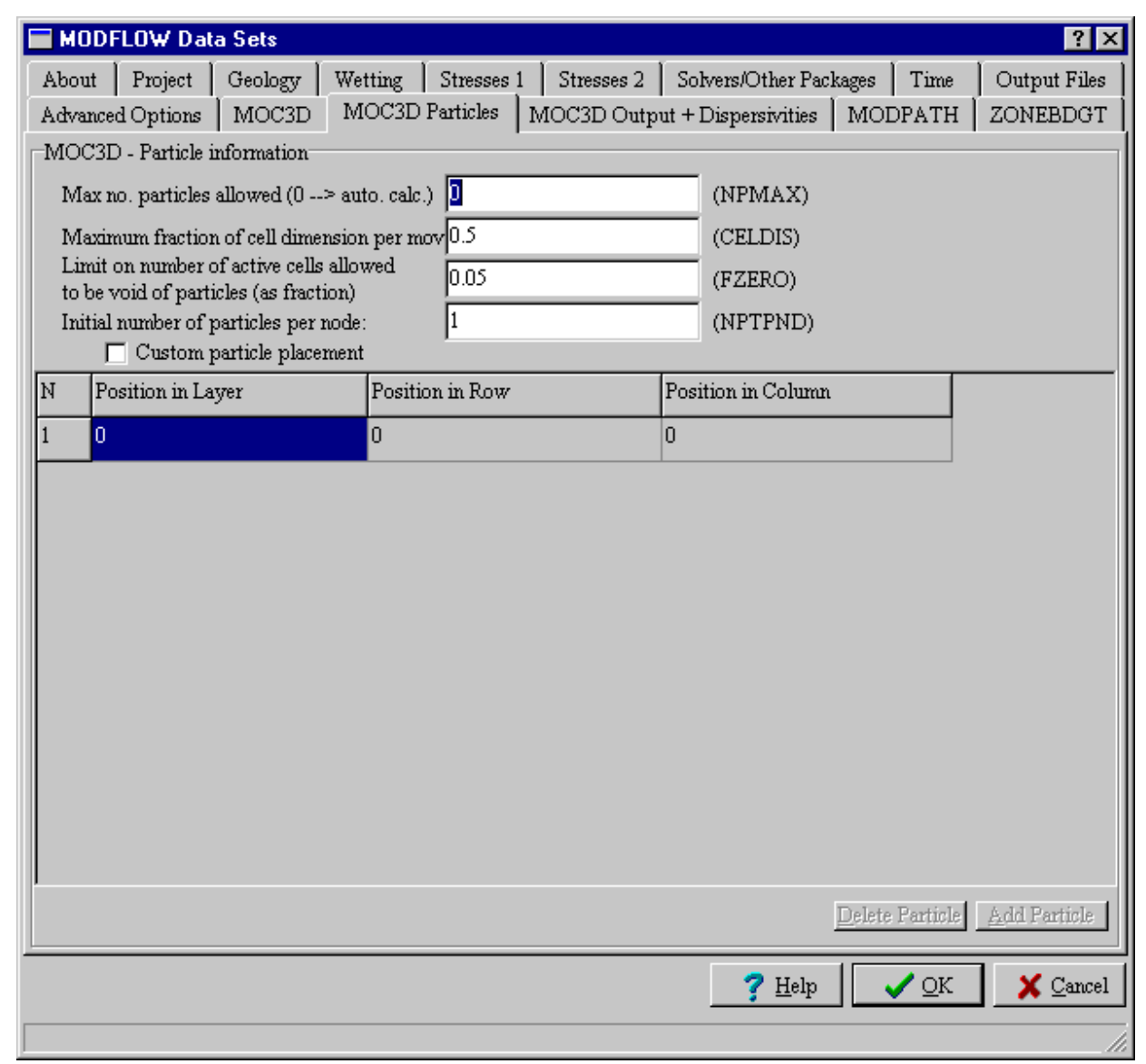

Figure 4. Revised Appearance of the MOC3D Particles Tab (formerly Particles Tab).

\section{MOC3D Output + Dipsersivities Tab}

A pair of radio buttons has been added to the MOC3D Output + Dipsersivities tab to allow the user to choose to the format in which in which concentration will be printed in if the concentrations are printed in a separate output file (file type CNCA).

\section{New Features}

\section{Context-sensitive help}

Context-sensitive help (figure 5) is available for the major dialog boxes created by the MODFLOW-GUI. These include the Edit Project Info, Run MODFLOW, MODFLOW Post Processing, and Display Horizontal Flow Barriers dialog boxes. To access the help on any of these dialog boxes, click on the Help button on the dialog box or click on a control (combo-box, check-box, etc.). Then press the F1 key. Another way to access the help is to click on the question-mark icon in the upper right corner of the dialog box and then click on a control such as a check box. 


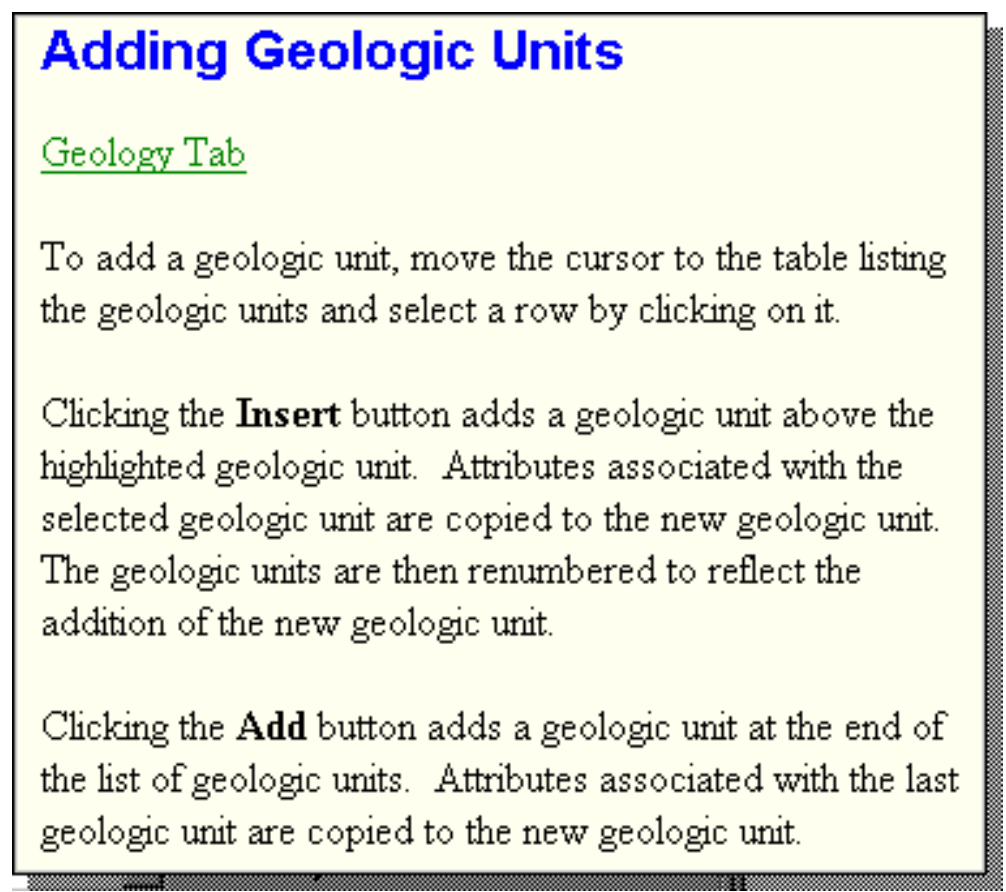

Figure 5. Example of context-sensitive help.

Help is also available for all the layers and parameters created by the PIE although this help is not context-sensitive. To access the help file, select PIEs|MODFLOW Help. It is possible to access the MODFLOW help without starting a MODFLOW project.

Deactivating Packages without Deleting the Data for the Package.

If the Use checkbox next to the check box for a package is not checked, the layers and parameters for that package will be retained in the Argus ONE project but the package will not be used in the model. You can check on uncheck these checkboxes to enable or disable a package without deleting the information you have entered for those packages.

Specifying Transmissivity, Vertical Conductance, and Confined Storage Coefficient.

The geology data table on the Geology tab has three new columns labeled Specify T, Specify Vcont, and Specify sf1 (figure 6). It may be necessary to resize the Edit Project Info Dialog box or to use the scroll bar under the Geology data table to see these new columns. These are used to decide whether to specify transmissivity, vertical conductance, and the confined storage coefficient respectively. If the user selects a cell in any of these three columns, a dropdown menu will appear. Select Yes to specify any of the three parameters directly. Select No to calculate these parameters from other parameters. If the user selects Yes, the appropriate information layers and parameters will be created. 


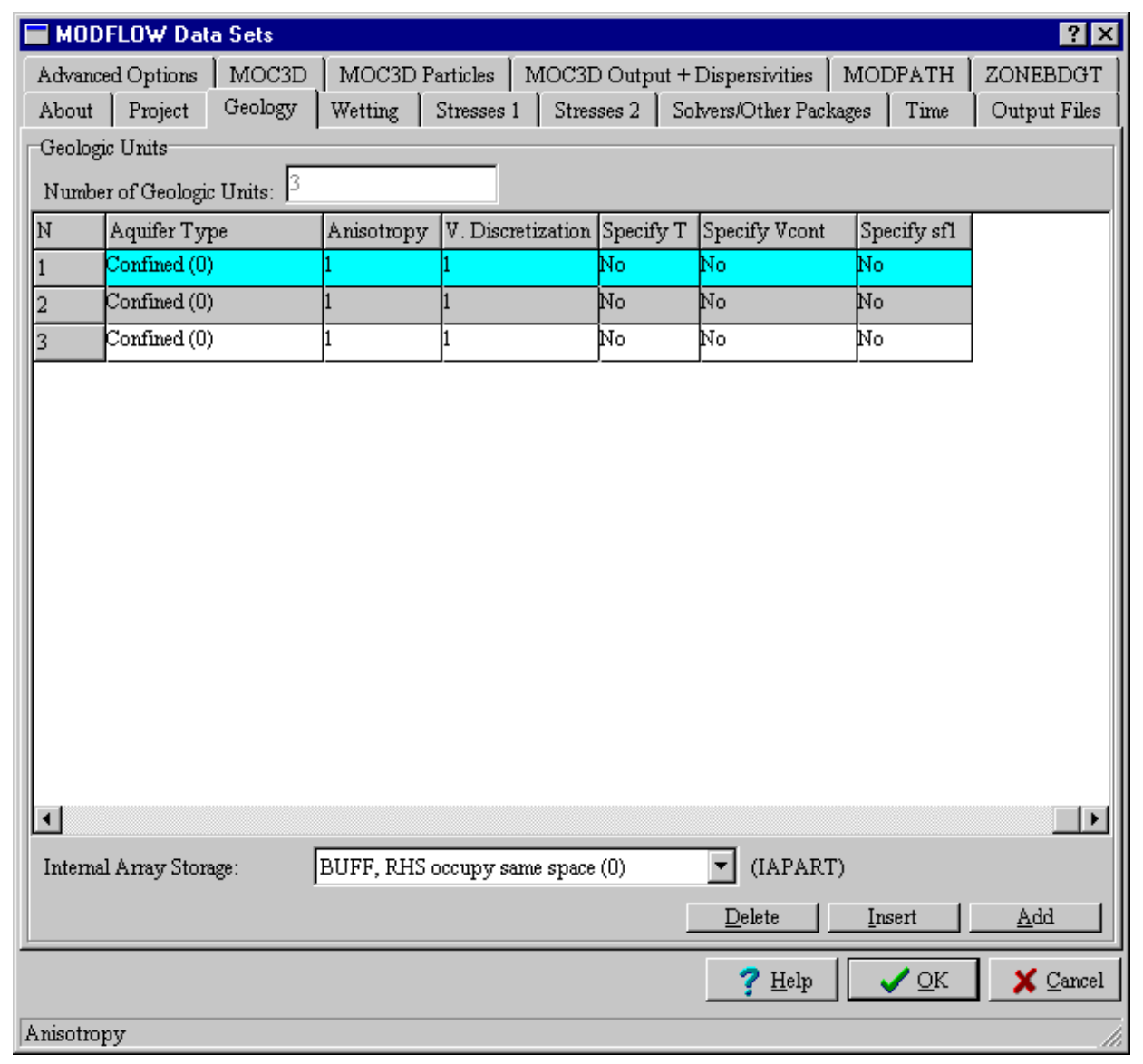

Figure 6. Geology tabs with columns used to choose whether to specify Transmissivity (Specify T), Vertical Conductivity (Specify Vcont), and Confined Storage Coefficient (Specify sf1).

\section{Saving Default Values}

Files with the extension ".val" are text files that are used to set defaults for all options in the Edit Project Info dialog box. If the user clicks the Save Val File button on the Advanced Options tab and accept the default file name and location, a ".val" file will be created that will be used for all new MODFLOW projects. The default file name is "modflow.val". The default location is the directory in which the MODFLOW-GUI is installed. The ".val" file will save all the information in the Edit Project Info dialog box. If the user saves it with a different file name or location, a ".val" file will be created that can be opened later by clicking the Open Val File button. Opening a ".val" file will cause the options specified in the ".val" file to override all the data in the Edit Project Info dialog box.

Files with the extension ".val" files created for versions 1 and 2 of the MODFLOW-GUI are not used by the current version of the MODFLOW-GUI. Users who have not edited the "modflow.val" file to specify default values, should delete the modflow.val file. Users who have edited the modflow.val file, should replace it with a new version created in the method described above. If an old version of a ".val" file is read by the MODFLOW-GUI, a warning message will be displayed. 


\section{Specifying Initial Head Formula}

The combo-box labeled Method for assigning the IBOUND parameter and prescribed heads in the initial head MODFLOW FD Grid parameter on the Advanced Options tab gives three choices for how initial head will be determined:

\section{Method from MF-GUI versions 1 and 2}

Average Points and Open Contours

\section{Use Point Contours First}

These options affect how prescribed head boundaries will be treated especially when open contours or point contours are used. For Method from MF-GUI versions 1 and 2, the initial head in a cell containing a contour on the Prescribed Head Unit[i] layer will be interpolated from all the contours on the layer. This was the method used in versions 1 and 2 of the MODFLOWGUI. For Average Points and Open Contours, any cells that have both point and open contours on the Prescribed Head Unit[i] layer will be assigned the average of the point and open contours on that layer. Locations inside closed contours will have the value of that contour unless the cell also contains a point or open contour. For Use Point Contours First, any cells that have both point and open contours on the Prescribed Head Unit[i] layer will be assigned the average of the point contours on that layer. If the cell contains no point contours but does contain an open contour, it will be assigned the average of the open contours on that layer. Locations inside closed contours will have the value of that contour.

These options also affect which cells are inactive. If Method from MF-GUI versions 1

and 2 is selected, all cells whose centers are outside the domain outline will be inactive. For the other choices, any cell on the domain outline will be either an active cell or a prescribed head cell even if its center is outside the domain outline.

\section{Use Binary Head File for Initial Heads}

If the Use MODFLOW binary head file as source of initial heads checkbox is checked, MODFLOW will read the initial heads directly from the file specified in the File Name edit box rather than from values entered in the GUI. This affects the heads at all cells including the prescribed head cells. Any changes in the grid will make this method invalid.

\section{Using Alternative Export Templates}

If the Use alternate River package export template, Use alternate Drain package export template, or Use Alternate GHB package export template check box is checked an alternative export template is used for the River Drain, or General-Head Boundary package. This alternative template allows you to set the value of all parameters in the river layers using expressions.

On the Line River Unit[i], Line Drain Unit[i], or Line GHB Unit[i], layers, there will be one boundary created in each cell in which there is an open contour. The bottom and stage stress will be evaluated at the block center. The conductance exported to MODFLOW will be the conductance parameter evaluated at the cell center multiplied by the lengths of all the contours in the block.

On the Area River Unit[i], Area Drain Unit[i], or Area GHB Unit[i] layers, there will be one boundary created in each cell in which the conductance parameter is a number (rather than \$N/A) at the block center. The bottom and stage stress will be evaluated at the block center. The conductance exported to MODFLOW will be the conductance parameter evaluated at the cell center multiplied by the area of the block. 


\section{Explicitly specify recharge or evapotranspiration layer}

If the Explicitly specify recharge layer or Explicitly specify evapotranspiration layer check box is checked, parameters will be added to the Recharge or Evapotranspiration layer that can be used to specify the MODFLOW layer to which recharge or evapotranspiration will apply instead of calculating the layer from the Elevation parameter.

\section{Stream Package}

Three additional MODFLOW Packages have been added to the interface; the Stream Package (Prudic, 1989), the Horizontal-Flow Barrier Package (Hsieh and Freckleton, 1993), and the Flow and Head Boundary Package (Leake and Lilly, 1997). To activate the stream package, go to the Stresses 2 tab (figure 7) in the Edit Project Info dialog box and check the STR checkbox. This will activate the other stream-related controls on the Stresses 2 tab. If the user attempts to activate both the stream package and MOC3D, a warning message will be displayed. If the user selects Steady Stress for the stream package, all the variables that are specified for the first stress period will apply to the remaining stress periods. However, there will still be parameters created for the other stress periods. This allows the user to switch between timevariable stress and steady stress without loss of information. If the user chooses to calculate flow, specify both the length and time units for the model. The length units are specified on the Stresses 2 tab. The time units are specified on the Time tab. If the user does not specify the time units, a warning message will appear when the Edit Project Info dialog box is closed or the input files for MODFLOW are exported. The user can choose whether or not to simulate stream tributaries and diversions. Depending on the choices made, parameters related to tributaries, diversions, and calculating flow will be created on the Stream Unit[i] information layers when the Edit Project Info dialog box is closed. See Prudic (1989) for more information about the Stream package. 


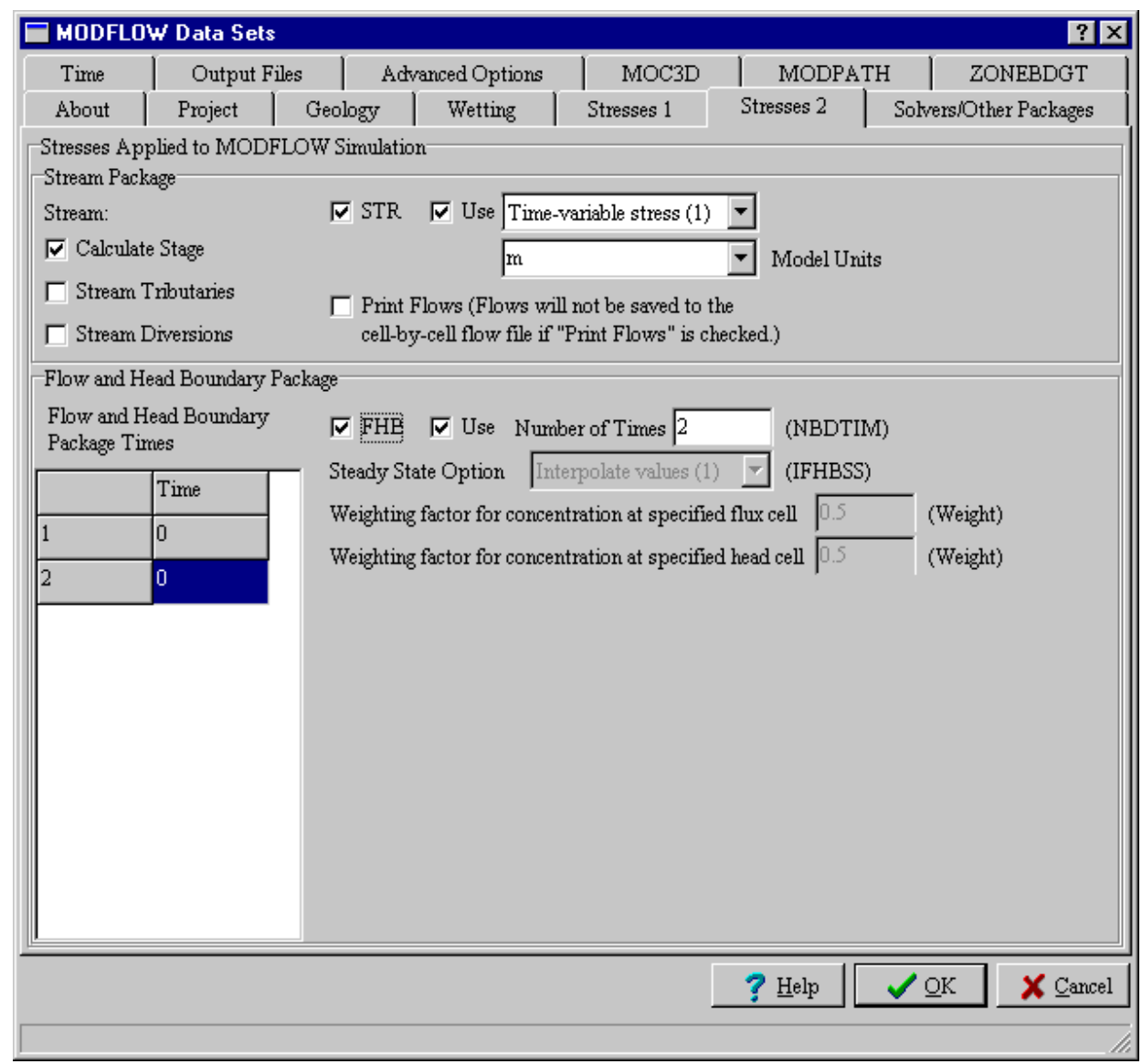

Figure 7. Stresses 2 tab used for selecting the Stream Package and Flow and Head Boundary Packages.

\section{Flow and Head Boundary Package}

To activate the Flow and Head Boundary package, change to the Stresses 2 tab (figure 7) of the Edit Project Info dialog box and select the Flow and Head Boundary check-box. This will activate some or all of the other controls related to the Flow and Head Boundary package. The controls that are activated depend on the current set-up of the model. In all cases, the user can set the number of Flow and Head Boundary times. This will change the number of Flow and Head Boundary times that can be edited. The first such time must always be zero. It can not be edited. All subsequent times must be larger than or equal to their predecessors. If invalid times are specified, a warning message will appear when the Edit Project Info dialog box is closed. The steady-state option for Flow and Head boundaries is only available for steady-state models with multiple stress periods. Weighting factor for concentration at specified flux cell and Weighting factor for concentration at specified head cell will only be available for models in which MOC3D is selected. More information about the Flow and Head Boundary Package is in Leake and Lilly (1997).

\section{Horizontal-Flow Barrier Package}

To activate the Horizontal-Flow Barrier package, change to the Solvers/Other Packages tab (figure 8) of the Edit Project Info dialog box and select the Horizontal-Flow Barrier check-box. There are no time-dependent parameters for the Horizontal-Flow Barrier package so 
there is no steady state option. See Hsieh and Freckleton (1993) for more information about the Horizontal-Flow Barrier package.

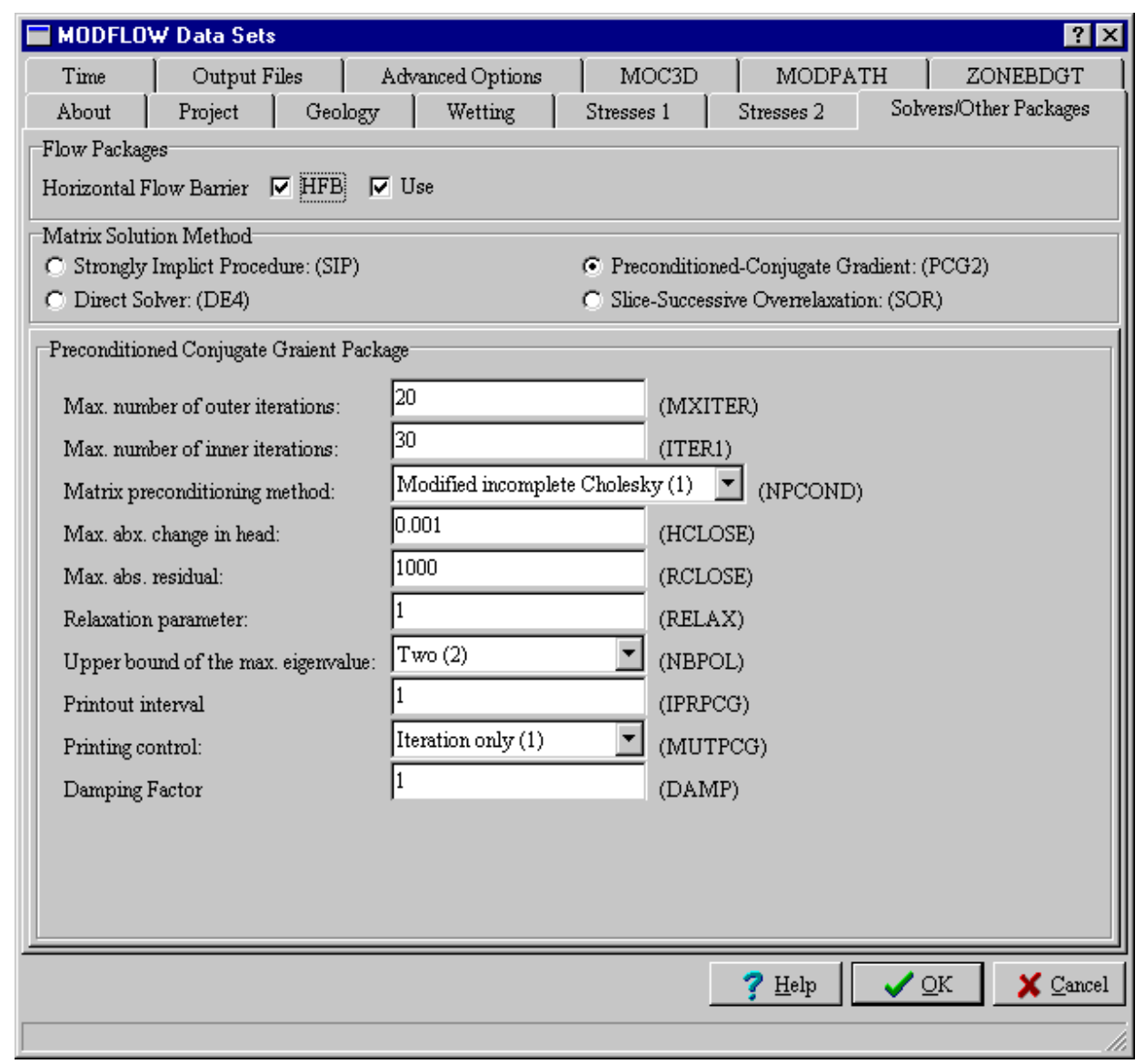

Figure 8. Solvers/Other Packages Tab.

MODPATH

To activate MODPATH, change to the MODPATH tab (figure 9) and select the MODPATH check-box. A new tab will appear labeled MODPATH Options (figure 10). In addition, if the user selects Compute locations at specific points in time and specify times individually on the MODPATH Options tab, another new tab will appear labeled MODPATH Times (figure 11). The descriptions for the MODPATH options below are largely quoted or paraphrased from those in the MODPATH 3.0 manual (Pollock, 1994). 


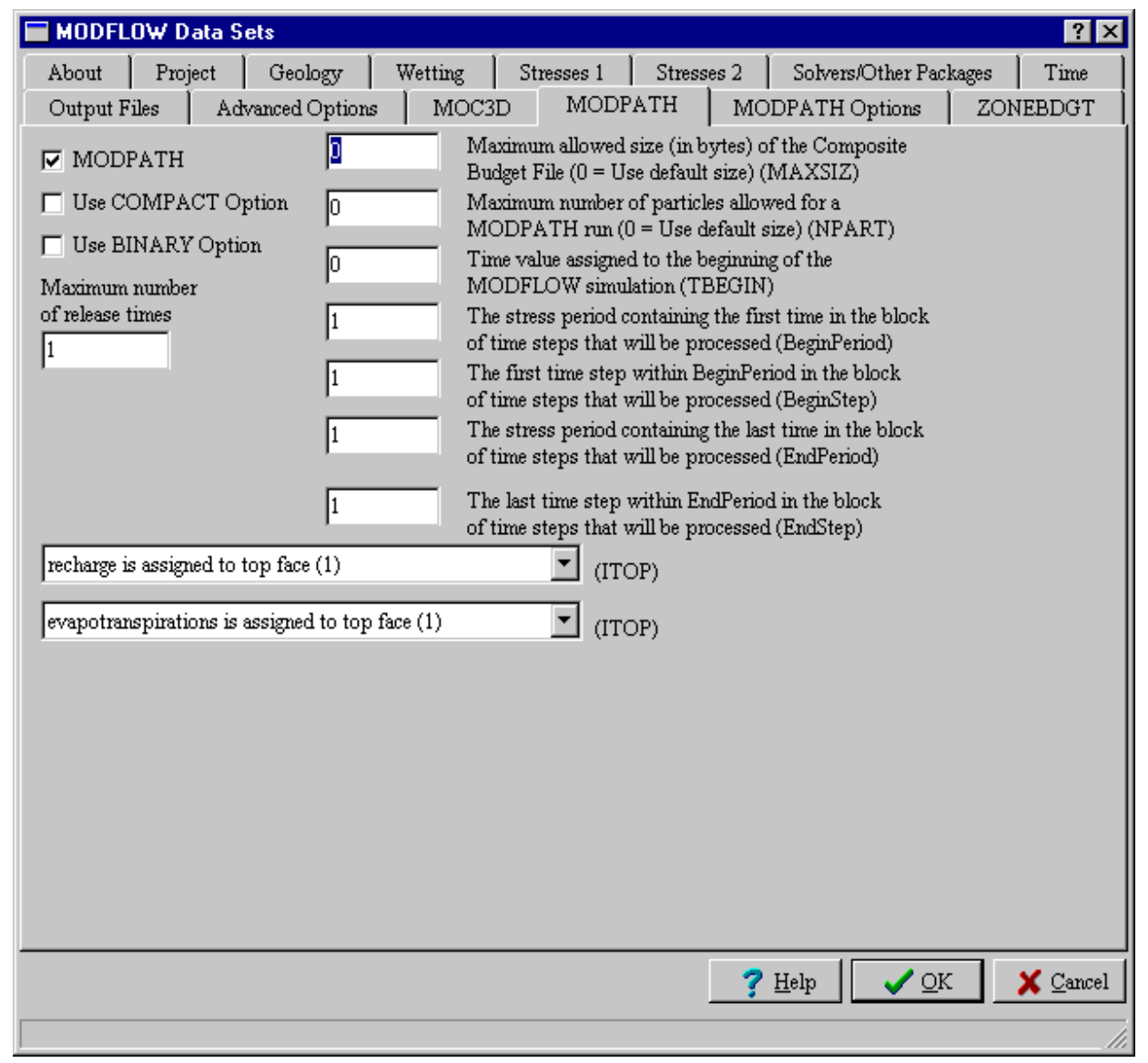

Figure 9. MODPATH Tab.

If the Use COMPACT Option check-box box is checked, MODPATH will generate endpoint, pathline, or time series files as text files using the global node number to indicate cell location. If it isn't checked, the cell locations will be designated using the row-column-layer grid indices (as in previous versions of MODPATH).

If the Use BINARY Option check-box is checked, endpoint, pathline, and time series files will be generated by MODPATH in binary form. If the BINARY option is used, it will also need to be used with MODPATH-PLOT to correctly read binary versions of these files. The MODFLOW-GUI does not read binary MODPATH output files so this option should not be used if the user intends to use the MODFLOW-GUI to display MODPATH results.

The Maximum Number of Release Times edit-box controls the maximum number of release times that can be specified for any object on MODPATH Particles Unit[i] layers. MAXSIZ is the maximum allowed size (in bytes) of the Composite Budget File. If MAXSIZ = 0 , the program uses a default value that is set in the MODPATH main program.

NPART is the maximum number of particles allowed for a MODPATH run. If NPART is set equal to 0, MODPATH automatically resets NPART to a default value that is defined in the MODPATH main program.

TBEGIN is the time value assigned to the beginning of the MODFLOW simulation. Any convenient value may be specified, including values less than zero.

BeginPeriod, BeginStep, EndPeriod, and EndStep specify the beginning and ending stress period and time-step numbers that will be processed by MODPATH. The interface will not allow the user to specify values that are beyond the range specified in the model. 
The Recharge ITOP parameter indicates whether the recharge is assigned to the top face of the cell. If ITOP $=0$, recharge is treated as an internal source. If ITOP $=1$, recharge is assigned as a vertical component of flow to the top face.

The Evapotranspiration ITOP parameter indicates whether the evapotranspiration is assigned to the top face of the cell. If ITOP $=0$, evapotranspiration is treated as an internal sink. If ITOP $=1$, evapotranspiration is assigned as a vertical component of flow to the top face.

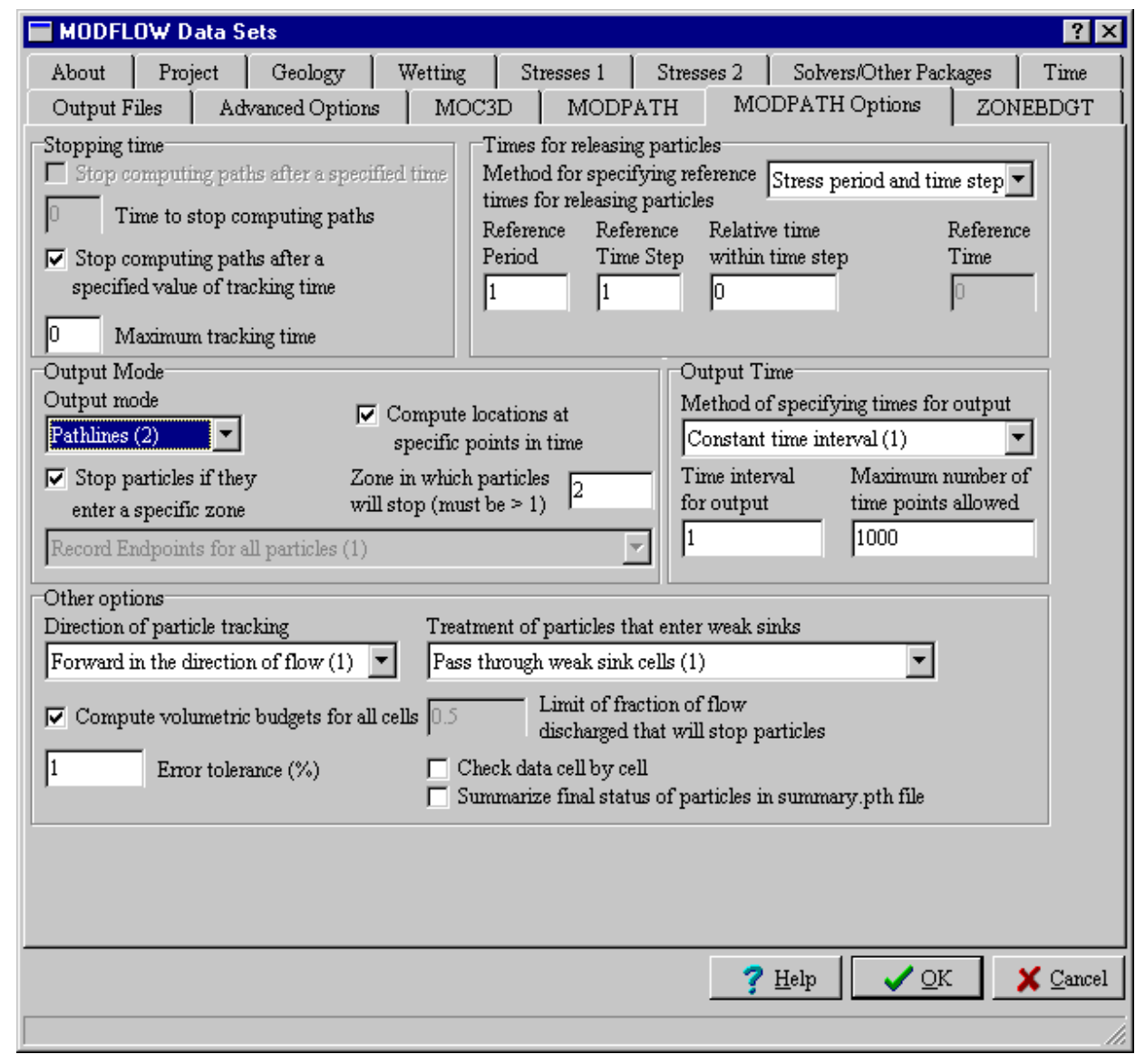

Figure 10. MODPATH Options Tab.

In steady-state models, the user can stop computing paths after a specified time, by checking the Stop computing paths after a specified time check-box. The user will then be able to enter the stopping time in the Time to stop computing paths check-box. In transient models, the user can stop computing paths after a specified time is reached by checking the Stop computing paths after a specified value of tracking time check-box. The user will then be able to enter a time in the Maximum tracking time edit-box.

The reference time for releasing particles is the time from which all other times are measured. It need not be the starting time of the model (although that is the default). The user may enter the reference time using either stress period, time step and relative time within a time step or the user can specify the reference time directly as measured from the beginning of the model. This option is only available for transient models.

Use the Output mode combo-box to select the type of data generated by MODPATH. The type of data can be one of the following: Endpoints (1): (initial and final locations of 
particles.), Pathlines (2): (locations are recorded where a particle crosses a cell boundary, at the end of each time step and at user-specified times.), or Time Series (3): (locations are recorded at user-specified times.)

If the user wishes to specify times at which MODPATH will generate output, check the Compute locations at specific points in time check-box and the Method of specifying times for output combo-box will become enabled. The user can choose this option only if the Output mode is Pathlines.

If the user checks the Stop particles if they enter a specific zone check-box, the Zone in which particles will stop edit-box will become enabled allowing the user to specify which zone particles will stop in. If the user chooses to have only endpoints in the output and chooses to have particles stop in a specific zone, the user can also decide whether to have Record endpoints for all particles or Record endpoints only for particles in a specific zone.

A weak sink is a cell that contains a boundary condition that removes water from the model but which also allows some water to flow to one or more adjacent active cells. Because MODFLOW does not define the precise location of sinks within cells, it is impossible for MODPATH to unambiguously determine whether a particle that enters a weak sink should be removed from the model or should enter an adjacent active cell. The user must decide what is the best option. MODPATH gives three choices; particles pass through weak sink cells, particles stop at weak sink cells, or particles can stop at weak sink cells that exceed a specified strength. If the treatment of particles that enter weak sinks is to Stop at weak sink cells that exceed a specified strength, specify the fraction of the flow discharged that will cause particles to stop. For example, if 70 per cent of the water that enters a cell is discharged through a well and the user specifies a fraction of 0.5 (50 per cent) then any particles entering the cell will be stopped. However, if only 30 per cent of the water entering the cell was discharged through the well, particles entering the cell would not stop at the cell but instead would be free to flow into adjacent cells.

The Compute volumetric budgets for all cells, Check data cell by cell, and Summarize final status of particles in summary.pth file check-boxes cause MODPATH to perform those functions. In the case of the volumetric budget, you must also specify a percentage Error tolerance in the Error tolerance (\%) edit-box. 


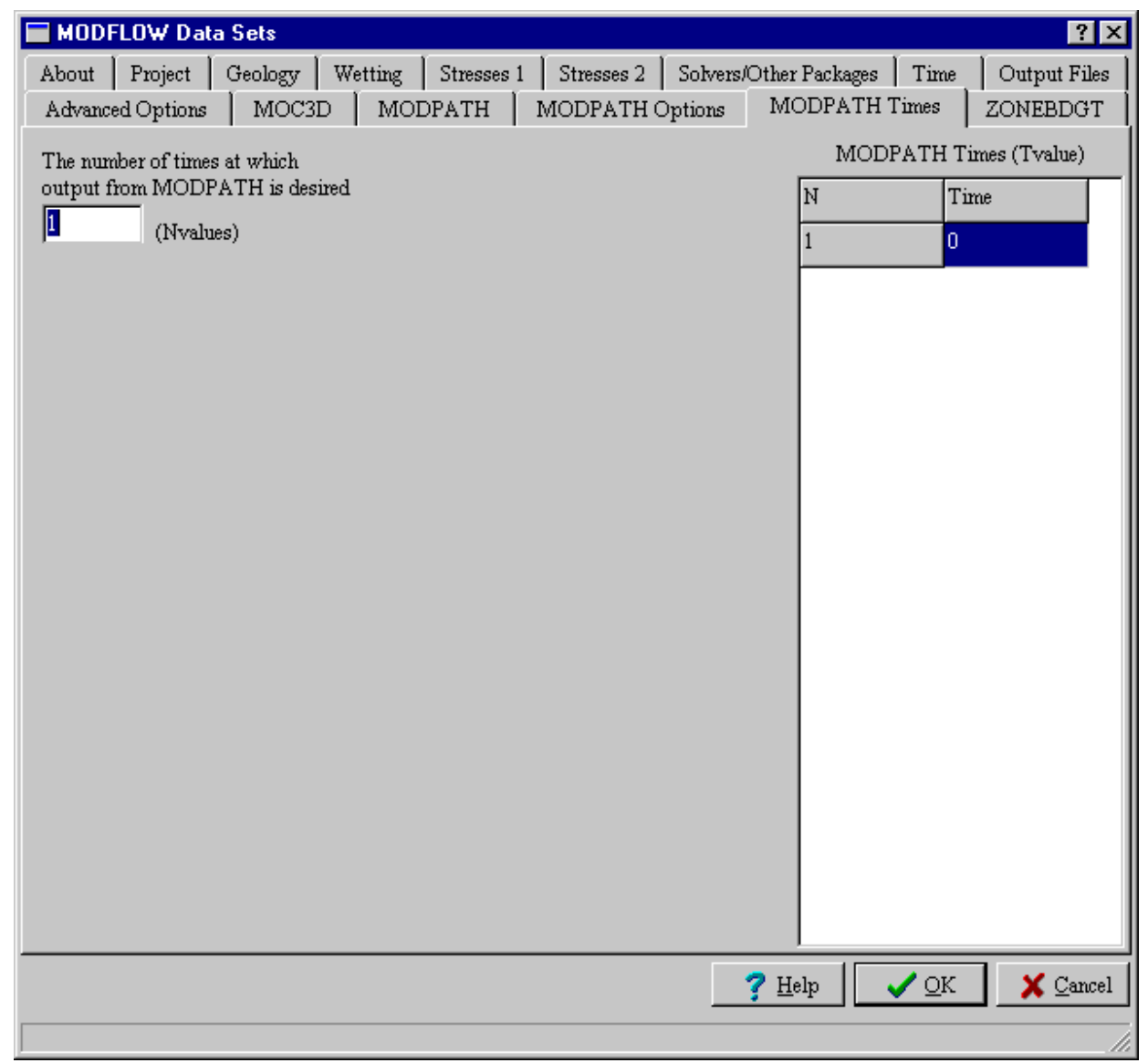

Figure 11. MODPATH Times Tab.

Depending on the Output mode, the user may have a choice about whether to compute locations at specific points in time. To specify output at specific points in time, the user must either specify a time interval for output or specify the times individually. In the latter case, the MODPATH Times tab (figure 11) will become visible and the user will be able to specify the number of times at which output from MODPATH is desired (Nvalues) and the times at which data will be generated (Modpath Time (Tvalue)). For more information about MODPATH, see Pollock (1994).

ZONEBDGT

If the ZONEBDGT check-box is checked on the ZONEBDGT tab (figure 12), information layers for ZONEBDGT will be created and options relating to ZONEBDGT in the Edit Project Info dialog box will become enabled. 


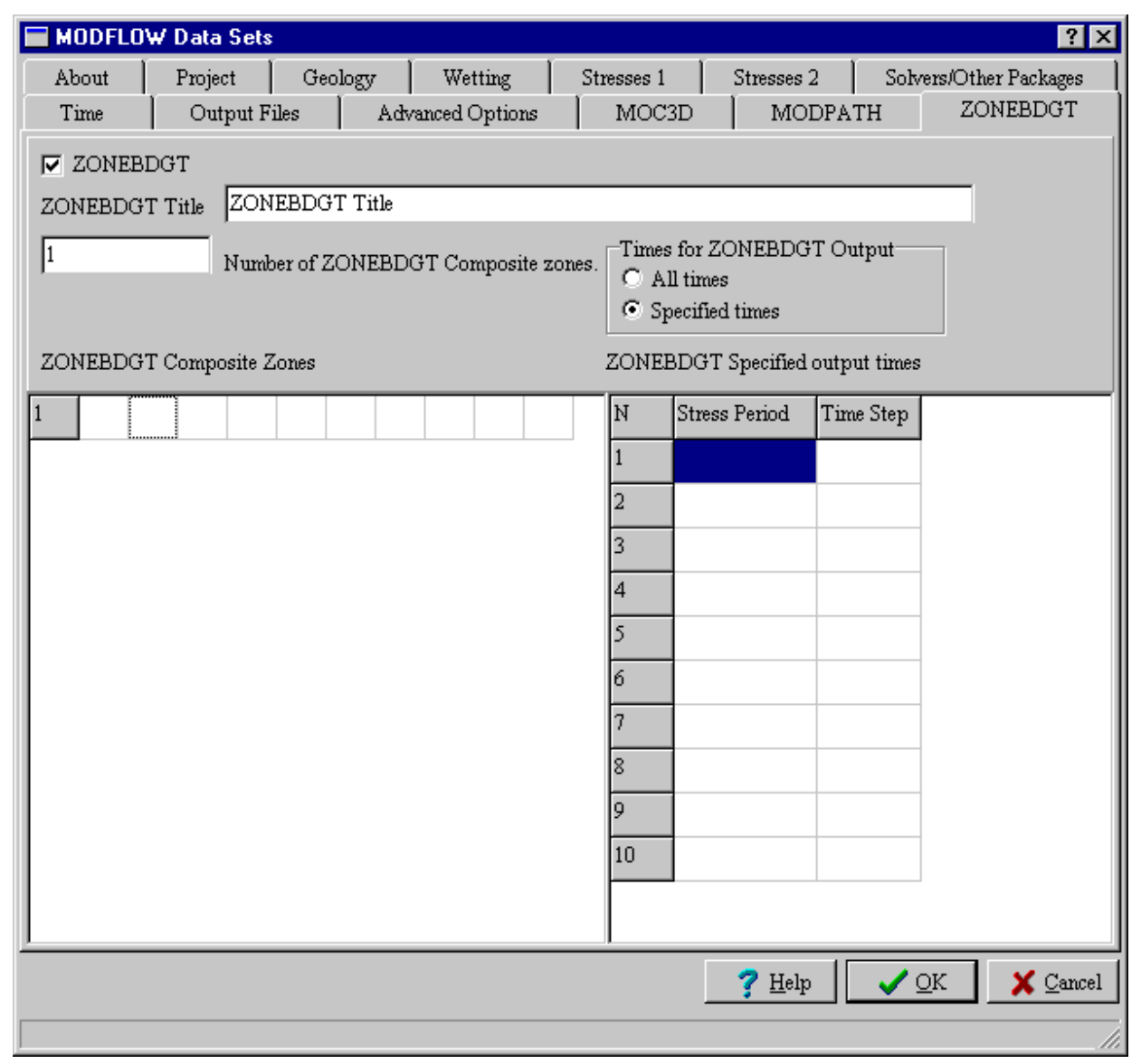

Figure 12. ZONEBDGT Tab.

ZONEBDGT Title is the title that will be printed on the ZONEBDGT output.

To use composite zones in ZONEBDGT, set Number of ZONEBDGT composite zones to a number greater than 0 and then enter the zone numbers in the ZONEBDGT Composite Zones table. The zones must match the primary zones in the ZONEBDGT information layers. The user may generate budgets for all times for which cell-by-cell flows are saved or specify up to ten times at which budgets will be generated. To do the latter, the user must enter the stress periods and time steps in the ZONEBDGT Specified output times table.

\section{Entering Spatial Data}

To provide an interface for the additional MODFLOW packages as well as MODPATH and ZONEBDGT, several new parameters and information layers have been added. Other layers and parameters have been renamed to better reflect their function. Finally, a new method of importing well data has been added. These changes are described here.

\section{Renamed Layers and Parameters}

The MODFLOW Grid Density layer has been renamed the MODFLOW Grid

Refinement layer to better reflect what the layer controls. The Density parameters on that layer and the MODFLOW Domain Outline layer have both been renamed to MODFLOW Grid Refinement and MODFLOW Cell Size respectively. The Maps Unit1 layer has been renamed the Maps layer because it is not associated with a specific geologic unit. On Line River Unit[i] 
and Area River Unit[i] layers, the Bottom parameter has been renamed Bottom Elevation for greater clarity. When opening files created by previous versions of the MODFLOW GUI, these layers and parameters are automatically changed to their new names. If any layers or parameters are renamed while opening a file, a dialog box will appear that informs the user about the renamed layers or parameters. In some cases, users may need to update expressions that they have created to reflect the new names.

\section{Locked Recharge Elevation parameter}

The Elevation parameter on the Recharge layer now has the Dont Override, Dont Eval Color, and Lock Def Val parameter locks set when that parameter is not used. The parameter is used only if recharge option (NRCHOP) on the Stress 1 tab of the Edit Project Info dialog box is set to Vert distribution in IRCH (2). This prevents users from entering data for this parameter unless the data will be used.

\section{Importing Well Data}

The MODFLOW GUI has a special mechanism for importing Well data. To import the well data do the following.

1. Select PIEs|Import Wells.

2. Enter the correct geologic unit in the edit box labeled "Geologic Unit" or click the "Use Multiple Units" checkbox. (If the "Use Multiple Units" checkbox is checked, the user must specify the geologic unit for each well individually.)

3. A dialog box will appear with a table with spaces for all the data defining the well. You may type the required information into the table. However, it is usually easier to import the data from a spreadsheet or from a tab-delimited text file.

To import the data from a spreadsheet, arrange the spreadsheet so that it has all the same data shown in the table headers and in the same order. Then select the block of data that you wish to import and copy it to the clipboard. Make Argus ONE active and click on the Paste from clipboard button. The data will be pasted from the clipboard.

To import the data from a tab-delimited text file, make a file containing the data. Any line that begins with a \# will be treated as a comment and ignored. Every other line must contain data for a single well. The data for each well must be in the same order as shown in the Well Data table. Each item in the line must be separated from the next item by a single tab character. Then click on the Read from file button and select the file from which you wish to read data.

You don't need to set the number of wells before pasting data into the table or reading it from a file; the number of wells will be set automatically when the data is read.

The data to be imported may be delimited by tab-characters or by commas, spaces, and tab-characters. If the latter option is used, the well name either must not include any spaces, tabs or commas or it must be enclosed in single or double quotation marks. For example, "A Well Name" and 'A Well Name' would both be acceptable. If you copied data to the clipboard from a spreadsheet and wish to paste it into the Well Data table, use the tab-delimited format.

4. Click on the OK button and the data will be imported into the correct Wells Unit[i] layer or layers.

\section{MOC3D Transport Subgrid}

The MOC3D subgrid boundary is now specified using an information layer named MOC3D Transport Subgrid. If there are no contours on the MOC3D Transport Subgrid 
layer, the MOC3D Subgrid will encompass the entire grid. If there are contours on the MOC3D Transport Subgrid layer, the location of each vertex of each contour on the layer will be compared to the row and column locations. The subgrid will extend from the lowest row and column adjacent to any vertex to the highest row and column adjacent to any vertex. The value assigned to the parameter on the MOC3D Transport Subgrid layer has no effect. The transport subgrid can be visualized with a new parameter on the MODFLOW FD Grid layer named Subgrid Boundary. (Previously there were separate parameters for each geologic unit named Subgrid Boundary[i].)

\section{IFACE[i]}

On a number of layers, there will now be an IFACE[i] parameter added if MODPATH is selected. The layers on which this parameter is present include Wells Unit[i], Line River Unit[i], Area River Unit[i], Line Drain Unit[i], Area Drain Unit[i], Point Gen Head Boundary Unit[i], Line Gen Head Unit[i], Area Gen Head Unit[i], and Stream Unit[i]. IFACE[i] is used to specify how MODPATH will treat the flow to or from a cell for stress period i. However, if steady stress has been chosen for the relevant package in the Edit Project Info dialog box, only IFACE1 will be used for the entire duration of the model. The other IFACE[i] parameters will be ignored. If IFACE[i] is from 1 to 6 , the flow is assigned to a cell face according to the diagram below. If IFACE[i] $<0$, the source/sink flow term is distributed uniformly across any of the faces 1 through 4 that form boundaries with inactive cells. If IFACE[i] $=0$ or IFACE[i] $>6$, the flow is treated as an internal source. If IFACE[i] is from 1 to 6 , the flow is assigned to a cell face according to the figure 13 .

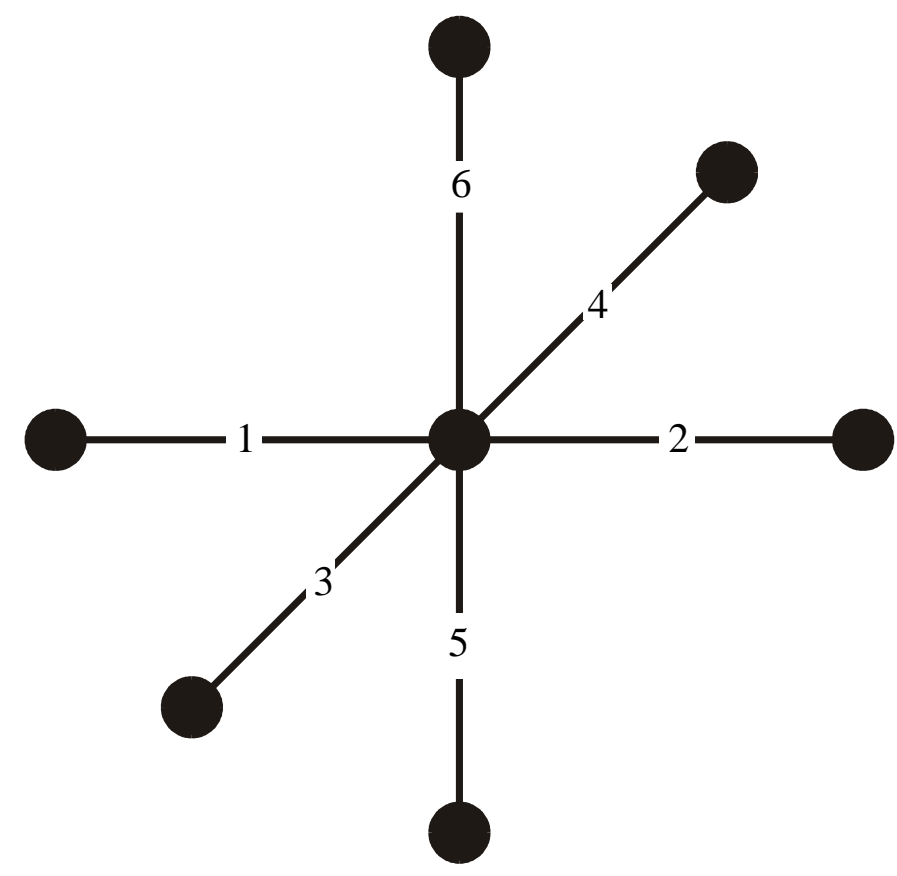

Figure 13. Interpretation of IFACE[i] = 1 to 6 .

\section{MODPATH information layers}

In addition to the IFACE parameter, two new information layers will be added for each geologic unit when MODPATH is selected: MODPATH Zone Unit[i], and MODPATH 
Particles Unit[i]. The Porosity Unit[i] layers will also be created if MODPATH is selected. This layer is also used with MOC3D.

MODPATH Zone Unit[i] represents the zone code used by MODPATH-PLOT to determine the color of pathlines and particle points. MODPATH requires that the zone code lie between 1 and 999 inclusive. Under rare circumstances the user may wish to override the default value of MODPATH Zone Unit[i]. If so the user must first unlock the default value. See the Argus ONE ${ }^{\mathrm{TM}}$ documentation for version $4.10 \mathrm{~m}$ for how to unlock parameter values.

MODPATH Zone Unit[i] is multiplied by MODFLOW FD Grid.IBOUND Unit[i] to determine the value exported to MODPATH.

MODPATH Particles Unit[i] contains several parameters that determine where within a cell particles are created. If IFACE $<0$, the particles are distributed uniformly across all of the faces 1 through 4 . If IFACE $=0$, the particles are placed within the cell. If IFACE is from 1 to 6, the particles are assigned to a cell face according to figure 13. X Particle Count, Y Particle Count, and $\mathbf{Z}$ Particle Count set the number of particles within or on the face of a cell in the $X$, $\mathrm{Y}$, and $\mathrm{Z}$ directions respectively. For example, if $\mathbf{X}$ Particle Count $=2, \mathbf{Y}$ Particle Count $=3$, and IFACE $=6$ there would be $2 \times 3=6$ particles on the top face of the cell. Release Time[i] is a release time for the particles specified by the contour. The release time is measured relative to the reference time specified for MODPATH.

\section{ZONEBDGT}

One layer for each geologic unit is created for ZONEBDGT: ZONDBDGT Unit[i]. Its single parameter is Primary Zone. ZONDBDGT Unit[i] layers are used to enter zones for which water budgets will be determined. Zone numbers may range from 1 to 25 .

\section{Stream Package}

One layer for each geologic unit is used to enter data for the stream package: Stream Unit[i]. Streams are drawn on this layer using open contours. Stream direction is determined by the order in which the user draws the contour representing the stream. The place where the user begins drawing the contour is the upstream end. The last vertex in the contour is at the downstream end. For contours with 3 or more vertices, the upstream end can be determined by the position of the label on the contour. The label is between the first and second vertices and is thus at the upstream end of the contour. If there are only two vertices, copy the contour to the clipboard and paste it in a text editor. Look at the coordinates of each vertex to determine which end is which. The upstream end will be the first vertex. The EditContours PIE (see Appendix 1) can be used to reverse the order of the vertices in a contour.

Each open contour on a Stream Unit[i] layer represents a stream segment. Segment Number must be a unique, positive integer to identify each open contour. Any segment which receives flow from another segment must have a higher segment number than the segment from which it receives flow.

The GUI renumbers segments in consecutive order as required by the Stream package during the export process. A segment can not branch nor can two contours have the same segment number. Where a stream branches, a new segment must begin. The branches can either be tributaries or diversions. Two or more tributaries can join to form a new segment or a segment can split into one or more diversionary segments and a mainstem. The mainstem is designated using Downstream Segment Number. Listing the upstream segment as its source in Upstream Diversion Segment Number designates the diversion. 
Downstream Segment Number is the segment number of a stream segment that receives flow from the current segment. This is illustrated in figure 14 where three segments (shown in green) all have a Downstream Segment Number of 201. The Segment Number of the remaining segment (shown in black) is 201 so it receives flow from the other three segments. Up to ten segments can join together to contribute flow to a single downstream segment. The flow from the current segment will be routed to the downstream segment. The Flow[i] in the downstream segment should be set to -1 . The number of a downstream segment must always be larger than the number of the segment from which it receives flow. If no segment is downstream of the current segment, leave Downstream Segment Number equal to 0 .

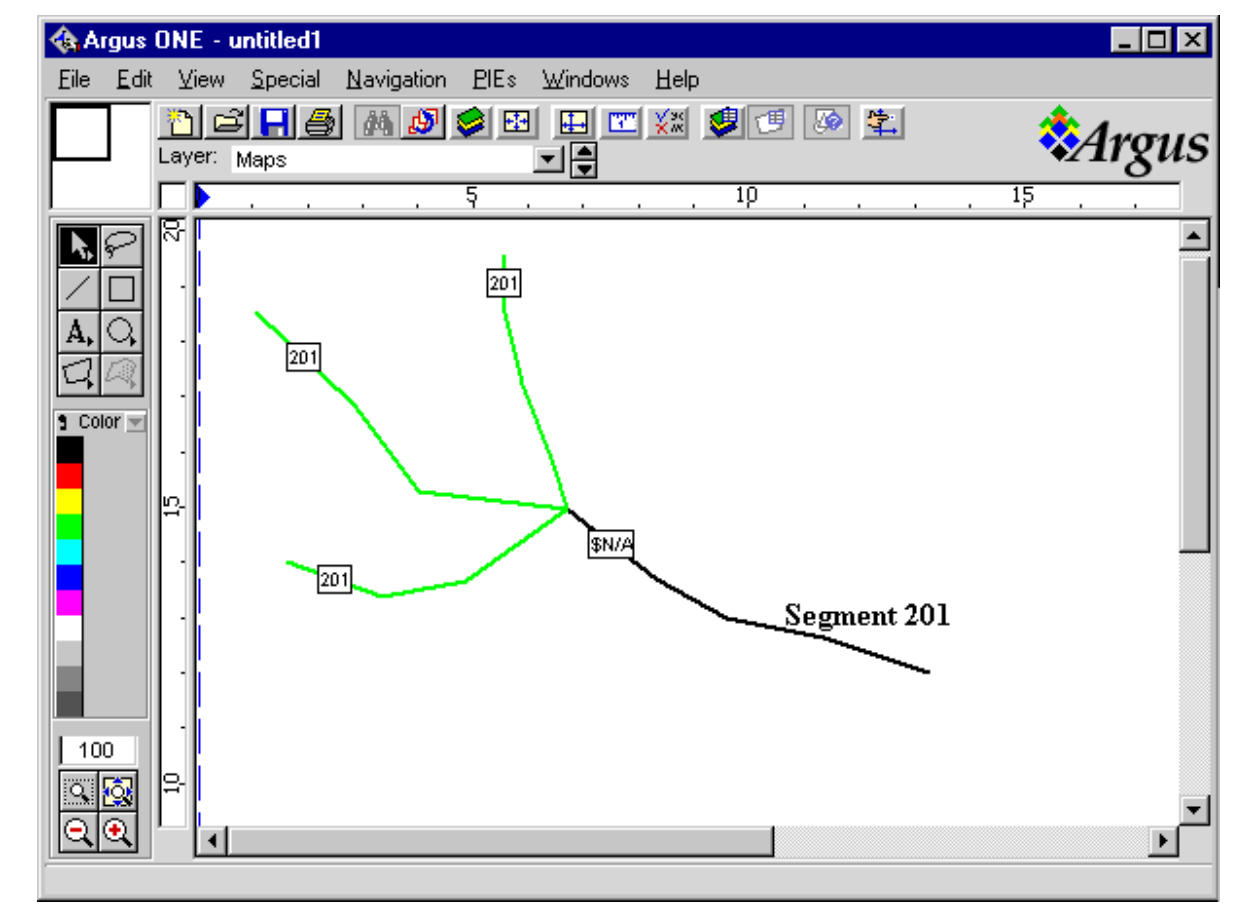

Figure 14. Illustration of the linkage among stream segments.

Upstream Diversion Segment Number is the segment number of a stream segment from which flow is diverted into the current segment. The segment number of the segment from which flow is diverted must always be less than the segment number of the segment that receives the diverted flow. If the current segment does not divert flow from another segment, leave Upstream Diversion Segment Number set to 0 .

Flow[i] is the streamflow into the upstream end of the current segment in stress period[i]. However, if steady stress has been chosen for the stream package in the Edit Project Info dialog box, only Flow1 will be used for the entire duration of the model. Other Flow[i] parameters will be ignored. In general, whenever there is a time-related parameter, only the first parameter will be used if steady stress has been chosen. If the flow in the segment will be the sum of the flows from its tributaries, set Flow[i] to -1. If the segment is a diversion, the value of Flow[i] is the amount that will be diverted.

Upstream Stage[i] is the stream stage at the upstream end of the current segment in stress period[i]. If Downstream Stage[i] is \$N/A, Upstream Stage[i] will be the stage for the entire length of the segment. If Downstream Stage[i] is not \$N/A, the stage at each cell will be 
determined by linear interpolation along the open contour from the upstream end to the downstream end. In general, whenever there is both an "upstream" and "downstream" parameter, setting the "downstream" parameter to \$N/A will cause the "downstream" parameter to be ignored. When Argus ONE uses an expression to set the value of a parameter for a contour, it always evaluates that expression at the same spot: the location of the first vertex. Thus an expression for a "downstream" parameter is evaluated at the upstream end. The current version of Argus ONE doesn't have any way of recognizing that a particular parameter should be evaluated anywhere other than the default location.

Streambed hydraulic conductivity is the hydraulic conductivity of the streambed material. Streambed hydraulic conductivity has units of (length/time). In the Stream package, "Cond" is the streambed hydraulic conductance. It is equal to KLW/M where

$\mathrm{K}=$ the hydraulic conductivity of the streambed material, (units = Length/time)

$\mathrm{L}=$ the length of the reach, (units = Length)

$\mathrm{W}=$ the width of the stream (units = Length), and

$\mathrm{M}=$ the thickness of the streambed material (units = Length).

The MODFLOW-GUI measures the length of each open contour in a cell and multiplies the length by Streambed hydraulic conductivity, and Width[i], and divides by the streambed thickness to determine "Cond". The streambed thickness is determined from the parameters Upstream bottom elevation[i], Upstream top elevation[i], Downstream bottom elevation[i], Downstream top elevation[i].

Upstream bottom elevation[i] is the elevation of the bottom of the streambed at the upstream end of the current segment in stress period[i].

Upstream top elevation[i] is the elevation of the top of the streambed at the upstream end of the current segment in stress period[i].

Upstream Width[i] is the channel width at the upstream end of the current segment in Stress Period[i]. Upstream Width[i] has units of length.

Slope[i] is the channel slope in stress period[i]. Slope[i] has units of length/length (dimensionless). Slope is used in calculating the stage of the river from the discharge.

Mannings roughness[i] is the Manning's roughness coefficient in stress period[i]. Manning's roughness is used in calculating the stage of the river from the discharge. Tables of Manning's roughness coefficient are present in most introductory surface-water-hydrology textbooks.

\section{Flow and Head Boundary Package}

The Point FHB Unit[i] layers are used to define Flow and Head boundaries with point contours. Only point contours should be used on Point FHB Unit[i] layers. The Line FHB Unit[i] layers are used to define Flow and Head boundaries with open contours. Only open contours should be used on Line FHB Unit[i] layers. The Area FHB Unit[i] layers are used to define Flow and Head boundaries with closed contours. Only closed contours should be used on Area FHB Unit[i] layers.

The Top Elev and Bottom Elev parameters on the Point FHB Unit[i] and Line FHB Unit[i] layers are compared with Elev Top Unit[i], Elev Bot Unit[i] and the vertical discretization of a unit to determine in which layer or layers a flow or head boundary should occur within the geologic unit. If the top and bottom elevation of the Flow and head boundary are outside the unit as specified in Elev Top Unit[i] and Elev Bot Unit[i] the boundary will be 
placed in either the uppermost or lowermost layer in the unit. For flow boundaries that will be split among several layers the flow will also be divided among those layers.

Head Time[i] on the Point FHB Unit[i] and Area FHB Unit[i] layers is the specified head at Time i. The "Time i" values are specified on the Stresses 2 Tab. Values at all times other than the specified times will be determined by linear interpolation among the specified times. (See Leake and Lilly, 1997.) If Head Time[i] is left at the default value of \$N/A, the contour represents a flux boundary rather than a head boundary. In the Area FHB Unit[i] layer, the head boundaries will be assigned to every layer within the geologic unit. MODFLOW does not allow both a specified flux and a specified head boundary at a single cell. If both are specified for a single cell, the specified flux boundary will be ignored.

Flux Time[i] on the Point FHB Unit[i] layers is the specified flux rate at Time i. The "Time i" values are specified on the Stresses 2 tab of the Edit Project Info dialog box. The total flux for a time step will be determined by taking the integral of the flux rate versus time function for the time step. (See Leake and Lilly, 1997.) If Flux Time[i] is left at the default value of \$N/A, the contour represents a specified head boundary rather than a specified flux boundary.

Head Concentration Time[i] on the Point FHB Unit[i], Line FHB Unit[i], and Area FHB Unit[i] layers is the solute concentration at the specified head cell at Time i. Flux Concentration Time[i] on the Point FHB Unit[i], Line FHB Unit[i], and Area FHB Unit[i] layers is the solute concentration at the specified flux cell at Time i. For both types of boundaries, values at all times other than the specified times will be determined by linear interpolation among the specified times.

Start_Line Head Time[i] on the Line FHB Unit[i] layers is the specified head at the start of an open contour at Time i. Values at all times other than the specified times will be determined by linear interpolation among the specified times. If Start_Line Head Time[i] is left at the default value of \$N/A, the contour represents a flux boundary rather than a head boundary. If Start_Line Head Time[i] is a number but End_Line Head Time[i] is \$N/A, The value of Start_Line Head Time[i] will be used all along the contour. If both Start_Line Head Time[i] and End_Line Head Time[i] are numbers, the starting head at intermediate cells will be determined by linear interpolation between Start_Line Head Time[i] and End_Line Head Time[i]. The direction of a contour can be determined by the methods described under the section entitled Stream Package.

Flux per Length Time[i] on the Line FHB Unit[i] layers and the Flux per Area Time[i] on the Area FHB Unit[i] layers are the specified flux rate per unit length at Time i. The Flux per Length Time[i] will be multiplied by the length of the contour within a cell to determine the total flux rate for that cell. The Flux per Area Time[i] will be multiplied by the area of the contour within a cell to determine the total flux rate for that cell. The total flux for a particular time step will be determined by taking the integral of the flux rate versus time function for the time step. If Flux per Length Time[i] or Flux per Area Time[i] are left at the default value of $\$ \mathrm{~N} / \mathrm{A}$, the contour represents a specified head boundary rather than a specified flux boundary. In the Area FHB Unit[i] layer, the flux boundaries will be assigned to every layer within the geologic unit. The flux will be divided among the layers. 


\section{Horizontal Flow Barrier Package}

To define horizontal flow barriers use open or closed contours on the Horizontal Flow Barrier Unit[i] layers. These layers have two parameters: Barrier Hydraulic Conductivity and Barrier Thickness.

Barrier Hydraulic Conductivity represents the hydraulic conductivity of the horizontal flow barrier. Barrier Thickness represents the thickness of the horizontal flow barrier. Barrier Hydraulic Conductivity is divided by the Barrier Thickness to obtain the hydraulic characteristic of the conceptual model. The hydraulic characteristic of the conceptual model is then adjusted by the angle of the barrier to obtain the hydraulic characteristic of the numerical model.

To visualize the location of the horizontal flow barriers in the numerical model, select PIEs|Display Horizontal Flow Barriers. This will display a dialog box in which the horizontal flow barriers can be displayed. Enter the unit number in the Unit Number edit-box and click on the Display button to display the horizontal flow barriers for that unit. If there are barriers on the selected unit, they will be displayed. If not, a warning message will appear. The grid is shown in this dialog box without any rotation. Use the check-boxes in the dialog box to indicate the correct coordinate direction. At present there is no zooming capability on this dialog box but it can be resized to make the grid larger. Click on the Close button to close this dialog box.

The GUI must adjust the hydraulic characteristic exported to MODFLOW based on the grid angle because the length of the flow barriers differs between the conceptual and numerical models. For example, the only difference between the two models in figure 15 is that in one the area surrounded by the horizontal-flow barrier is rotated 36 degrees. However, when the models were run, the leakage through the flow barrier in model 2 was much higher than it was in model 1 .

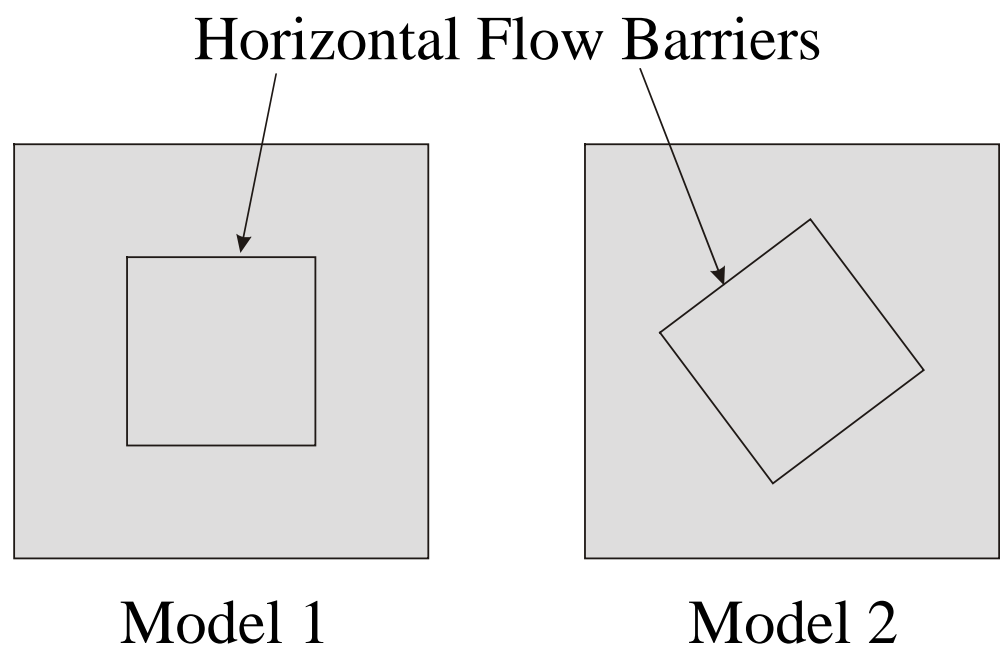

Figure 15. Two models that differ only in the orientation of the area surrounded by a horizontal-flow barrier.

A close-up of Model 2 reveals the problem (figure 16). In MODFLOW it is impossible to specify a flow barrier that is at an angle to the grid. Instead a zigzag line of flow barriers along the cell boundaries must approximate the actual flow barrier. The total length of the flow barriers in the numerical model is longer than the angled flow barrier they represent in the 
conceptual model. Thus, there is more area through which flow could occur in the numerical model than in the conceptual model.

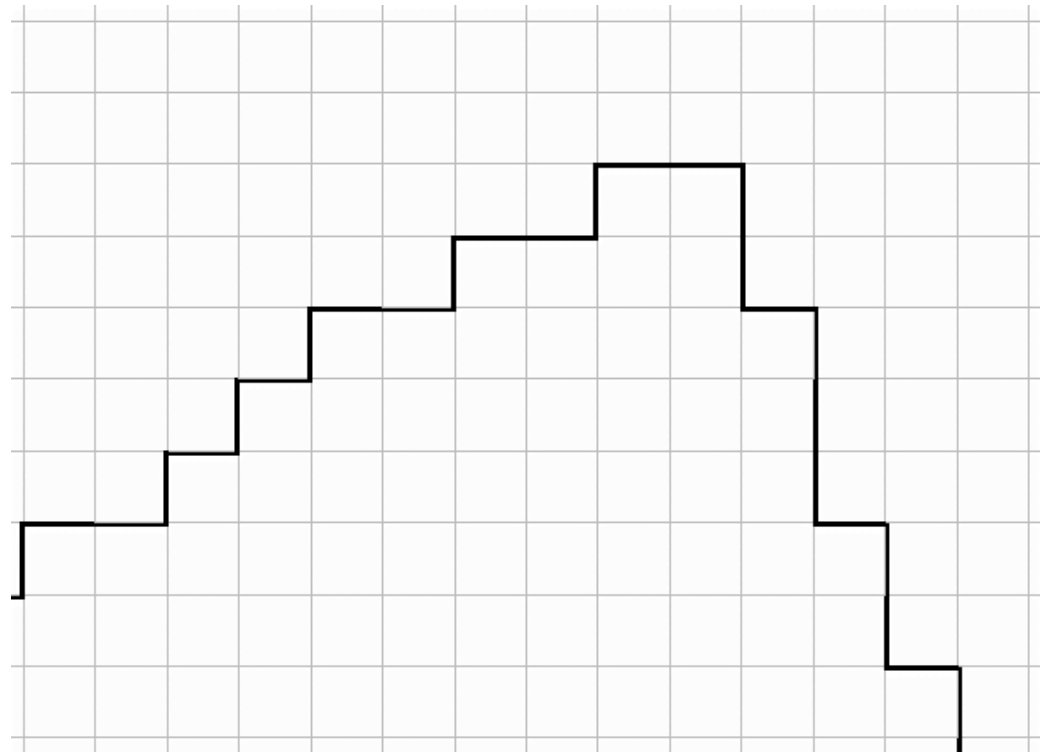

Figure 16. Close up of a section of the horizontal-flow barrier in model 2.

To compensate for the excessive flow barrier length in the numerical model, the hydraulic characteristic of the barriers (HYDCHR) must be reduced. The method used to reduce the hydraulic conductivity in the MODFLOW-GUI is shown in figure 17.

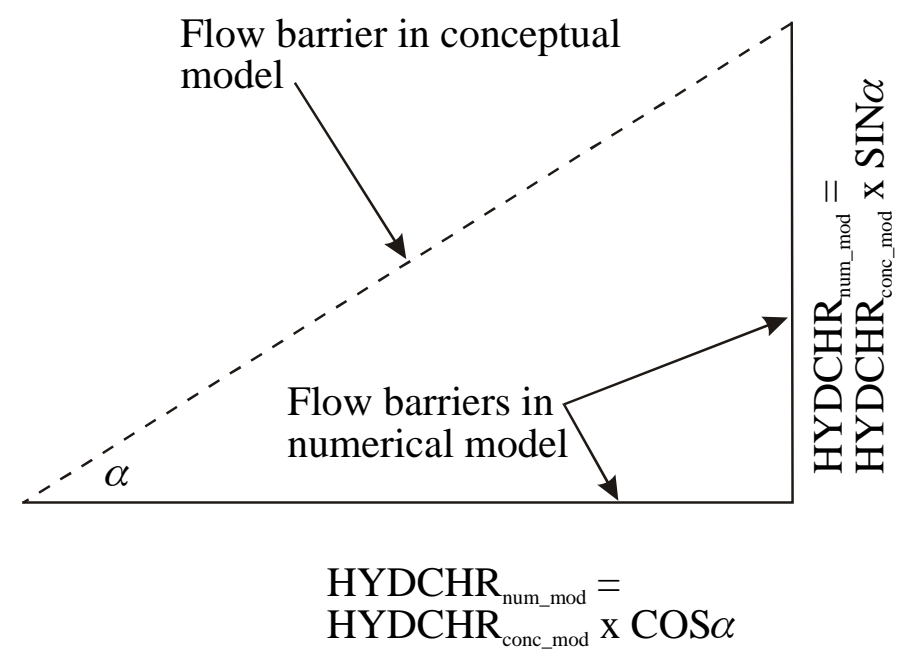

Figure 17. Method to calculate the reduction of HYDCHR when horizontal-flow barriers are at an angle to the grid.

$\mathrm{HYDCHR}_{\text {num_mod }}=$ Hydraulic characteristic of numerical model. HYDCHR conc_mod $_{\text {m }}=$ Hydraulic characteristic of conceptual model. 


\section{Running MODFLOW, MOC3D, MODPATH, or ZONEBDGT}

\section{Creating Input Files}

Selecting Run MODFLOW/MOC3D, Run MODPATH, or Run ZONEBDGT from the PIEs menu accesses the Run MODFLOW/MOC3D dialog box (figure 18). These menu items are only present if the MODFLOW FD Grid layer is the active layer. Use the radio buttons to select which model to run and whether or not to run the model or just create the input files for the model. For MOC3D models, users can choose to either run MODFLOW (without solute transport) or MOC3D (with solute transport) by checking or unchecking the Run MOC3D to simulate solute transport check-box. If the input files for a model have already been created and the data for one or more packages have not changed since the last time the model was run, there is no need to create a new copy of that input file. Instead, the user can save time during the process of exporting the MODFLOW input files by not exporting a new copy of the input file for the package. All those packages whose check-boxes are both checked and enabled will be exported to the MODFLOW input files.

In some special cases, the user may elect to develop their own export template for one or more MODFLOW Packages. In such cases, there is no need for the usual export template to create the input files for those packages so the user may elect not to create them with the usual export template.

The full paths to the executables should be displayed in edit-boxes on the Model Paths tab of the Run MODFLOW/MOC3D dialog box. If the executable for the chosen model is not at the location specified in the edit-box, the background of the edit-box and the status bar will change to red and a warning message will be displayed in the status bar to indicate that the path is incorrect (figure 18). Normally, the user should correct the path before attempting to create the input files. Although it is possible to export the input files using an incorrect path, Argus ONE ${ }^{\mathrm{TM}}$ will not be able to start the model if the path is incorrect. Type the correct path or click on the Browse button to set the correct path. When a model is saved, the paths for all of the models will be saved in a file named modflow.ini in the directory containing the MODFLOW PIE. Modflow.ini will be read whenever a new MODFLOW project is created or an old one is read so that the model paths do not need to be reset frequently. 


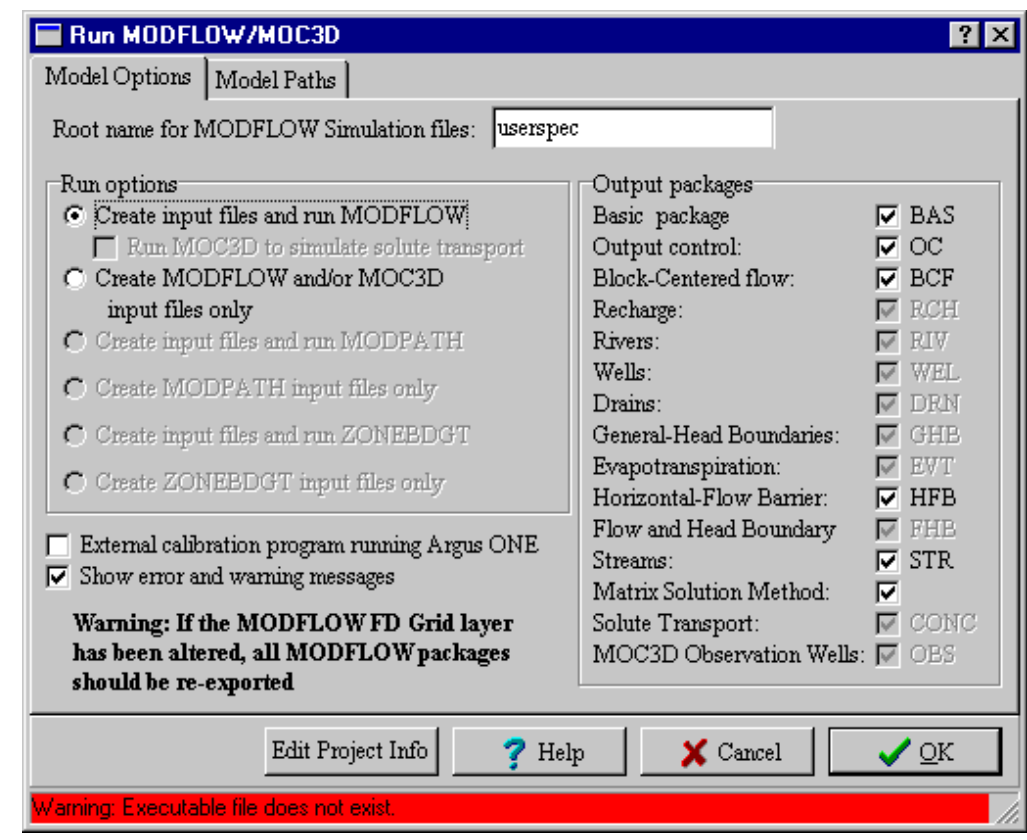

Figure 18. Revised Run MODFLOW/MOC3D Dialog box. In this example, MOC3D is not installed at the location specified in the MOC3D Path edit-box so the background of the status bar, would appear red.

If any of the non-spatial data for the model need to be edited, click the Edit Project Info button to show the Edit Project Info dialog box. Click on the OK button in the Run MODFLOW/MOC3D dialog box to begin exporting the input files for the selected program. Click on the Cancel button to close the Run MODFLOW/MOC3D dialog box without exporting input files for any program.

Because MODPATH and ZONEBDGT use the output from MODFLOW (or MOC3D) as part of their input, the user must ensure that the required output files are in the directory in which MODPATH or ZONEBDGT will be run. Normally, this is most easily accomplished by running MODPATH or ZONEBDGT in the same directory in which the model was run.

\section{Processing the Export Template}

When the user clicks on the OK button, the PIE modifies the export template (modflow.met) before passing it on to Argus ONE ${ }^{\mathrm{TM}}$. When the export template has been processed and passed to Argus ONE ${ }^{\mathrm{TM}}$, a dialog box is displayed for selecting the directory in which the input files for the model should be generated. (The model will generate its output files in this same directory.) The file name (MODFLOW_FD_Grid.exp) in the dialog box may be ignored. If a file by that name already exists, Argus $\mathrm{ONE}^{\mathrm{TM}}$ will generate a warning message stating that MODFLOW_FD_Grid.exp will be overwritten. This warning message may be ignored. Click OK to ignore the warning message.

Two progress bars will then appear. Argus ONE ${ }^{\mathrm{TM}}$ generates one and a PIE generates the other (figure 19). The progress bar generated by Argus ONE ${ }^{\mathrm{TM}}$ contains a "barbershop" progress bar. One way to abort the export process by selecting the window containing the "barbershop" progress bar and pressing Ctrl-C. A PIE generates the other progress bar. It shows how much of the export template has been processed by Argus ONE ${ }^{\mathrm{TM}}$. It also displays warning and error about inconsistencies or errors in the input specified by the user. These warnings can be 
suppressed by unchecking the Show Error and Warning Messages check box in the Run MODFLOW/MOC3D dialog box. prior to starting the export process. An Abort Simulation on this second progress bar and may also be used to stop the export process.

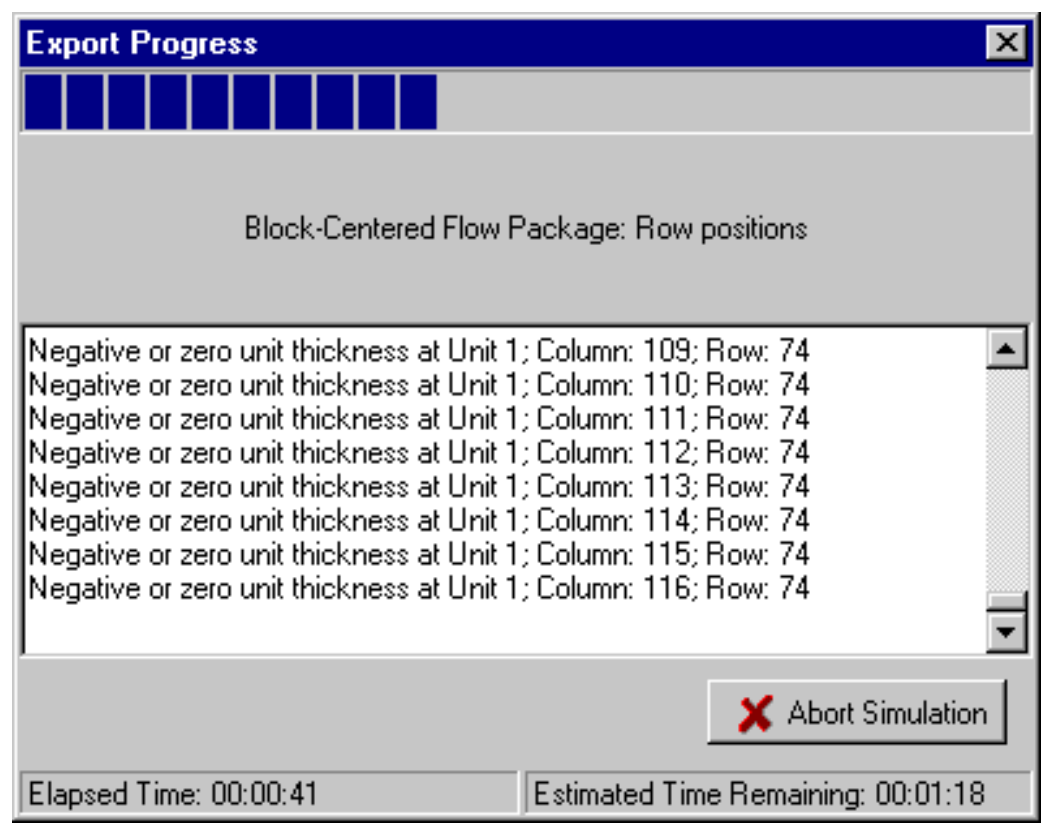

Figure 19. PIE-Generated Progress Bar with error messages.

\section{Using the MODFLOW PIE with Calibration Programs}

The MODFLOW PIE has been designed to allow calibration programs such as UCODE (Poeter and Hill, 1998) to use it to create MODFLOW input files and run MODFLOW. If the checkbox labeled External Calibration Program running Argus ONE is checked, the DOS window in which MODFLOW runs will close as soon as MODFLOW finishes running. In addition, the batch file used to run MODFLOW will have a command to try to start a copy of WaitForMe.exe (see Appendix 5). If the calibration program starts another copy of WaitForMe.exe before exporting the MODFLOW input files, that copy will continue running until the batch file attempts to start the new copy. Attempting to start a new copy will cause both copies to close. The calibration program can detect the closure of the first copy of WaitForME before attempting to process the MODFLOW output files. The SelectChar program (see Appendix 5) may be useful in writing a batch file that will start Argus ONE exporting the MODFLOW input files. The following is an example of such a batch file.

UcodeTest.mmb d:IPROGRA 1 \ARGUSI 1 \ArgusPIElGETMYD 1 1SelectChar.exe alt-P d:IPROGRA 1\ARGUSI 1\ArgusPIE\GETMYD 1 ISelectChar.exe M O chr-13 d:IPROGRA 1\ARGUSI 1\ArgusPIElGETMYD 1\WaitForMe.exe

This batch files makes UcodeTest the active program. If the MODFLOW FD Grid layer is the active layer, it will then activate the PIE's menu and start running MODFLOW. Finally it starts a copy of WaitForMe which will be closed when a second copy starts after MODFLOW has finished executing. 
Another PIE, MODFLOW_ReadFileValue, is useful in defining parameters to be calibrated by the calibration program (See Appendix 4). It can be used to read the current value of a calibration parameter from a text file and use that value to define the value of an Argus ONE parameter or contour.

These PIE's are useful in allowing calibration programs to run MODFLOW through Argus ONE. However, in simple cases, it may be faster to have the calibration program construct the MODFLOW input files directly rather than constructing them through Argus ONE.

\section{Running independent templates with the MODFLOW PIE}

The MODFLOW PIE comes with two separate templates that may be useful in some circumstances but which must be run manually. These include contour2data.met and statistics.met. Both these templates will need to be modified slightly by the user to fit their individual needs.

\section{Converting contours on information layers to data points on data layers}

In some cases, the user may wish to convert contours on an information layer to data points on a data layer. The primary advantage of this is that interpolation among data points on a data layer can be significantly faster than interpolation among contours on a contour layer especially if there are a large number of contours or the contours contain many vertices. To make the conversion, make the MODFLOW FD Grid layer the active layer and select File|Export|Edit Template. The export editor will appear. Click on the Load button and select the file contour2data.met distributed with the MODFLOW GUI. Read the comment at the beginning of the export template. Follow the instructions for how to modify the template for your purposes. The modification consists of changing one line to refer to the layer for which you wish to convert the contours. When you are done making the change, click the Done button to return to the Argus ONE main window. Then select File|Export|By Template. You must have created a grid on the MODFLOW FD Grid layer for this option to be available. When the export process is done, save your file. Then delete the contours on the layer you wish to convert to a data layer. Next select View|Layers. Select the layer you wish to convert on the upper half of the Layers dialog box. Under Type, select the down-arrow next to Information and select Data. This option is locked on certain layers such as Wells Unit1 where converting a layer to a data layer would interfere with the functioning of the MODFLOW GUI. Click on the Done button. Make the layer you just converted the active layer. Select File|Import <layer name $>\mid$ Text File. Select Scattered data. Click OK and then select the file exported by the export template (Points.exp) and click on the Open button. The data will be imported into the data layer.

\section{Preparing Calibration Statistics}

A common task in groundwater modeling is preparing calibration statistics for comparing modeled and observed heads or drawdowns with measured values. The following describes one method of preparing such statistics.

1. Import your model results into Argus ONE using the Post Processing PIE (PIEs|MODFLOW/MOC3D Post Processing).

2. Create a global variable named Number of Observation Times. (Edit|Edit Global Variables). Set the value of this variable to the number of times at which you have observations. 
3. Create another global variable named Number of Model Layers. Set the value of this variable to the number layers in the MODFLOW model. If you have non-simulated units or one geologic unit represents multiple model layers be sure to set the variable to the number of model layers not the number of geologic units.

4. Create a new information layer named Observations Layer1. (See the Argus ONE documentation on how to create information layers.)

5. Create two new parameters on the Observations Layer1 layer named Observations1, and Model Results1.

6. Set the expression for Observations1 to $\$ \mathrm{~N} / \mathrm{A}$.

7. Set the expression for Model Results1 so as to link it to the data layer and parameter containing your model results for the first observation time. The data layer for MODFLOW is normally named MODFLOW Data. The parameter names for the model results depend on the stress periods and times that you have imported.

8. Select the Observations1 parameter and click on the Duplicate button in the lower half of the Layers dialog box to duplicate that parameter. The duplicates will be named

Observations2, Observations3... Make as many duplicates as you have observation times.

9. Select the Model Results1 parameter and duplicate it just as you did the Observations1 parameter.

10. Set the expressions for the Model Results2, Model Results3, ... parameters so that they are linked to the correct layers and parameters for your model results.

11. Select the Observations Layer1 layer in the upper half of the Layers dialog and click on the Duplicate button in the upper half of the dialog box to make copies of the layer. Make as many copies as you have MODFLOW model layers.

12. In each copy of the Observations Layer[i] set the expressions for the Model Results[i] parameters to the correct values.

13. Create point contours on the Observations Layer[i] layers at each of your observation points and assign the Observations[i] parameters your observation values. Do not override the Model Results[i] parameters.

14. Create an export template that will calculate and print the statistics you desire. To start creating an export template, make the MODFLOW FD Grid layer the active layer and select File|Export|Edit Template. Consult the Argus ONE documentation for more information on export templates. The export template Statistics.met distributed with the MODFLOW GUI will calculate a variety of commonly used calibration statistics and or may be used as a starting point for your own template.

15. Run the export template by selecting File|Export|By Template. You can only do this if the MODFLOW FD Grid layer is the active layer and there is a grid on that layer.

\section{Files Created for MODFLOW-96, MODPATH, and ZONEBDGT Simulations}

When creating MODFLOW-96 input files from within Argus ONE, a variety of files are created as documented previously in Shapiro and others (1997) and Hornberger and Konikow (1998). In addition to those files, the revised GUI may also additional files for MODFLOW simulations as documented in Table 2. 
Table 2. New Files Created for MODFLOW Simulations.

\begin{tabular}{|c|c|c|}
\hline Filename & \multicolumn{2}{|l|}{ Purpose } \\
\hline Rootname.i[Number] & \multicolumn{2}{|c|}{ Unit[Number+1]. } \\
\hline Rootname.h[Number] & \multicolumn{2}{|c|}{ File containing the initial head array for Geologic } \\
\hline Rootname.s[Number] & \multicolumn{2}{|c|}{ File containing the storage coefficient array for Geologic } \\
\hline Rootname.s[Number] & \multicolumn{2}{|c|}{ File containing the specific yield array for Geologic } \\
\hline Rootname.k[Number] & \multicolumn{2}{|c|}{$\begin{array}{l}\text { File containing the hydraulic conductivity or transmissivity array } \\
\text { for Geologic Unit[Number }+1] \text {. }\end{array}$} \\
\hline Rootname.z[Number] & \multicolumn{2}{|c|}{ File containing the vertical conductance array for Geologic } \\
\hline Rootname.str & \multicolumn{2}{|c|}{$\begin{array}{l}\text { File containing information for the stream package. This file is } \\
\text { created only if the stream is chosen in the Stresses } 2 \text { tab. }\end{array}$} \\
\hline Rootname.hfb & \multicolumn{2}{|c|}{$\begin{array}{l}\text { package. This file is created only if the horizontal-flow barrier is } \\
\text { chosen in the Other Packages/Solvers tab. }\end{array}$} \\
\hline Rootname.fhb & \multicolumn{2}{|c|}{$\begin{array}{l}\text { File containing information for the Flow and Head Boundary } \\
\text { package. This file is created only if the Flow and Head } \\
\text { Boundary package is chosen in the Stresses } 2 \text { tab. }\end{array}$} \\
\hline \multicolumn{3}{|c|}{ 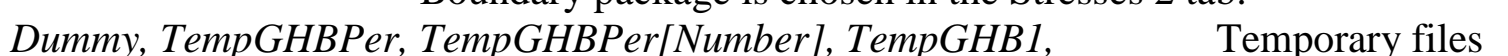 } \\
\hline \multicolumn{2}{|c|}{ TempRivPer, TempRivPer[Number], TempRiver1, TempDrainPer, } & used during the \\
\hline \multicolumn{3}{|c|}{ TempDrainPer[Number], TempDrain1, TempWellPer, } \\
\hline \multicolumn{2}{|c|}{ TempWellPer[Number], TempWell1, TempStream1, TempStream2, } & $\begin{array}{l}\text { These files are } \\
\text { normally deleted }\end{array}$ \\
\hline \multicolumn{2}{|c|}{ TempFHB5Line[Number], TempFHB6Line[Number], } & before the end of \\
\hline \multicolumn{2}{|c|}{ TempFHB7Line[Number], TempFHB8Line[Number], } & the export \\
\hline \multicolumn{3}{|c|}{ TempFHB5Point[Number], TempFHB6Point[Number], } \\
\hline \multicolumn{3}{|c|}{ TempFHB7Point[Number], TempFHB8Point[Number], } \\
\hline \multicolumn{3}{|c|}{ TempFHB5Area[Number], TempFHB6Area[Number], } \\
\hline \multicolumn{3}{|c|}{ TempFHB7Area[Number], TempFHB8Area[Number], FHBTemp } \\
\hline
\end{tabular}

When creating input files for MODPATH, the files shown in Table 3 may be created. MODPATH.BAT is used to run the model from the directory in which the files were created (for example, if the model was not executed from within Argus ONE). Files must be exported with the Create input files and run MODPATH or Create MODPATH input files only options in the Run MODFLOW/MOC3D Dialog Box selected for MODPATH.BAT to be created and used. 
Table 3. Files Created for MODPATH.

\begin{tabular}{ll}
\hline \multicolumn{1}{c}{ Filename } & \multicolumn{1}{c}{ Purpose } \\
\hline MODPATH.BAT & $\begin{array}{l}\text { A DOS-executable batch-file created by the export template that } \\
\text { contains the path of the executable for MODPATH. } \\
\text { The name file used by MODPATH to specify the names of files } \\
\text { that will be used by MODPATH. }\end{array}$ \\
Rootname.pnm & $\begin{array}{l}\text { The main MODPATH data file. } \\
\text { Rootname.mpa }\end{array}$ \\
Rootname.ip[Number] & $\begin{array}{l}\text { File containing a MODPATH zone array for geologic unit } \\
\text { [Number+1]. }\end{array}$ \\
Rootname.prt & File containing MODPATH particle starting locations. \\
Rootname.tim & The MODPATH time file. \\
Rootname.rsp & File containing responses to interactive queries in MODPATH. \\
Aummy & A temporary file used during the export process. This file is \\
& normally deleted before the end of the export process. \\
\hline
\end{tabular}

When creating input files for ZONEBDGT, the files documented in Table 4 may be created. Zonebdgt.bat is used to run the model from the directory in which the files were created (for example, if the model was not executed from within Argus ONE). Files must be exported with the Create input files and run ZONEBDGT or Create ZONEBDGT input files only options in the Run MODFLOW/MOC3D Dialog Box selected for Zonebdgt.bat to be created and used.

Table 4. Files Created for ZONEBDGT.

\begin{tabular}{ll}
\hline \multicolumn{1}{c}{ Filename } & \multicolumn{1}{c}{ Purpose } \\
\hline Zonebdgt.bat & $\begin{array}{l}\text { A DOS-executable batch-file created by the export template that } \\
\text { contains the path of the executable for ZONEBDGT. }\end{array}$ \\
Rootname.zbi & The input file for ZONEBDGT. \\
Rootname.zon & $\begin{array}{l}\text { The zone file for ZONEBDGT. } \\
\text { Aummy }\end{array}$ \\
& $\begin{array}{l}\text { A temporary file used during the export process. This file is normally } \\
\text { deleted before the end of the export process. }\end{array}$ \\
\hline
\end{tabular}

\section{Files Created by Executing MODFLOW-96, MODPATH, and ZONEBDGT}

When MODFLOW-96 is executed from within Argus ONE, a variety of files are created as documented previously in Shapiro and others (1997) and Hornberger and Konikow (1998). In addition to those files MODFLOW-96 may also produce the files documented in Table 5 for MODFLOW simulations. 
Table 5. Files Created by MODFLOW.

\begin{tabular}{cl}
\hline Filename & \multicolumn{1}{c}{ Purpose } \\
\hline Rootname.bs & $\begin{array}{l}\text { The file of cell-by-cell flows between the stream and aquifer from the } \\
\text { stream package if it is specified in the Output Files dialog that cell-by- } \\
\text { cell flows from the stream package are to be exported, and the export of } \\
\text { this information is to be placed in a separate file. This file is created in a } \\
\text { binary format. } \\
\text { The file of cell-by-cell stream flows among stream cells from the stream } \\
\text { package if it is specified in the Output Files dialog that cell-by-cell } \\
\text { flows from the stream package are to be exported. This file is created in } \\
\text { a binary format. This information is always placed in a separate file. } \\
\text { The file of cell-by-cell flows from the Flow and Head Boundary } \\
\text { package if it is specified in the Output Files dialog that cell-by-cell } \\
\text { flows from the Flow and Head boundary package are to be exported, } \\
\text { and the export of this information is to be placed in a separate file. This } \\
\text { file is created in a binary format. }\end{array}$ \\
\end{tabular}

Files created when running MODPATH and ZONEBDGT from within Argus ONE include the files documented in table 6.

Table 6. Files Created by MODPATH and ZONEBDGT.

\begin{tabular}{ll}
\hline \multicolumn{1}{c}{ Filename } & \multicolumn{1}{c}{ Purpose } \\
\hline Rootname.mpo & The MODPATH composite budget file. \\
Rootname.mli & The MODPATH summary output file. \\
Rootname.end & The MODPATH endpoint file. \\
Rootname.lin & The MODPATH pathline file. \\
Rootname.zbl. & The output file from ZONEBDGT. \\
\hline
\end{tabular}

\section{Visualizing Results}

\section{Visualizing results from MODFLOW or MOC3D}

To visualize the results of a MODFLOW or MOC3D model, select

PIEs|MODFLOW/MOC3D Post Processing. A dialog box will appear in which the user can choose to read output from MODFLOW head or drawdown files, MOC3D concentration files or MOC3D velocity files (figure 20). Choose the type of data to visualize and click on the Select Data Set button. Depending on the choice, the user will be able to select formatted head files (with the extension "fhd"), formatted drawdown files (with the extension "fdn"), concentration files (with the extension "cna"), or velocity files (with the extension "vla"). Choose only files that were created with the finite-difference grid in the MODFLOW FD Grid layer of the current project file. 


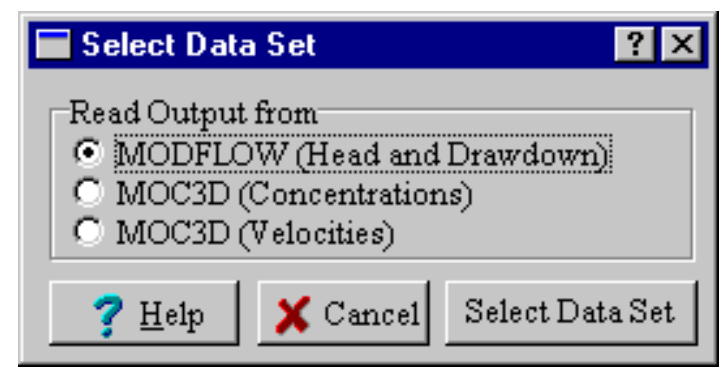

\section{Figure 20. Dialog box to select type of data set for post-processing.}

The data sets in the file will be read and their captions displayed in the MODFLOW Post-Processing dialog box(figure 21). Choose the data set or sets to plot, the type of chart to create, the model layer for the chart, and whether data values for inactive or dry cells should be imported in this dialog box. Click OK to create a data layer containing the data and a map layer containing the postprocessing charts. If the default names for either or both of these layers already exists, the Layer Already Exists dialog box (figure 22) will appear. Radio buttons on this dialog box allow the user to choose between overwriting the existing layer and creating a layer with a new name. If latter option is selected, the user can choose either to accept a default name or to type a new name. 


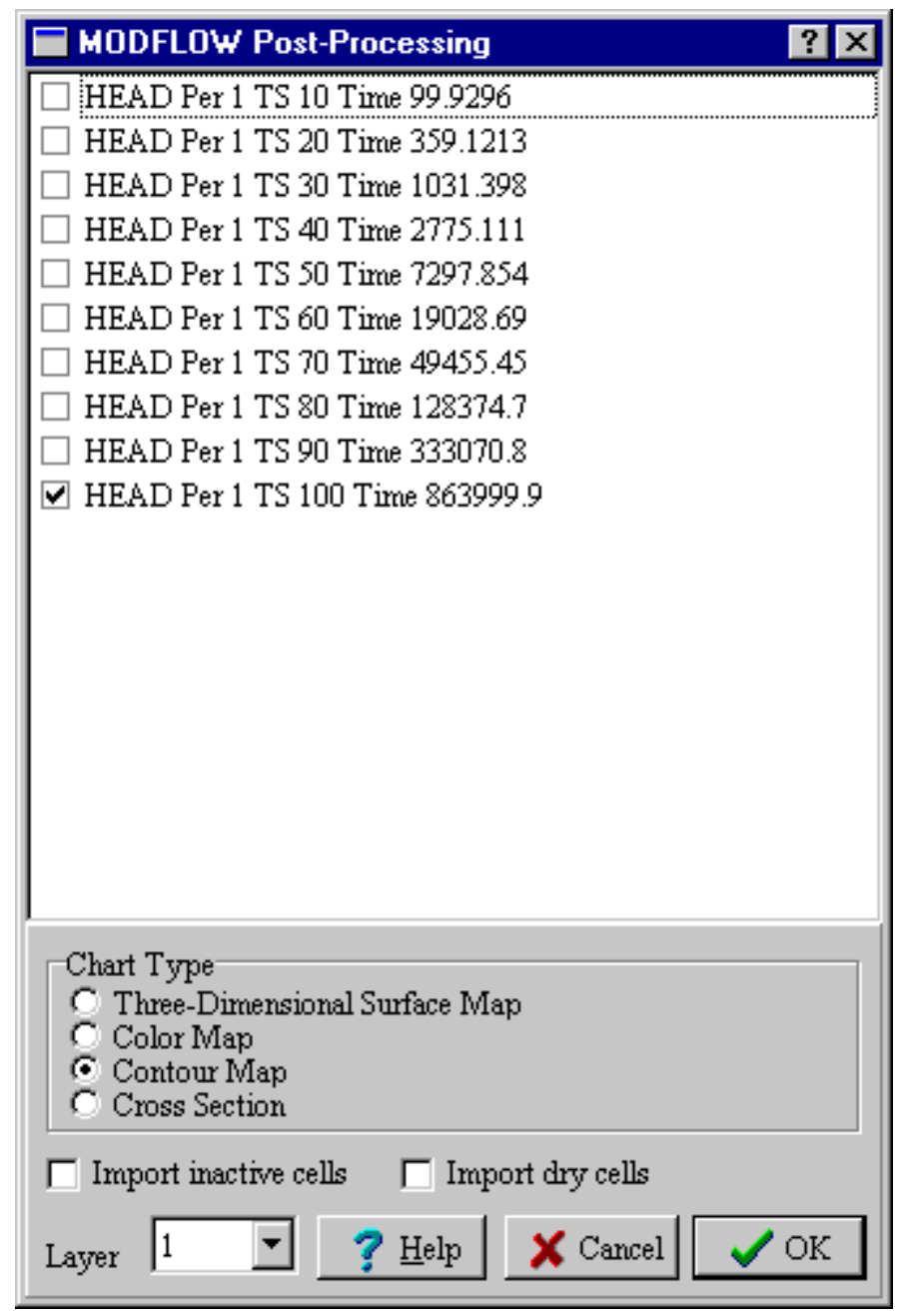

Figure 21. MODFLOW Post-Processing Dialog Box.

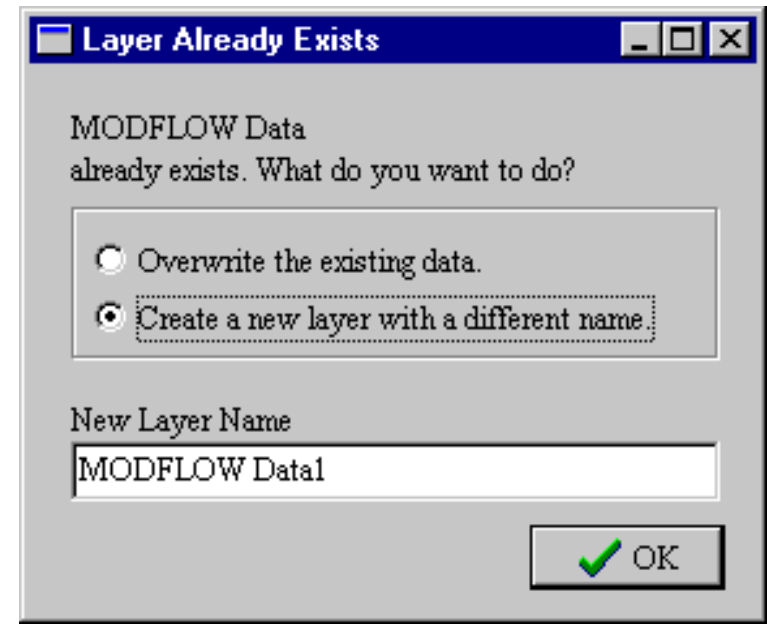

Figure 22. The "Layer Already Exists" Dialog Box.

If the user chooses to read a velocity file, the radio buttons for chart type will be disabled and a vector plot will be created. See the Argus ONE ${ }^{\text {TM }}$ documentation for more information 
about vector plots. To create a vector plot the user must choose pairs of $X$ and $Y$ velocities. The $\mathrm{Z}$ velocities will also be read and displayed on the list of available data sets but the PIE does not have a method for creating velocity plots along vertical profiles.

\section{Visualizing Results from MODPATH}

To plot the results from MODPATH, the user may either use MODPATH-PLOT (a separate program) or use Argus ONE ${ }^{\mathrm{TM}}$ to display the results. To use Argus ONE ${ }^{\mathrm{TM}}$ to display the results, select PIEs|Plot MODPATH Results. The Plot MODPATH Results dialog box (figure 23) will appear. Choose the type of data you wish to import by selecting the data type in the group of radio buttons labeled Data type. Click on the Read Data button and select the file. The data will be displayed in the dialog box. For endpoint files, there will also be a statistical summary of the data. After clicking OK, the data will be plotted as contours in an Argus ONE ${ }^{\mathrm{TM}}$, information layer named MODPATH Pathlines or MODPATH Endpoints. Pathline contours will have four parameters Starting Layer, Starting Time, Ending Layer, and Ending Time. Endpoints will have two additional parameters: Starting Zone and Ending Zone.

The statistical summary of MODPATH endpoints includes information about travel distance and travel velocity. This distance refers only to the distance traveled in a straight, horizontal line from the starting to the ending point. Vertical travel and deviations from a straight line along the travel path are ignored. The velocities are calculated from the horizontal, straight-line distances and thus have the same limitations as do the distances.

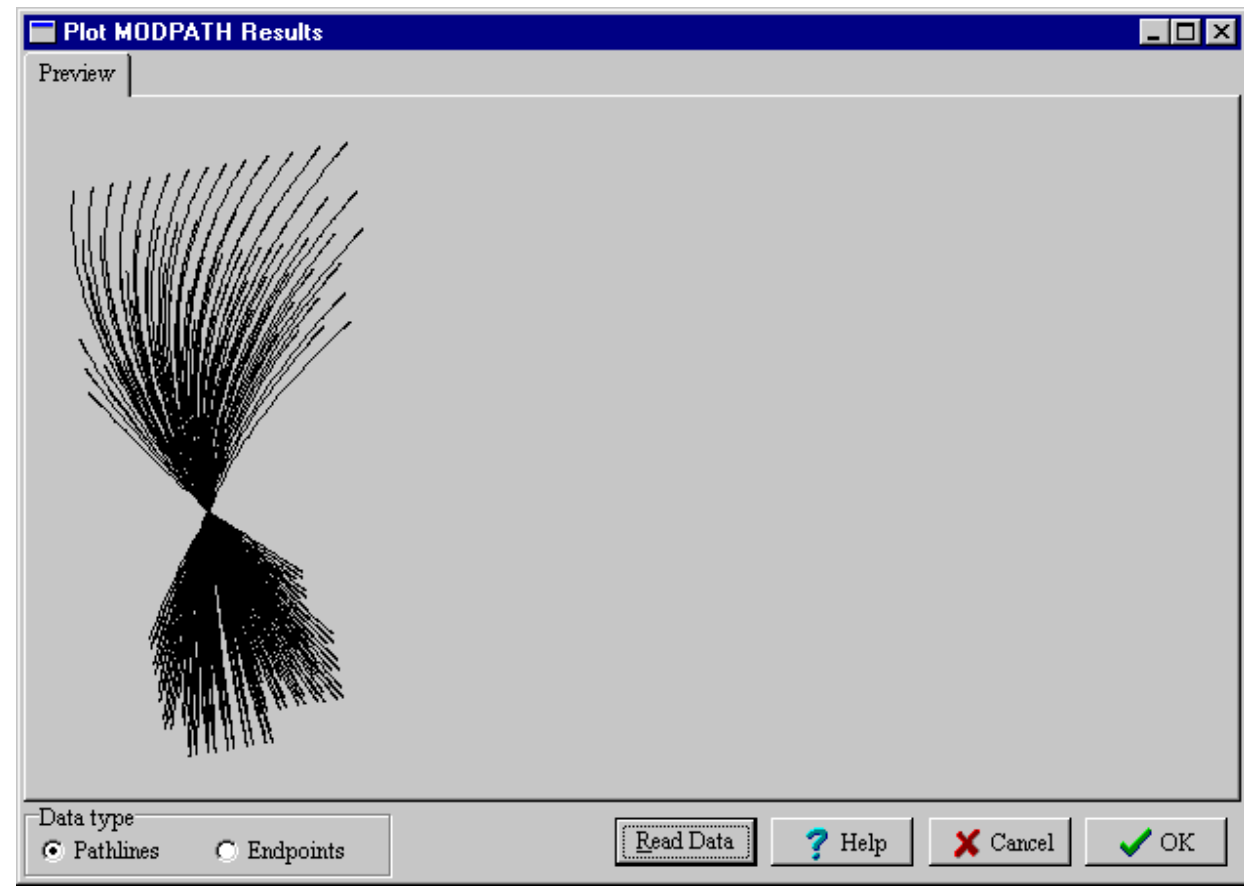

Figure 23. Plot MODPATH Results Dialog box after reading a set of pathlines.

\section{Visualizing Results from ZONEBDGT.}

To visualize results from ZONEBDGT, the user may use Budgeteer.exe as described in Appendix 2. 


\section{Example}

\section{Problem Description}

The following example is modified from Hornberger and Konikow (1998). It is designed to illustrate the new features of the MODFLOW-GUI. That example was loosely based on the ground-water contamination problem documented at the Rocky Mountain Arsenal, Colorado (Konikow, 1977). Because the example is greatly simplified, it does not represent any actual field situation. The information needed to define the problem are in the base map (figure 24, rma_map.dxf) and Table 7.

Table 7. Parameter values for two-dimensional sample problem.

\begin{tabular}{ll}
\hline Parameter & Value \\
\hline hydraulic conductivity & $0.0001 \mathrm{~m} / \mathrm{s}$ \\
storage coefficient & 0.0 \\
effective porosity & 0.20 \\
saturated thickness & $12 \mathrm{~m}$ \\
longitudinal dispersivity & $30 \mathrm{~m}$ \\
horizontal transverse dispersivity & $3 \mathrm{~m}$ \\
initial concentration & $0.0 \mathrm{mg} / \mathrm{L}$ \\
total simulation time & 20 years \\
Pumping rate: Well 1 & $-0.001 \mathrm{~m}^{3} / \mathrm{s}$ \\
Pumping rate: Well 2 & $-0.002 \mathrm{~m}^{3} / \mathrm{s}$ \\
Infiltration rate: disposal pond & $0.025 \mathrm{~m}^{3} / \mathrm{s}$ \\
Head in lake & $75 \mathrm{~m}$ \\
Stream Stage: east & $26 \mathrm{~m}$ \\
Stream Stage: west & $3 \mathrm{~m}$ \\
Streambed top elevation: east & $24 \mathrm{~m}$ \\
Streambed top elevation: west & $1 \mathrm{~m}$ \\
Streambed bottom elevation: east & $23 \mathrm{~m}$ \\
Streambed bottom elevation: west & $0 \mathrm{~m}$ \\
Stream width & $10 \mathrm{~m}$ \\
Streamflow & $30 \mathrm{~m} / \mathrm{s}$ \\
\hline
\end{tabular}




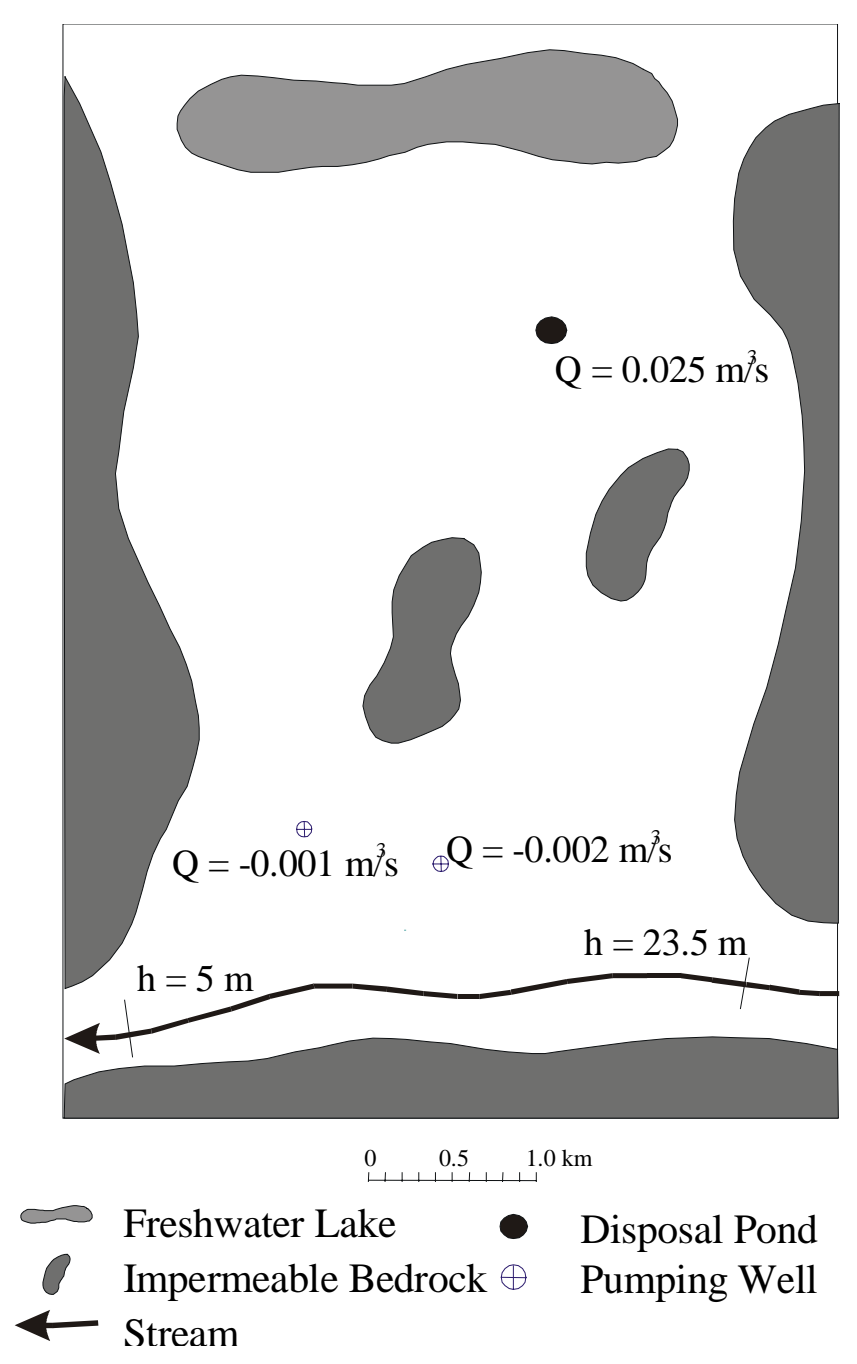

Figure 24. Base map for a two-dimensional sample problem.

The model area is bounded on the east, west, and south by impermeable bedrock outcrops that act as no-flow barriers. Two additional bedrock outcrops occur within the model domain and are also treated as no-flow areas. To the north, a lake acts as a constant-head boundary. A stream to the south acts as a head-dependent flux boundary. The stream slopes from east to west. The area also has a disposal pond, and two pumping wells.

\section{Create a New Model}

1. First start Argus ONE ${ }^{\mathrm{TM}}$. Then start a new MODFLOW model by selecting PIEs|New MODFLOW Project. The Edit Project Info dialog box will appear. Click on the OK button to close it without making any changes. This starts a new MODFLOW project. Next activate the Maps layer by clicking to the left of the "eye" icon in the Layers floater. A check mark should appear to the left of the eye icon to indicate that Maps is the active layer. A file containing a digitized map (rma_map.dxf) of the problem is included with the standard release of the MODFLOW GUI. Import rma_map.dxf into the project by selecting File|Import Maps|DXF File.... Then select rma_map.dxf. A dialog box will appear with a message that the objects are too large to fit in the current project. Accept the default choice to fit only the 
imported objects. Then select Scale and Units from the Special menu. Change the label for units to "m". Check the scale at the bottom of the map to make sure that the scale in the map matches the scale used in Argus ONE ${ }^{\mathrm{TM}}$. In this case it should match. (If it didn't match, it would be necessary to adjust the size of the map objects to match the scale in Argus ONE ${ }^{\mathrm{TM}}$.)

\section{Define the Study Area}

2. Next define the boundary of the model. Click outside the objects on the map to deselect all of them and then select the rectangle at the edge of the figure and copy it to the clipboard using either Edit|Copy or Ctrl-C. Make MODFLOW Domain Outline the active layer and paste it into that layer using either Edit|Paste or Ctrl-V. Double click on the contour just pasted into the MODFLOW Domain Outline. A dialog box will appear. In the dialog box assign MODFLOW Grid Cell Size a value of 100. This number sets the size of the grid blocks in the model. To learn more about controlling the grid cell size, see the Argus ONE ${ }^{\mathrm{TM}}$ help and the online help for the MODFLOW Domain Outline and MODFLOW Grid Refinement layers. (To access the online help, for the MODFLOW PIE select PIEs|MODFLOW Help.)

The northern boundary will go through the center of the lake, so we need to move that edge of the boundary to the south. If the boundary is not already selected, select it. Click on the "Lasso" button on the left margin of the Argus One ${ }^{\mathrm{TM}}$ main window and use to circle the vertices in the upper half of the rectangle. They should turn from black to white to indicate that they are selected. Click on the "Navigate" button (it has an arrow on it) next to the Lasso button. Click on the line on the top half of the rectangle. While holding the mouse button down, move it down to the middle of the lake. This will drag the top boundary south to the middle of the lake. We won't be modeling the area in the upper left and right hand corners of the mapped area, so we will need to adjust the boundary a little more. Locate the "Add Vertex" button below the Lasso button. Click on it and then click on the domain outline where it meets the edge of the lake. Now switch back to the "Navigate" button and click on the nodes in the upper left and right hand corners and drag each of them south so that the boundary is perpendicular to the direction of the area between the impermeable bedrock and the lake. It should look similar to the model shown in figure 25 . 


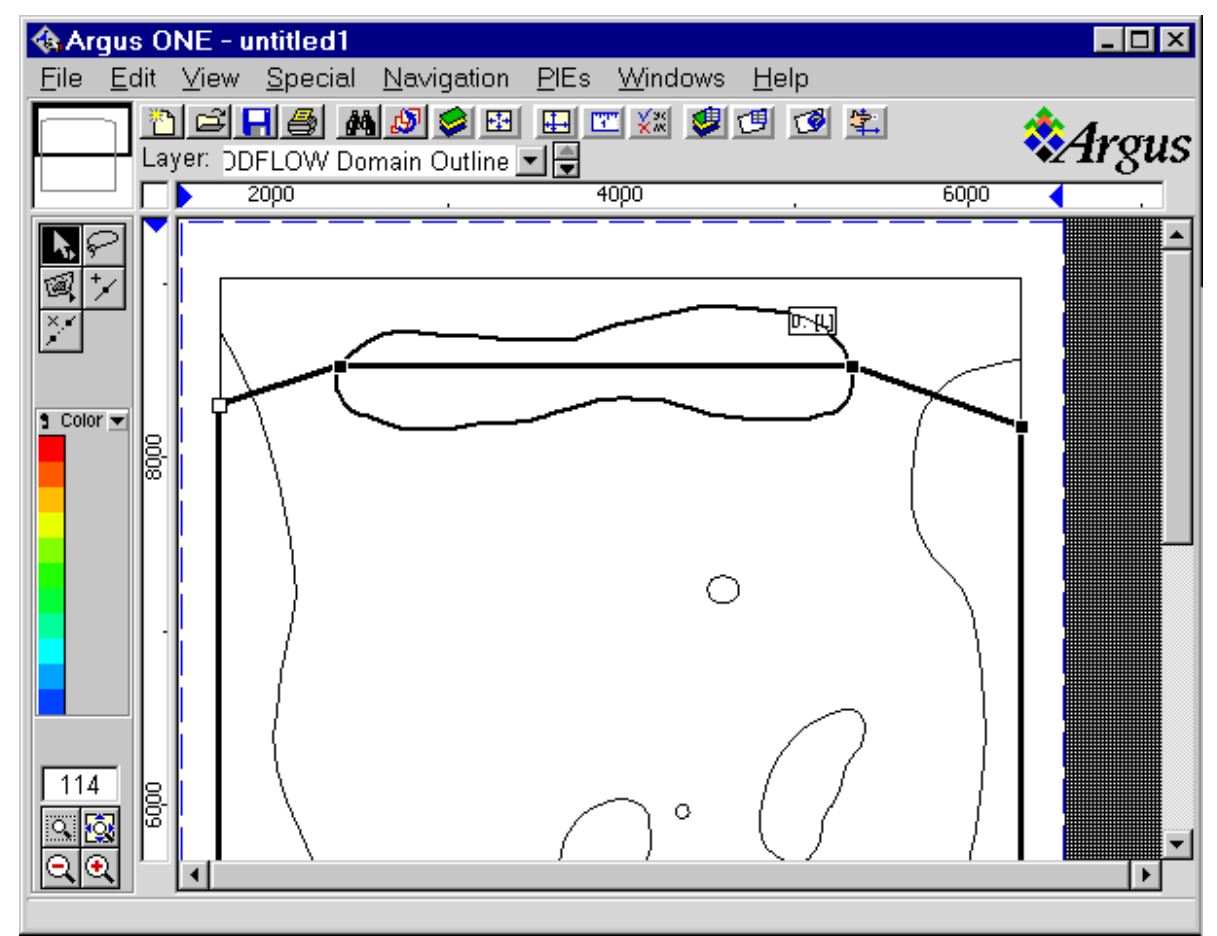

Figure 25. Domain Outline.

\section{Defining Specified-Head Boundaries}

3. Now we will create a specified-head boundary to represent the lake. Change to the Maps layer and click on the line that represents the lake. Copy it to the clipboard and paste in Prescribed Head Unit1 layer. Double click on the lake contour and assign it a specified head of 75.

\section{Choosing the Stream Package}

4. The river at the south end of the model could also be defined as a specified-head boundary, but in this case we will treat it as a stream boundary instead. Thus, we will need to use the stream package. To select the stream package, select PIEs|Edit Project Info and then select the Stresses 2 tab. Click the stream (STR) check-box to activate the stream package.

\section{Changing the Number of Geologic Units}

5. We will only use one geologic unit in this model. At present there are three units present. To get rid of the extra units, first click on the Geology tab. Next click on one of the cells in the bottom row to select it and then click on the Delete button. That unit will be deleted. Click the delete button again to delete another unit. Because at least one geologic unit must be present, the delete button will be disabled at this point so it is impossible to delete the last geologic unit.

\section{Accessing Context-Sensitive Help}

6. The Edit Project Info dialog box has extensive context-sensitive help. To see an example, click on the question mark icon in the upper right-hand corner of the dialog box. A 
question mark will appear next to the cursor. Now click on the Internal Array Storage combobox near the bottom of the Geology tab. The online help will be displayed. In some cases, the online help is too extensive to be displayed in this manner. For example, try clicking on the question mark icon and then click on the table displaying the data about each geologic unit. The context-sensitive help will appear but, except on screens with very high resolution, much of it probably will not be visible. In such cases, click on the Help button and then follow the links for the item of interest. In this case, click on Attributes of Geologic Units to see the help for all the items in the table.

\section{Finish Changing the Number of Geologic Units}

7. We are now done with the Edit Project Info dialog box so click on the OK button to accept all the changes in the dialog box. A layer named Stream Unit1 should have been added and all layers related to geologic units 2 and 3 should have been deleted.

\section{Defining a Stream Boundary}

8. Next we will place a stream on the south end of the model. Make Maps the active layer and copy the contour representing the stream and paste it into Stream Unit1. The stream slopes from an elevation of $26 \mathrm{~m}$ in the east to $3 \mathrm{~m}$ in the west. The contour direction and thus the direction of the stream is defined by the order of the vertices in the contour. Because Argus $\mathrm{ONE}^{\mathrm{TM}}$ can not place arrows on contours to indicate their direction, other characteristics must be used to indicate the direction of the contour. One characteristic that can be used is the position of the label on a contour. The label is always placed between the first and second nodes on a contour. In this case the label is on the right so the direction of the contour is correct (figure 26).

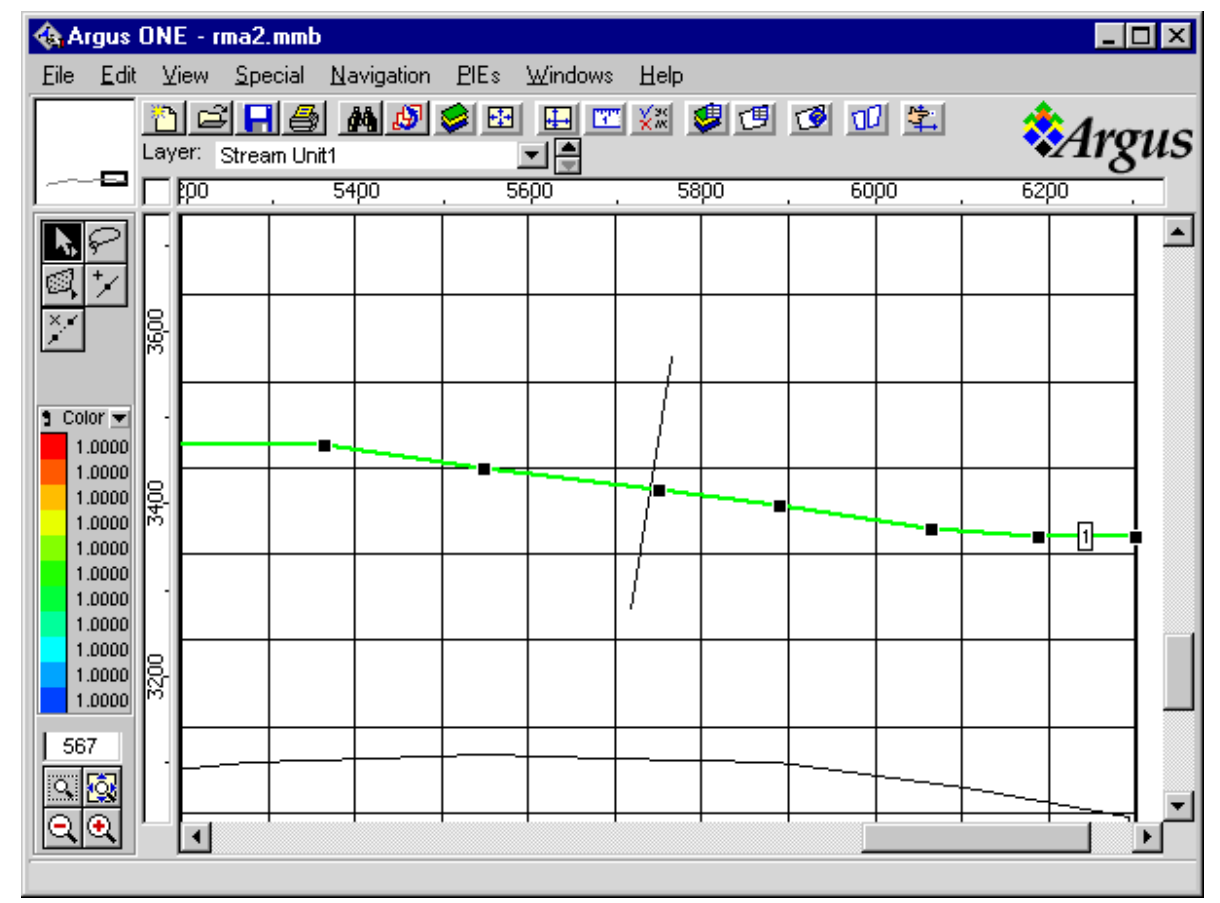

Figure 26. The label of the stream segment indicates the stream flows from right to left. 
If the contour direction is wrong, it is possible to reverse the direction of the contour using the following procedure. First cut the contour to the clipboard by selecting it and then selecting Edit|Cut or Ctrl-X. Then select File|Import|Reverse Contours on Clipboard. A dialog box will appear. Select the Stream Unit1 Layer. The contour will be pasted back onto the selected layer but its direction will be reversed. This option is only available if the EditContours PIE is installed (see Appendix 1).

Now double-click on the contour to bring up a dialog box with the parameters for the layer. There are 11 parameters for this layer. To see what these parameters represent, close the dialog box by clicking on the Cancel button and select PIEs|MODFLOW Help. Double click on Spatial Data and then on Layers related to specific geologic units and then on Stream Package. The information about each parameter that can appear on the Stream Unit[i] layers will be under Stream Unit[i] parameters. There is also general information about the Stream package.

Double-click on the stream contour again. Each stream contour must have a unique Segment Number. Each Segment Number must be a positive integer. We can assign this segment a Segment Number of 1. The stream bed sediments have the same hydraulic conductivity as the aquifer, so we will link the two. Click on the OK button. Select View|Layers... to bring up the layers dialog box. Select Stream Unit1 in the list of layers if it is not already selected. Select Streambed hydraulic conductivity in the list of parameters. In the Value column a button labeled " $\mathrm{fx}$ " will appear. Click it to bring up the Expression editor. Locate Hydraulic Cond Unit1 in the list of layers and select it. The $\mathbf{K x}$ and $\mathbf{K z}$ parameters will appear in the list of parameters. Double-click on $\mathbf{K x}$. The expression shown in the upper part of the expression editor should now be Hydraulic Cond Unit1.Kx. Click the OK button to close the expression editor and then click the Done button to close the Layers dialog box. Now double click on the stream contour again. Select the Streambed hydraulic conductivity parameter and delete its value. Click on another parameter and the linked value of hydraulic conductivity should appear. The measured flow at the upstream end of the stream is $30 \mathrm{~m}^{3} / \mathrm{s}$, so assign Flow1 a value of 30. This represents the flow into the upstream end of the stream segment during stress period 1. The stage at the upstream end is $26 \mathrm{~m}$ and at the downstream end it is $3 \mathrm{~m}$, as mentioned previously. Assign those parameters. In between the upstream and downstream end, the stream stage will be determined by linear interpolation along the length of the stream. The streambed top and bottom elevations vary from 24 and $23 \mathrm{~m}$ respectively at the upstream end to 1 and $0 \mathrm{~m}$ respectively at the downstream end. Set Upstream Bottom Elevation 1 to 23 and Upstream Top Elevation1 to 24. Set Downstream Bottom Elevation1 to 0 and Downstream Top Elevation1 to 1. Finally set the Upstream width1 to 10. The Downstream width1 can remain at \$N/A. This means that Downstream width1 will be ignored and the width will be equal to 10 all along the length of the segment.

\section{Define No-Flow Boundaries}

9. Now we will define the no-flow boundaries. Change to the Maps layer and select all five contours representing the impermeable bedrock. Copy them to the clipboard and paste them in the Added Inactive Area Unit1 layer. Assign all of them a value of 0 if they do not already have that value. To assign them all at once, select them all, double clicking on one of them, set the parameter value to 0 and then clicking the "Set All" button. 


\section{Other Packages and Options}

10. Now we will go to the Edit Project Info dialog box to set a number of other parameters in the model. Select PIEs|Edit Project Info. On the Project tab set the project name and title to "MFGUI 3.0 example problem". On the Stresses 1 tab check the Wells checkbox (WEL). On the Stresses 2, check the Flow and Head Boundary check-box (FHB). Change Number of Times to 1. On the Solvers/Other Packages tab, check the Horizontal Flow Barrier check-box (HFB). The solver can remain set to PCG2. On the PCG2 tab, change HCLOSE and RCLOSE to 0.0001. On the Time tab, change the time units to seconds. In the table, change the value for Length (PERLEN) of the first item from 1 to $6.31152 \mathrm{E}+8$. (This is approximately the number of seconds in 20 years.) On the Output Files tab, change the Rootname for MODFLOW Simulation files to "rma2". On the MODPATH tab, check the MODPATH check-box. All the default values for MODPATH are acceptable so there is no need to make no other changes for MODPATH. On the ZONEBDGT tab, select the ZONEBDGT check-box. Change the ZONEBDGT title to "MFGUI 3.0 example problem". The other ZONEBDGT default values are acceptable. Now click on the OK button. Several new information layers will be added to the project.

\section{Save the Project}

11. Now might be a good time to save the project. Select File|Save to save it. If no file name has already been assigned, the user will be prompted to choose one. A suitable file name might be rma2.mmb.

\section{Setting the Top Elevation}

12. We will assume that the top of the unit is a plane surface tilted to the southeast. The slope towards the south is 0.01 and the slope toward the east is 0.005 . At $(4000,8600)$ the top elevation is $75 \mathrm{~m}$. From this it is easy to derive an expression for the top elevation: $\mathrm{E}=75+$ $0.005(\mathrm{x}-4000)+0.01(\mathrm{y}-8600)$ where E equals the elevation and $\mathrm{x}$ and $\mathrm{y}$ are the $\mathrm{x}$ coordinates. To enter the expression, bring up the Layers dialog and then bring up the Expression editor for Elevation Top Unit1. Be careful to choose the Elevation Top Unit1 layer and not the Elev Top Unit1 parameter that appears in the MODFLOW FD Grid layer. The expression should appear as follows.

$75+0.005 *(\mathrm{X}()-4000)+0.01 *(\mathrm{Y}()-8600)$

In the expression "X()" and "Y()" are functions found under the category "Mathematical".

\section{Set Aquifer Properties}

13. The saturated thickness of the aquifer is $12 \mathrm{~m}$, so the expression for Elevation Bottom Unit1 should be "Elevation Top Unit1 - 12".

14. Set the Hydraulic Conductivity.Kx parameter to $1.0 \mathrm{E}-4 \mathrm{~m} / \mathrm{s}$. Because this is a twodimensional problem, $\mathbf{K z}$ can be ignored. After changing the hydraulic conductivity, go back to Stream Unit1 and check the value of the streambed hydraulic conductivity. It should give the same value as the Hydraulic Conductivity.Kx because the two were linked previously.

15. Leave Porosity Unit1 set to 0.2 , the correct value. Set the Initial head equal to the top elevation of the layer. The best way to do this is to use the Expression editor as described previously in step 12 . 


\section{Create Pumping Wells}

16. There are two pumping wells in the model. Their pumping rates and locations are shown in figure 24 . We will assume that the wells fully penetrate the aquifer, so we will set the top and bottom elevations of the well screen equal to the top and bottom elevations of the aquifer. Link them using the expression editor. The expression for Top Elevation on the Well Unit1 layer should be Elevation Top Unit1. The expression for Bottom Elevation on the Well Unit1 layer should be Elevation Bottom Unit1. Click on the Done button and activate the Well Unit1 layer. Now select the Point contour tool. To do this, locate the contour button on the left side of the Argus ONE ${ }^{\mathrm{TM}}$ main window. It is underneath the navigate button. Click on the contour button and hold down the mouse button until a pop-up menu appears. Select the third item in the menu to select the point contour tool. Its symbol should look like a cross. Now click once at the location of one of the pumping wells to check the values assigned to the top and bottom elevations. They should now be set correctly by the expressions. Set the pumping rates to the values shown in figure 24 . The negative values of the pumping rates indicate that these wells pump water out of the aquifer rather than into it. Stress1 is the parameter used to set the pumping rate for the first (and, in this case, only) stress period. The default values of IFACE1, a MODPATH parameter, can be left. By default, the contours will be labeled with the value of their first parameter. If you wish them to be labeled with their pumping rate, color the contours by their pumping rate. You can do this by selecting the down arrow next to Color on the left side of the Argus ONE main window and then selecting Stress1.

\section{Create Specified-Flow Boundary}

17. The disposal pond will be modeled with the Flow and Head Boundary package. Change to the Maps layer and select the oval that represents the disposal pond. Copy it to the clipboard and paste it in the Area FHB Unit1 layer. Now double click on the contour in the Area FHB Unit1 layer. This contour will represent a specified-flux boundary, so delete the value of " 0 " for Head Time1 that was copied from the Maps layer and click on the OK button.

We wish to have a specified flux for the contour but the value we must enter is the specified flux per unit area. To make it easier to enter the correct value, we will add a new parameter to the Area FHB Unit1 layer named Flux and create an expression that will calculate the flux per unit area and assign that value to the Flux per Area Time1 parameter. Bring up the Layers dialog box (View|Layers...). Select Area FHB Unit1 if it is not already selected. In the lower half of the Layers dialog box, click on the "New" button to create a new parameter. Type in the name Flux as the name of the parameter. Set the default value for the Flux parameter to "\$N/A" (= not available). (An easy way to do this is to click on the " $\mathrm{N}$ " in the expression editor.) Now set the default value of the Flux per Area Time1 parameter to "If(ContourArea()>0, Flux / ContourArea(), \$N/A)". (The If() function is listed under the category "Mathematical" in the Expression editor. The "ContourArea()" function is listed under the category "Contour".) This function checks if the contour area is greater than 0 . If it is, the value of the parameter is set to the total flux divided by the contour area. Otherwise the value of the parameter is $\$ \mathrm{~N} / \mathrm{A}$. If a value is assigned to the Flux parameter, the value of the Flux per Area Time1 parameter will be set automatically. Now double click on the contour that represents the disposal pond in the Area FHB Unit1 layer and assign the Flux parameter a value of 0.025 . Click OK to close the dialog box. Now double click on the contour again. The Flux per Area Time1 should be calculated as 1.15257e-06. 


\section{Run MODFLOW}

18. We will now create the grid, run the model and plot the results. Change to the MODFLOW FD Grid layer. Locate the Magic Wand tool on the left-hand side of the main Argus ONE window. Click anywhere within the Domain Outline and a grid will be created. You can create or modify your grid at any time without needing to reenter any data provided that you enter all you data on information layers rather than overriding the values of individual grid cells.

If you wish, you may wish to examine the values of individual grid cells or to color the grid by the value of one of the grid parameters. To examine the value of an individual grid cell, double click on the cell. To color the grid by one of the grid parameters, click on the down arrow next to Color on the left side of the main Argus window and then select one of the parameters from the list of grid parameters.

Next, run MODFLOW. Select PIEs|Run MODFLOW/MOC3D. Check that the dialog box has the correct path for the MODFLOW executable by clicking on the Model Paths tab. If the path is wrong, the edit-box and the status bar will have a red background. If the path is wrong, either type in the correct path or click on the appropriate Browse button and locate it. When the path is correct, click on the OK button. As the PIE processes the export template, a progress bar will appear on screen. After the PIE has passed the export template to Argus $\mathrm{ONE}^{\mathrm{TM}}$, a prompt-message will appear to select a directory. Ignore the file name, MODFLOW_FD_Grid.exp, in the Enter export file name: dialog box. Only the directory, not the file name, is used. When directory is selected, Argus ONE ${ }^{\mathrm{TM}}$ will begin to process the export template. Two progress bars will appear. Argus ONE ${ }^{\mathrm{TM}}$ generates "barbershop-pole" progress bar that can be used to halt the export process. A PIE generates the other progress bar. This second progress bar displays warning and error messages as well as the progress through the export template. When the export process is complete, MODFLOW will begin to run.

\section{Plot Heads Generated by MODFLOW}

19. To plot the results of the model, select PIEs|MODFLOW/MOC3D Post Processing. Click the Select Data Set button and select the file rma2.fhd. Click the Open button and then the $\mathbf{O K}$ button to make a contour plot the head in layer 1 (figure 27). 


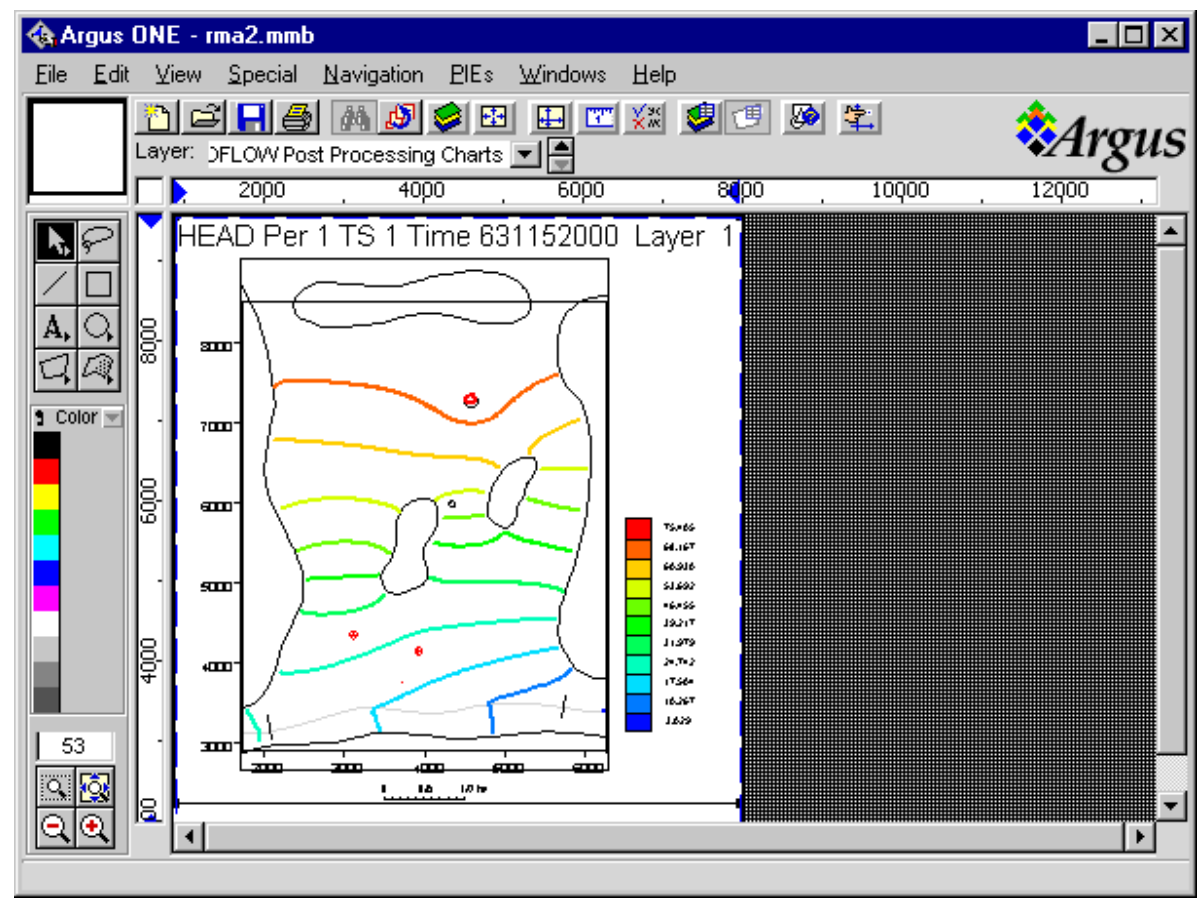

Figure 27. Heads Generated by MODFLOW Simulation.

\section{Define MODPATH Particle Starting Points}

20. Now try using MODPATH to determine the locations that receive water that infiltrated at the disposal pond. First, define the starting locations of the particles for MODPATH. Make MODPATH Particles Unit1 the active layer and zoom in on the area with the disposal pond. Draw four contours on that layer as shown in figure 28. 


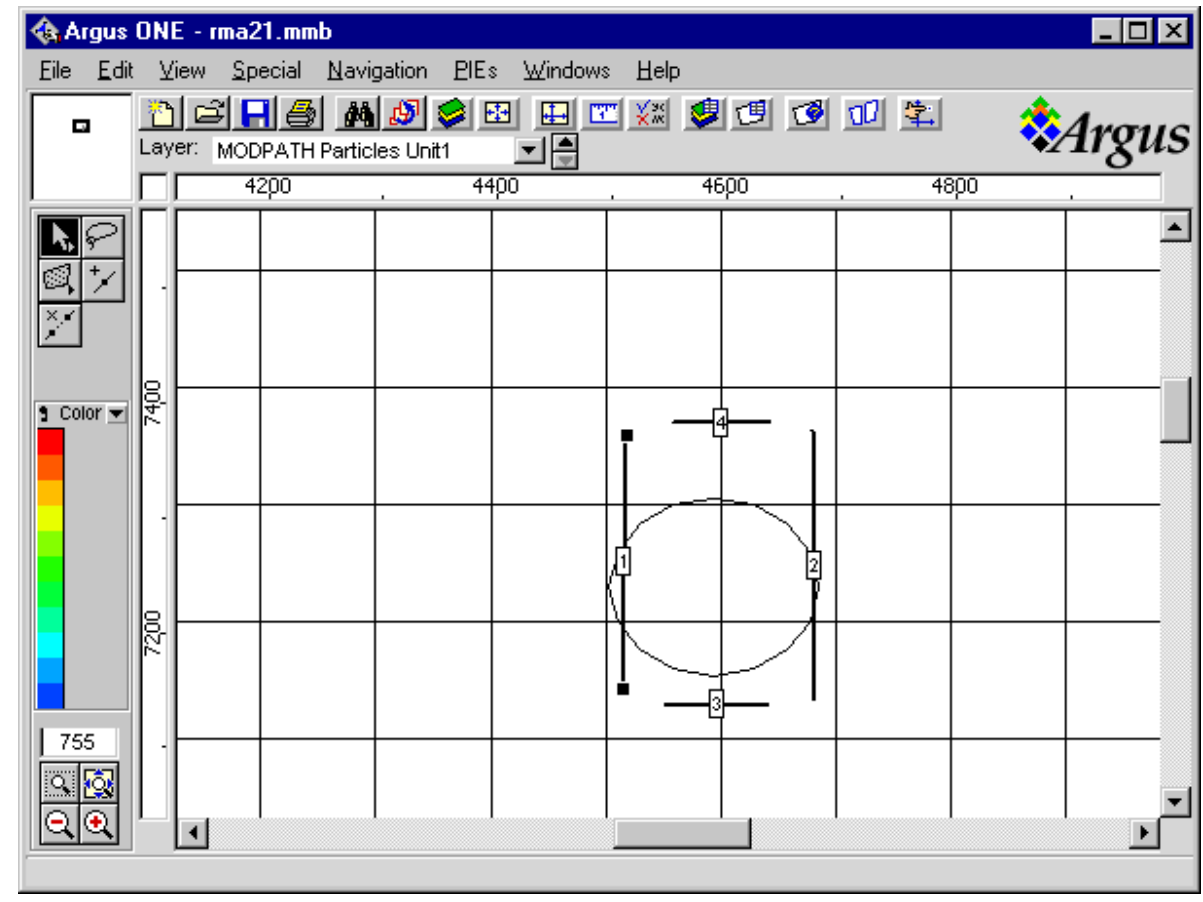

Figure 28. Contours on "MODPATH Particles Unit1" layer.

Select all 4 contours and double click on 1 of them. Assign X Particle Count, $\mathbf{Y}$ Particle Count, and Z Particle Count values of " 5 ". Assign Release Time1 a value of 0. Click the Set All button and then the OK button. Now just select one contour at a time. Set IFACE for the contour on the left to 1. Set IFACE for the contour on the right to 2. Set IFACE for the contour on the bottom to 3. Set IFACE for the contour on the top to 4.

\section{RUn MODPATH}

21. To run MODPATH, change to the MODFLOW FD Grid layer and select PIEs|Run MODPATH. Make sure the path for MODPATH is correct. Click the OK button to start exporting the MODPATH input files and run MODPATH. Be sure to run MODPATH in the same directory in which you ran MODFLOW because MODPATH needs some of the MODFLOW input and output files as input.

\section{Plot MODPATH Results}

22. To plot the results from MODPATH, select PIEs|MODPATH Post Processing. Click on the Read Data button and select a pathline file created by MODPATH. It will have the extension "lin". The data will be read and plotted in the dialog box. If the file is large, this may take a while and a progress bar will be displayed. To import this data into Argus ONE ${ }^{\mathrm{TM}}$, click the OK button. Another progress bar will be displayed as the data are imported into Argus $\mathrm{ONE}^{\mathrm{TM}}$. The progress bar may appear somewhat "jerky" in the way it progresses and Argus $\mathrm{ONE}^{\mathrm{TM}}$ may redraw several times during the process of drawing the contours. This is normal. It is possible to speed up the process of exporting contours by making sure that the redraw process is fast. The redraw process is faster if only a small portion of the model is displayed, no cells are colored, and layers with lots of contours are hidden. The pathlines will be plotted on a layer named MODPATH Pathlines as illustrated in figure 29. Each contour will have four parameters: Starting Layer, Starting Time, Ending Layer, and Ending Time. 


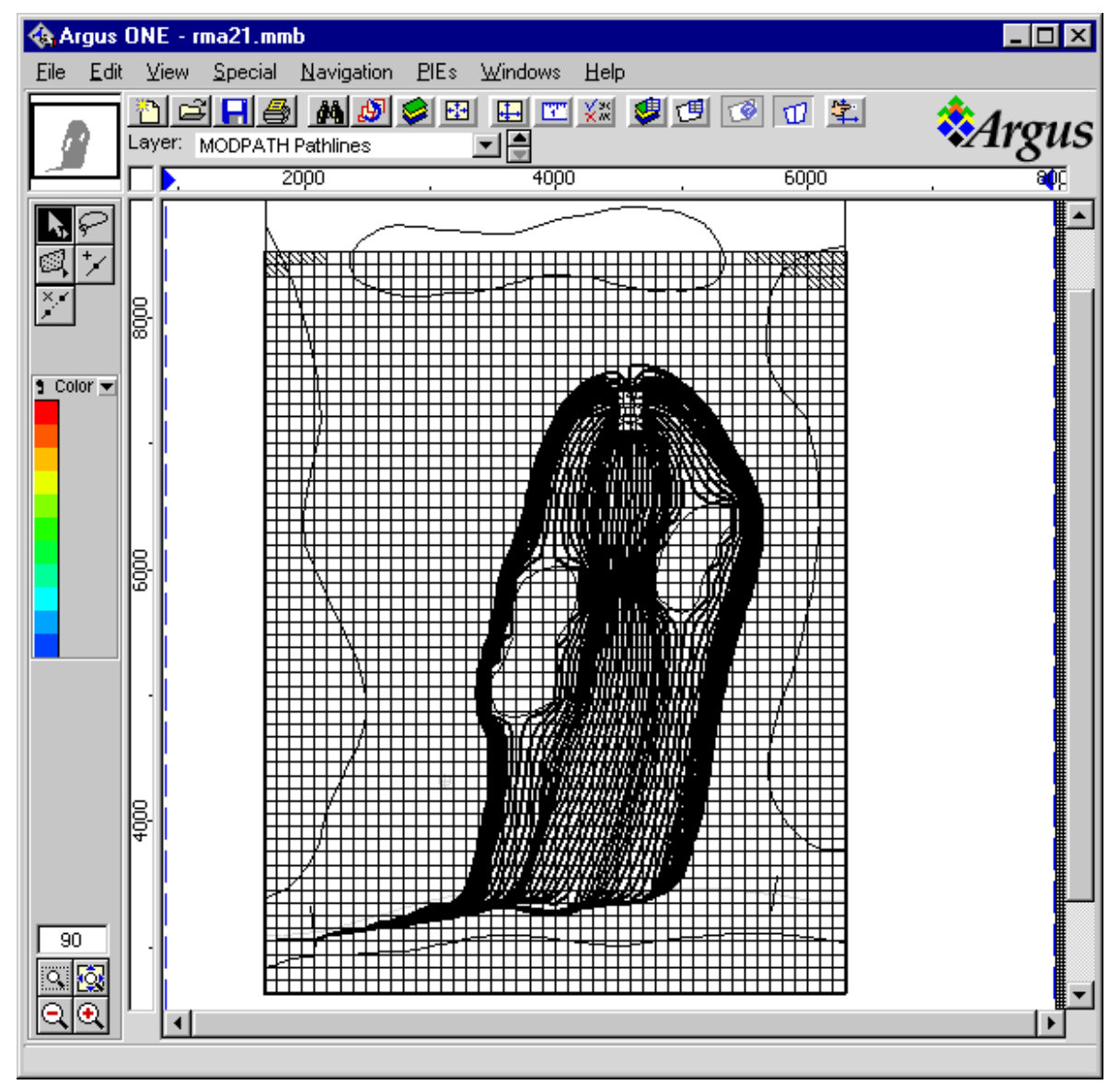

Figure 29. MODPATH Pathlines.

\section{Define Horizontal-Flow Barrier and Rerun MODFLOW}

23. We will now modify the model to include a slurry wall extending between the two, internal, bedrock outcrops and see how the slurry wall affects the head distribution and particle tracks. Change to the Horizontal Flow Barrier Unit1 layer and select the open contour tool. Draw an open contour between the two, internal, bedrock outcrops (figure 30). Accept the default values for the contours. To see exactly how the PIE translates the contours to flow barriers, select PIEs|Display Horizontal Flow Barriers and click on the Display button. Rerun MODFLOW and MODPATH as before and plot the results. The only difference in the procedure is that when plotting the results, prompt-message will appear to overwrite the existing data or to create new layers. For the heads, it will be necessary to create two new layers, one for the data and one for the post-processing charts. For MODPATH, it will only be necessary will to create one new layer. Examine the results in the vicinity of the flow barrier. There should be an abrupt change in head at the location of the barrier and more of the particles should go around the internal bedrock outcrops rather than between them (figure 31). 


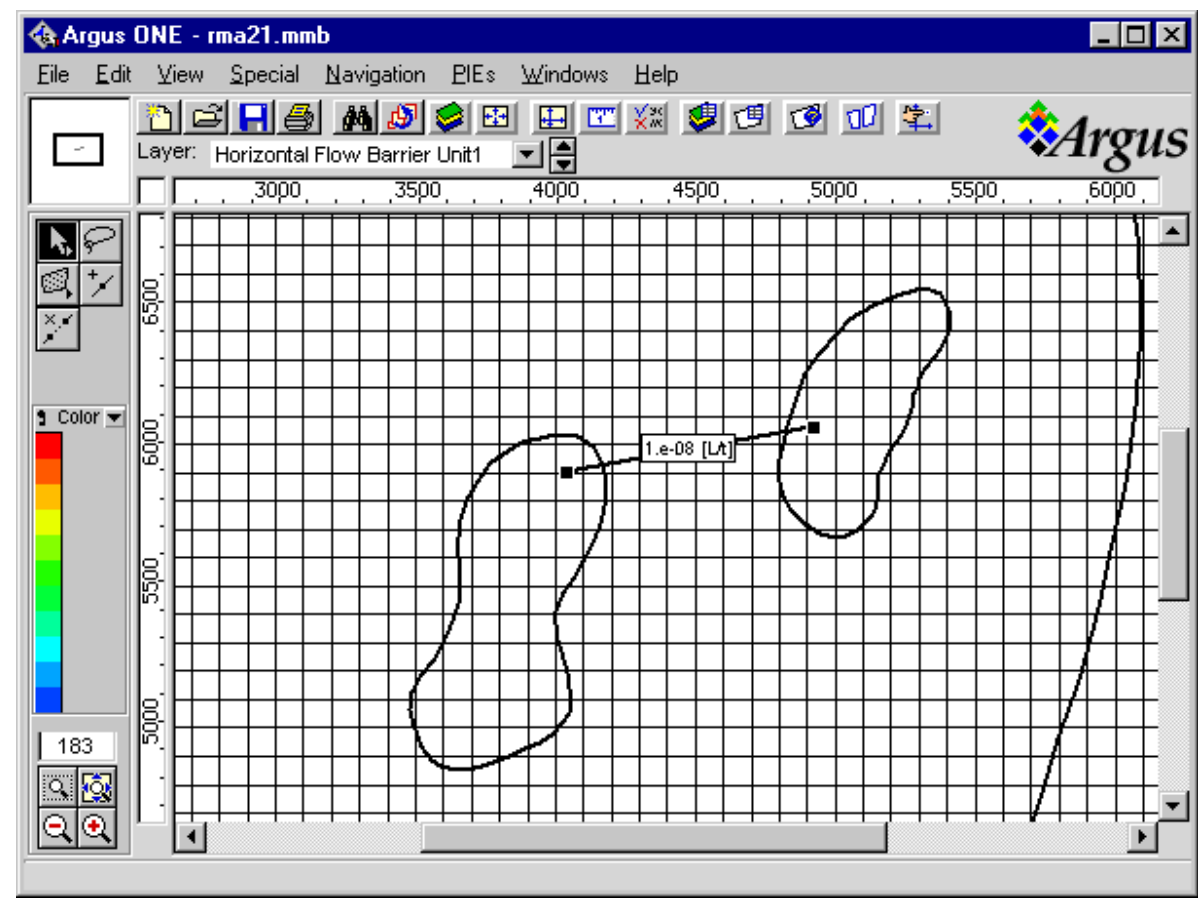

Figure 30. Slurry wall connecting the two, internal, bedrock outcrops.

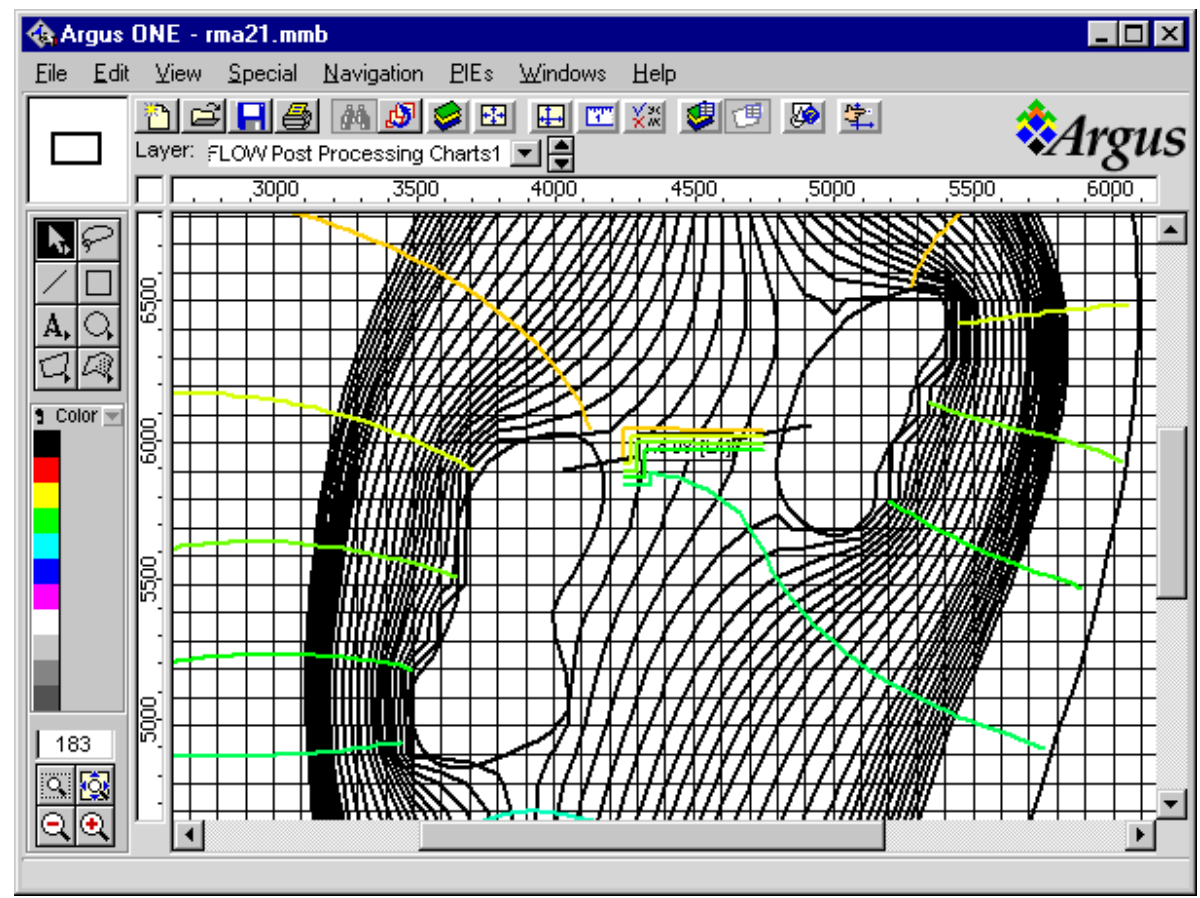

Figure 31. Pathlines and head contours in the vicinity of the horizontal-flow barrier.

\section{Use ZONEBDGT}

24. Finally, we will use ZONEBDGT to check that the fluxes for the FHB package were calculated correctly and to add up the fluxes between the stream and the aquifer. (We might 
want to know the total flux so that we could compare it with measured values of baseflow.) We will also create a ZONEBDGT zone for each of the two pumping wells and define a composite zone comprising the two primary zones around the wells. Change to the ZONEBDGT Unit1 layer and draw closed contours around the stream, each pumping well, and the disposal pond (figure 32). Assign each contour a different value. In figure 32, the primary zone for the stream is 1 , the primary zones for the wells are 2 and 3 , and the primary zone for the disposal pond is 4 . To create the composite zone, select PIEs|Edit Project Info and go to the ZONEBDGT tab. Change the number of ZONEBDGT composite zones to 1 and enter " 2 " and " 3 " in the first two cells in the ZONEBDGT Composite Zones table. Click on the OK button. Change to the MODFLOW FD Grid layer and select PIEs|Run ZONEBDGT. The process of running ZONEBDGT is much the same as that used to run MODFLOW or MODPATH. When ZONEBDGT is done, open the output file from ZONEBDGT in a text editor. The extension of the output file will be "zbl". For the zone containing the disposal pond, specified flows into the model should be $0.25000 \mathrm{E}-01$ which is the same as the flow we actually specified $(0.025)$. The composite zone comprises the two zones containing the two pumping wells. It should have a combined pumping rate out of the aquifer of $0.30000 \mathrm{E}-02$. Our specified rates were -0.001 and -0.002 so this matches the values we specified. The stream has fluxes both into and out of the aquifer although the flux out of the aquifer is far larger than the flux into the aquifer. In some cases it might be important to determine which cells had flow from the aquifer. To do this, you could open the Edit Project Info dialog box. On the Stress 2 tab you could select the Print Flows check-box. If the input files for the Stream package were then regenerated and MODFLOW was re-run, the flows would be printed in the MODFLOW listing file. However, the stream cell-by-cell flows would no longer be in the cell-by-cell flow file. If ZONEBDGT was run again, it would not calculate the correct fluxes for the stream. This is because the current version of the stream package does not provide a mechanism for simultaneously printing these flows and saving them in the cell-by-cell flow file. 


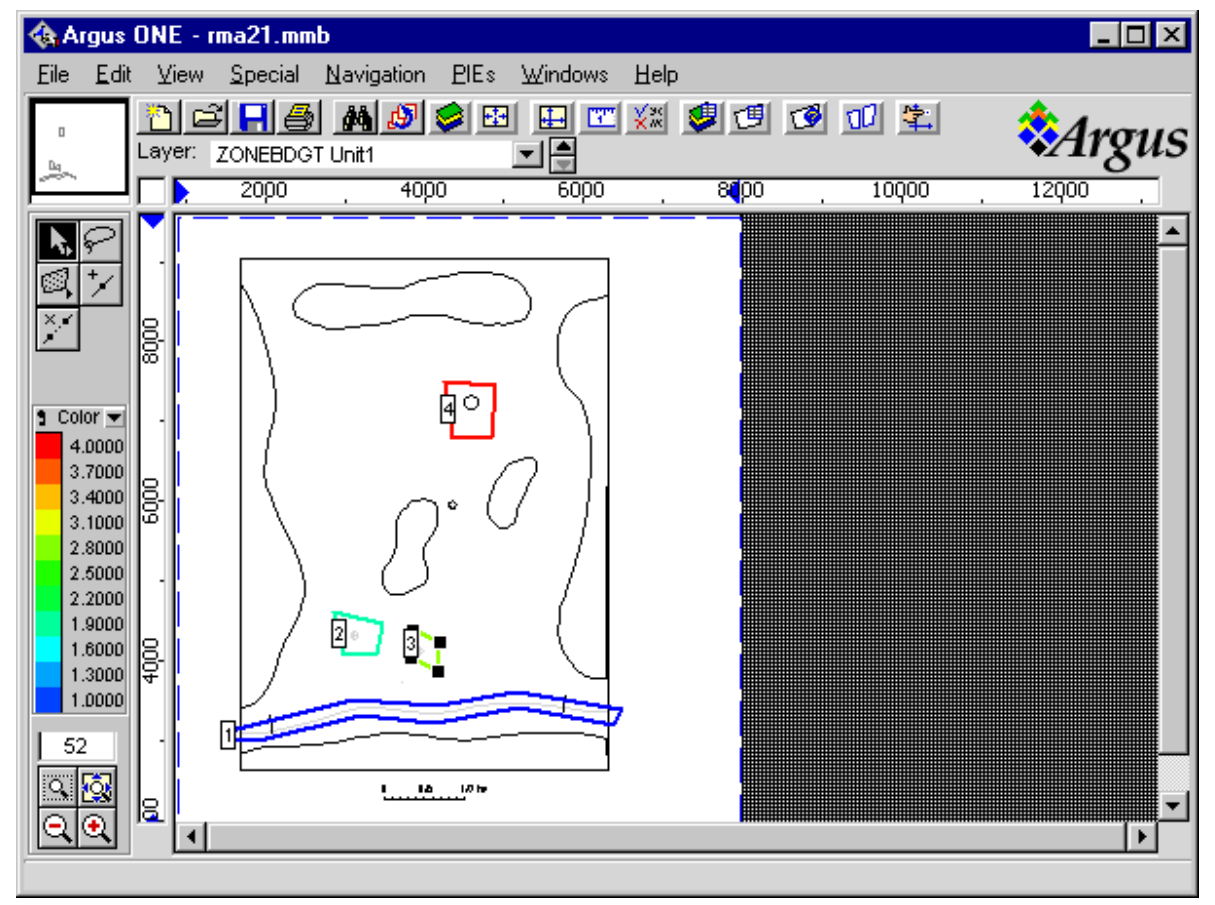

Figure 32. ZONEBDGT Primary zones.

\section{View ZONEBDT Results}

25. Another way of examining the results of ZONEBDGT would be to use the Budgeteer program (Appendix 2). Start Budgeteer by locating Budgeteer.exe on and double clicking on it. Select File|Open and then find the ZONEBDGT output file and select it. The data for the first zone will be plotted for each time step of the model (figure 33). Use the checkboxes to decide which budget items to plot. Use the Plot Type radio buttons to choose whether to make a bar graph of data for an individual time step or a time series plot. Use the combo-boxes to choose which zone or time step to plot. 


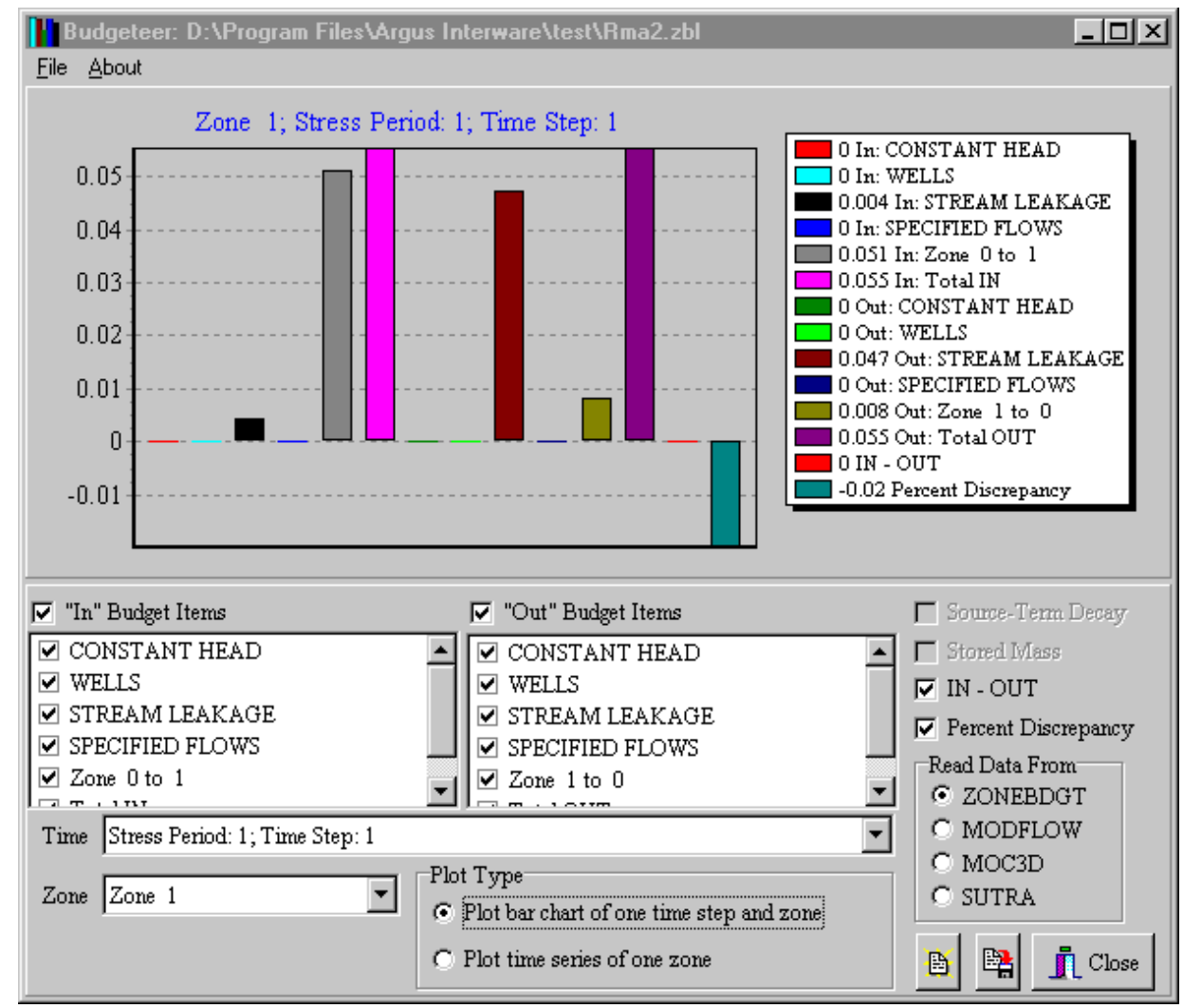

Figure 33. Budgeteer: Bar Chart of an Individual Zone.

\section{Customizing the MODFLOW PIE}

The MODFLOW PIE has been designed to make it easy to customize it for special purposes. A customized GUI might support other MODFLOW packages that were written outside the USGS or entirely separate programs that rely on MODFLOW. In most cases customization will require additions to the source code of the GUI. If these additions are done properly, it will be possible to incorporate future revisions of the GUI into a customized version easily. All that will be needed is to add any new source code files in the updated USGS version of the GUI to a project, recompile the PIE, and update the export template. Details on the proper method to prepare a customized version of the MODFLOW-GUI will be in a read_me file distributed with the source code.

The PIE's were developed using Borland ${ }^{\mathrm{TM}}$ Delphi 4.0 Professional. With minor modifications, it should be possible to compile the PIE with Borland ${ }^{\mathrm{TM}}$ Delphi 4.0 Standard. To do so, the user must provide a replacement for the PowerInt function in a unit named "Powers.pas" and the line " $\{\$ D E F I N E$ MathUnitPresent $\}$ " should be commented out or deleted in ModflowUnit.pas. Rubenking (1996, p. 435-436) presents a suitable PowerInt function. This has not been tested and it is possible that other changes would also be required.

\section{Conclusions}

The MODFLOW GUI is an efficient and effective method of creating the input files for MODFLOW, MOC3D, MODPATH, and ZONEBDGT. Because data for the model is entered in a form that is independent of the grid, the grid can be changed without reentering data. 
MODFLOW GUI V 3.0 adds a number of new capabilities to the model. The major changes are the addition of a help-system and added support for MODPATH, ZONEBDGT, and several additional MODFLOW packages.

\section{References}

Andersen, P. F., 1993, A Manual of instructional problems for the U.S.G.S. MODFLOW model: Robert S. Kerr Environmental Research Laboratory, Office of Research and Development, U. S. Environmental Protection Agency, EPA/600/R-93/010, 279 p.

Argus Interware, Inc., 1997, User's Guide Argus ONE ${ }^{\mathrm{TM}}$, Argus Open Numerical Environments - A GIS Modeling System, Version 4.0, Jerico, NY, Argus Holdings, Limited, 506 p.

Harbaugh, A.W., 1990, A computer program for calculating subregional water budgets using results from the U.S. Geological Survey modular three-dimensional ground-water flow model: U.S. Geological Survey Open-File Report 90-392, 46 p.

Harbaugh, A.W., and McDonald, M.G., 1996, User's documentation for MODFLOW-96, an update to the U.S. Geological Survey modular finite-difference ground-water flow model: U.S. Geological Survey Open-File Report 96-485, 56 p.

Hornberger, G.Z., and Konikow, L.F., 1998, Addition of MOC3D solute- transport capability to the U.S. Geological Survey MODFLOW-96 graphical-user interface using Argus Open Numerical Environments: U.S. Geological Survey Open-File Report 98-188, 30 p.

Hsieh, P.A. and Freckleton, J.R., 1993, Documentation of a computer program to simulate horizontal-flow barriers using the U.S. Geological Survey modular three-dimensional finite-difference ground-water flow model: U.S. Geological Survey Open-File Report 92477, $32 \mathrm{p}$.

Konikow, L.F., 1977, Modeling chloride movement in the alluvial aquifer at the Rocky Mountain Arsenal, Colorado: U.S. Geological Survey Water-Supply Paper 2044, 43 p.

Konikow, L.F., Goode, D.J., and Hornberger, G.Z., 1996, A three-dimensional method-ofcharacteristics solute-transport model (MOC3D): U.S. Geological Survey WaterResources Investigations Report 96-4267, 87 p.

Leake, S.A., and Lilly, M.R., 1997, Documentation of a computer program (FHB1) for assignment of transient specified-flow and specified-head boundaries in applications of the modular finite-difference ground-water flow model (MODFLOW): U.S. Geological Survey Open-File Report 97-571, 50 p.

McDonald, M.G., and Harbaugh, A.W., 1988, A modular three-dimensional finite-difference ground-water flow model: U.S. Geological Survey Techniques of Water-Resources Investigations, book 6, chap. A1, $586 \mathrm{p}$. 
Poeter, E. P. and Hill, M. C., 1998, Documentation of UCODE, a computer code for universal inverse modeling: U.S. Geological Survey Water-Resources Investigations Report 984080, 116 p.

Pollock, D.W., 1994, User's Guide for MODPATH/MODPATH-PLOT, Version 3: A particle tracking post-processing package for MODFLOW, the U.S. Geological Survey finitedifference ground-water flow model: U.S. Geological Survey Open-File Report 94-464, 6 ch.

Prudic, D.E., 1989, Documentation of a computer program to simulate stream-aquifer relations using a modular, finite-difference, ground-water flow model: U.S. Geological Survey Open-File Report 88-729, 113 p.

Rubenking, Neil, 1996, Delphi Programming Problem Solver: Forest City, CA, IDG Books Worldwide, $604 \mathrm{p}$.

Shapiro, A.M., Margolin, J., Dolev, S., and Ben-Israel, Y., 1997, A graphical-user interface for the U.S. Geological Survey modular three-dimensional finite-difference ground-water flow model (MODFLOW-96) using Argus Numerical Environments: U.S. Geological Survey Open-File Report 97-121, 50 p.

Voss, C.I., 1984, A finite-element simulation model for saturated-unsaturated, fluid-densitydependent ground-water flow with energy transport or chemically-reactive single-species solute transport: U.S. Geological Survey Water-Resources Investigations Report 844369, 409 p. 


\section{Appendix 1: Edit Contours PIE}

The Edit Contours PIE is used to edit the positions of individual vertices in contours. To use it, move to an Information, Maps, or Domain Outline layer and select File/Import <layer name $>\mid$ Edit Contours. The user will be prompted for a layer name. Select a layer. The PIE will read all the contours from the layer and display them. Click on any vertex, and a dialog box will appear in which it is possible to edit the vertex position. When done, click OK. The PIE will then clear the layer and write a new set of contours with the new vertex positions.

Warnings:

1. The parameter values assigned to contour may be lost if you have selected "Special|Preferences" and among the clipboard preferences, you have turned off "copy contour parameter values".

2. If \#1 does not apply, the contour parameter values will be the same as they were originally; however, any parameters that were set as default values will now be specified in the contour itself. To go back to having the contour value being set by the default value for the layer, edit the contour and delete the parameter value.

3. The PIE does not check for contours that are illegal in Argus ONE. A contour is illegal if it crosses another contour and "Allow Intersection" is not turned on for that layer. A contour is also illegal if it crosses itself even if "Allow Intersection" is turned on. Argus ONE will not accept illegal contours so illegal contours will be lost if you specify contours that are illegal. For this reason, it is best to back-up your file before using the Edit Contours PIE.

4. The parameter name will be lost if you have selected "Special|Preferences" and among the clipboard preferences, you have turned off "copy contour name".

5. The parameter icon will be lost if you have selected "Special|Preferences" and among the clipboard preferences, you have turned off "copy contour icon index".

The PIE also contains another function: "Reverse Contours on Clipboard". It reverses the order of the vertices in a contour. To use it, cut one or more contours to the clipboard and then select File|Import <layer name>|Reverse Contours on Clipboard. Select the layer in which the contours should be placed and click the OK button. Both of the above warnings apply to the Reverse Contours on Clipboard function.

Installation instructions: Place EditContoursPie.dll and EditContours.hlp in <Argus directory $>\backslash$ ArgusPIElEditContours. 


\section{Appendix 2: Budgeteer}

Budgeteer.exe is a simple program to read the output file from ZONEBDGT (Harbaugh, 1990), MODFLOW (McDonald and Harbaugh, 1988; Harbaugh and McDonald, 1996), MOC3D (Konikow, and others 1996), and SUTRA (Voss, 1984). It plots the results, and saves the data in a form that can be readily imported into spreadsheet programs. To run the program, double-click on its icon in Windows Explorer. Then select File|Open or click the Open button. A dialog box will appear. Select an output file from ZONEBDGT, MODFLOW, MOC3D, or SUTRA and click on the Open button. The results will be plotted. It is possible to control the format of the plot in a number of ways. There is a pair of radio buttons that allow the user to plot the results for either a single zone in a single time step or for all the time steps or a single zone. If the user chooses to plot a single time step, the data will be plotted as a bar graph. Otherwise, it will be plotted as a line graph. There are check-boxes that can be used to select which budget items will be plotted and combo-boxes in which it is possible to select the ZONEBDGT zone and time step to plot. The latter is enabled only if the user chooses to plot data for a single time step. If the user selects File|Save or clicks on the Save Data button, the data will be saved as a tab-delimited text file. Such files can be readily imported into most commercial spreadsheets. The program is not designed to provide publication-quality plots, but rather to provide rapid analysis of budget data and a method of exporting the data in a form that programs capable of making provide publication-quality plots can readily utilize.

Installation instructions: Place Budgeteer.exe in any directory. Consult the online help for the operating system for instructions on how to add an icon for the program to the Start menu or Program Manager.

\section{Appendix 3: RotateCells}

RotateCells.dll is a PIE that can take row or column positions provided by Argus ONE and convert them to $(\mathrm{X}, \mathrm{Y})$ coordinates. This could be done entirely by an export template, but using a PIE can make the export template simpler and easier to understand and perhaps faster too.

RotateCells.met is an export template that will export the row and column numbers followed by the X and Y coordinates of the four corners of the cell. It uses the RotateCells PIE. RotateCells.met can be used to reproducing the grid in other programs. Users may modify RotateCells.met to meet their specific requirements.

The PIE provides two functions, Rotated $\mathbf{X}$ and Rotated $\mathbf{Y}$. Rotated $\mathbf{X}$ has three arguments: $\mathrm{X}, \mathrm{Y}$, and GridAngle. $\mathrm{X}$ is a column position. $\mathrm{Y}$ is a row position. GridAngle is the angle of the Grid. Rotated $X$ returns the $X$-coordinate of the point defined by the intersection of the row and column positions. Rotated $\mathbf{Y}$ is just like Rotated $\mathbf{X}$ except that it returns the $\mathrm{Y}$ Coordinate.

Installation instructions: Place RotateCells.dll and RotateCells.met in <Argus directory $>\backslash$ ArgusPIE $\backslash$ RotateCells. 


\section{Appendix 4: MODFLOW_ReadFileValue}

functions.

MODFLOW_ReadFileValue.dll is a function PIE for Argus ONE. It contains three

1. MODFLOW_RF_Get_Value_From_File(Key, Default_Value, [FileName])

FileName is an optional parameter. If FileName is not specified, FileName will be given the value of "Default.txt". The function checks if it has already opened FileName. If it hasn't, it reads FileName into memory. If FileName does not exist, it creates a new version of the FileName in memory. It then checks for Key in FileName. If any full line in FileName is equal to Key, the next line is converted to a double-precision real number and returned as the result of RF_Get_Value_From_File. If none of the lines in FileName is equal to Key, the result of RF_Get_Value_From_File is "Default_Value".

2. MODFLOW_RF_Clear_Files() clears all files that it currently has in memory. This function is called at the beginning of the export of MODFLOW input files.

3. MODFLOW_RF_Save_Files() saves all files that it currently has in memory. This function is called at the end of the export of MODFLOW input files.

\section{Further Notes:}

FileName can be either a fully qualified path name or just a file name. If it is just a file name, MODFLOW_ReadFileValue.dll will look for FileName in the current directory.

The format of files to be read by MODFLOW_RF_Get_Value_From_File is as follows. Any line that starts with the character "\#” or which consists entirely of blanks is considered a comment. Lines that are not comments must come in pairs, the first of which consists of a string and the second of which consists of a real number. The first line is treated as a Key and the second as the value to be associated with that Key. When a file is read, any comments are associated with the Key that precedes them. If no Key precedes a comment, the comments are associated with the file rather than with a Key. When a file is saved, the comments associated with the file are saved first followed by the Key's, their associated values and comments. The order of the Key's in the new file may be different from what it was in the original file.

This PIE is useful for allowing external parameter estimation programs such as UCODE to interact with Argus ONE. 


\section{Appendix 5: GetMyDirectory, SelectChar.exe, and WaitForMe.exe}

SelectChar.exe is a console program that simulates a keyboard event based on its command line arguments.

In the following [Char] is used to represent any character and $[\mathrm{N}]$ represents any number

If a command line argument contains "Alt-[Char]", SelectChar.exe will simulate depressing the Alt key and the [Char] key simultaneously.

If a command line argument contains "Ctrl-[Char]", SelectChar.exe will simulate depressing the Ctrl key and the [Char] key simultaneously.

If a command line argument contains "Chr-[[N] ]", SelectChar.exe will simulate depressing the key whose key code is [N].

For any other command line argument, SelectChar.exe will simulate depressing the first character in the command line argument.

If SelectChar.exe is called with no command line arguments, it will simulate a carriage return.

WaitForMe.exe is a program that can run until it is closed. It is only possible to run one copy of WaitForMe.exe at a time. If you attempt to run a second copy, the first copy will be activated instead. It can be closed by activating it and typing a carriage return. The purpose of this is to start the program before doing something else and then activate it again when that "something else" is done. You can then close it by running SelectChar.exe. An external program, such as UCODE, can be waiting for WaitForMe.exe to finish executing before continuing.

These three files are primarily useful for allowing an external program such as UCODE to run MODFLOW through Argus ONE and wait until MODFLOW has finished executing before continuing. In the MODFLOW GUI 3 and Sutra PIE 1.0.2 or later, if you define a Global variable named "Calibrate" and set its value to True $(=1)$. Argus ONE will activate and then close WaitForMe.exe in the directory containing GetMyDirectory.dll after running MODFLOW. It will also allow the DOS window in which MODFLOW or SUTRA ran to close. For this to work, GetMyDirectory.dll, SelectChar.exe, and WaitForMe.exe must all be in the same directory and must be in the ArgusPIE directory or a subdirectory of the ArgusPIE directory. 


\section{Appendix 6: HydrographExtractor.exe}

HydrographExtractor.exe is a program for reading MODFLOW formatted head or drawdown files and extracting hydrographs for selected cells.

To use it, first, assign the row, column, and layer of each cell for which you wish to create a hydrograph. Next, Click on the "Read" button to read a MODFLOW formatted head or drawdown file. The data will be graphed and also written to an on-screen text box in a tabdelimited format. The text may be saved to a file by clicking on the save button. Most commercial spreadsheets can readily import tab-delimited text files such as the one saved by this program. If you wish to quit in the middle of reading a head or drawdown file, click on the "Cancel" button.

HydrographExtractor.exe accepts two optional command line parameters. The first parameter is the name of a file containing the locations of the cells to be read. The first number in the file must be an integer specifying how many cell locations will be read from the file. After that there must be groups of three integers specifying the column, row, and layer of each cell. The data in this file are read in free format. Numbers must be separated by spaces, tabs, or endof-line characters. The second optional parameter is the name of the formatted head or drawdown file from which data are to be read.

Examples:

Typing any of the following three lines will start Hydrograph Extractor.

HydrographExtractor.exe

HydrographExtractor.exe CellLocations.txt

HydrographExtractor.exe CellLocations.txt Heads.fhd 


\section{Appendix 7: Web-Based Tutorial}

A web-based tutorial (originally prepared for version 1 of the MODFLOW GUI by Argus Interware) has been updated to reflect changes made in versions 2 and 3 of the MODFLOW GUI. The purpose of the tutorial is to teach users how to use MODFLOW, the MODFLOW GUI, and Argus ONE. Five of the examples in the tutorial are drawn from Andersen (1993). The tutorial includes two other examples. In one, the user makes simple changes to an existing model to become familiar with the process of editing model information and to observe the effects of making simple changes in models. In the other, the user creates a simple model based on topographic and geologic information.

The tutorial comes in the form of a self-extracting executable named MODFLOW_Tutorial.EXE. When MODFLOW_Tutorial.EXE is run, a series of web pages and example models are extracted. To begin the tutorial, the user should double-click on a file named DoubleClickMe.html. The file will be opened by the default web browser on their computer. 